Designing a game
for upper limb
rehabilitation
following a stroke 


\title{
Designing a game for upper limb rehabilitation following a stroke
}

By

\author{
Dana Fridman
}

\begin{abstract}
A thesis
submitted to the

Victoria University of Wellington

in fulfilment of the

requirements for the degree of

Master of Design Innovation
\end{abstract}

Victoria University of Wellington 
Thank you for playing and for your support.

My family and friends, co-students, the Smart Interactions team, and the staff at Victoria University of Wellington.

Supervisors: Kah Chan, Dr. Brian Robinson and

Dr. Edgar Rodriguez-Ramirez.

Music therapists: Andrea Robinson.

Neuro-physiotherapists: Dr. Nada Signal and Dr. Denise Taylor.

Health psychologist: Dr. Nicola Kayes.

The participants and their care givers.

Technical support: Lukas Stoecklein and Matt Everitt.

Equipment: Andrew Matautia and the media

design department.

Model: Warwick McLeod.

MDI CoRE scholarship: Smart Interactions CoRE MedTech. 


\section{Content}

$\begin{array}{ll}\text { Abstract } & 12\end{array}$

$\begin{array}{ll}\text { Introduction } & 14-15\end{array}$

$\begin{array}{lr}\text { Literature review } & 16-25\end{array}$

$\begin{array}{lr}\text { Engagement } & 16-17\end{array}$

Game design for rehabilitation $\quad$ 18-19

$\begin{array}{ll}\text { Rehabilitation methods } & 20-23\end{array}$

$\begin{array}{lr}\text { Rhythmic Auditory Stimulation } & \text { 20-21 }\end{array}$

$\begin{array}{ll}\text { Rhythm games } & 21\end{array}$

Motor learning $\quad 22$

$\begin{array}{lr}\text { Feedback provision } & 22-23\end{array}$

$\begin{array}{ll}\text { Able-M } & 24-25\end{array}$

$\begin{array}{ll}\text { Methodology 26-27 } & \end{array}$

$\begin{array}{ll}\text { User Personas } & 28-34\end{array}$

$\begin{array}{ll}\text { Meetings with therapists } & 35-37\end{array}$

$\begin{array}{ll}\text { Field observations } & 38-39\end{array}$

Design criteria $\quad 40$

Design process $\quad 41$

Concepts $\quad 42-43$

Game model 44-45

Development 46-71 
First person rhythm game

Third person rhythm game

Narrative

$50-53$

Calibration

54-57

Going forward

$58-59$

Feedback provision

$60-61$

Rhythmic obstacles

$62-63$

Musical steps- Feedback provision

64

Rhythmic elements

65

Rhythmic rewards

68

Final prototype

$72-81$

Planet one description

$77-80$

Planet two description

$80-81$

Testing

82-83

Results

84-89

Conclusions

$90-93$

Acknowledgments

94

References

96-102

Appendix

$103-118$

Figure list

$119-122$ 


\section{Abstract}

\section{Background:}

Many stroke survivors suffer from motor impairments such as upper limb hemiparesis accompanied by cognitive and emotional impairments that can affect their ability to function. Rehabilitation interventions are effective in promoting the return of function. However, patients' engagement is necessary in order to maintain the improvements, and research shows that stroke survivors need more opportunities to engage with rehabilitation outside of the clinic. Digital games can offer a solution by providing an engaging context for performing the exercises correctly and learning new skills.

\section{Aims:}

This research aims to increase engagement with upper limb rehabilitation following a stroke through a custom digital game that facilitates effective rehabilitation methods, and is played with the Able-M, a game controller designed for upper limb rehabilitation by Im-Able.

\section{Methods:}

The development process was based on a human-centred design approach that consisted of a literature review, personas generation, exploratory studies including field observations in a clinic and discussions with therapists, iterative design through qualitative studies including user observations, interviews with patients, and feedback from a neuro-physiotherapist.

\section{Conclusions:}

Based on the design process, the game prototype includes the following elements: Adaptive gameplay for physical and cognitive challengeskill balance, obstacles to increase challenge, feedback provision to enhance engagement and facilitate motor learning, rhythmic elements to facilitate rhythmic auditory stimulation, narrative based on user research to facilitate focus diversion, and different navigation mechanisms to promote neuroplasticity. High contrast, bird eye view, and third person perspective for ease of use. Limitations and directions for further research are discussed. 


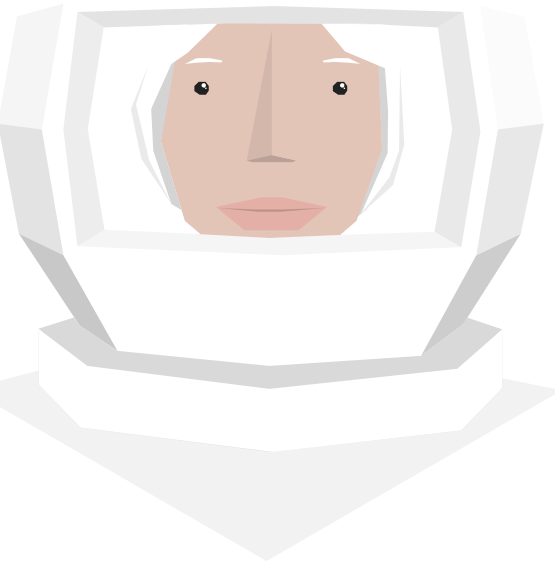




\section{Introduction}

Stroke is one of the leading causes of disability, influencing both males and females, mostly at ages 75 and older (Feigin, 2014; Murray et al., 2013). Many stroke survivors suffer from upper limb hemiparesis (Lai, Studenski, Duncan, \& Perera, 2002), accompanied by cognitive and emotional impairments (Haring, 2002) that can affect their ability to function and drastically change their lives.

Neuroplasticity refers to the ability of the brain to change its structure, function, and connections. Neuroplasticity can promote the return of function and can take place after a stroke as the result of experience. Studies show that behaviour, enriched environment, and cognitive and skill training can promote neuroplasticity through suitable designs of exercises. Salience, motivation, and attention are crucial in gaining these changes. Maintaining these improvements requires engagement with rehabilitation interventions (Cramer et al., 2011; Kolb, \& Whishaw, 1998).

Different stroke rehabilitation interventions are effective in promoting neuroplasticity. However, research shows that stroke survivors' ability to drive their own recovery outside of the clinic is limited by dealing with their loss.

Patients report that they need more opportunities for rehabilitation as most of their time outside of the clinic feels "dead and wasted" (Eng et al., 2014, p.4), while waiting for something to happen.

Performing these exercises by themselves can be a mundane experience, however games can offer a solution by providing an engaging experience for patients (Chang, Han \& Tsai, 2013) while distracting them from the repetitive movements (Burdea, 20 02; Pollock, 2014). The games can provide an opportunity to practice and learn new skills, ensuring patients are performing the exercises correctly, and supporting neuroplasticity in the clinic or at home.

\section{Aim}

The main aim of this research is to develop a game for upper limb rehabilitation following stroke using the Able-M. Able-M is a game controller designed specifically to support repetitive movements for upper limb rehabilitation (Rodriguez, Chan $\&$ McCarthy, 2015; Jordan, Sampson, Hijmans, King \& Hale, 2011).

In order to develop the game, this research will recognise design criteria.

\section{The design criteria will be established with the following intentions:}

1. Engage players with the rehabilitation movements of the Able-M.

2. Facilitate effective rehabilitation methods in the game design (Rhythmic Auditory Stimulation and Feedback Provision). 


\section{Methods}

\section{A. Design criteria development}

This research proposes a design criteria that will fulfill the following requirements:

\section{Able-M:}

The interactions needed to be performed with the Able-M by the player (i.e. Movements of the arm across a surface to move the mouse on the computer screen and finger lift movements to click).

\section{Engagement:}

Game design elements that will engage players with these interactions, based on literature review and discussions with therapists. (i.e. challenge-skill balance, feedback, and a narrative)

\section{Effectiveness:}

Effective rehabilitation methods to promote motor learning and enhance rehabilitation outcomes based on literature review, field observations and discussions with therapists. (i.e. Rhythmic Auditory Stimulation and Feedback Provision).

\section{B. Iterative design}

Developing prototypes to facilitate the criteria (see development process). Qualitative studies with healthy individuals along the development process were conducted aiming to gather information on needed iterations before testing with patients.

\section{Qualitative studies}

The researcher discussed with therapists and conducted qualitative studies with patients, including user observations and one-on-one semistructured interviews, in order to recognize if the criteria are facilitated in the prototypes, and if they achieve their intentions.

\section{Data analysis}

The researcher used constant comparative analysis and inductive reasoning processes to analyze the qualitative data.

Patients report that they need more opport unities for rehabilitation as most of their time outside of the clinic feels "dead and wasted" while waiting for something to happen. 


\section{Literature review}

\section{Engagement}

Stroke survivors' engagement with rehabilitation is necessary in order to promote and maintain the therapeutic outcomes of rehabilitation. Engagement was identified by Bright et al. (2015) as the process of engagement - "Engaging with", and the state of engagement - "Engaged in". The process of engagement is associated with the trusting relationship, which emerges from feedback and self-reciprocity. The state of engagement is a result of the process of engagement and requires the patient to invest in the rehabilitation. This can be affected by both extrinsic and intrinsic factors, and by self-efficacy (Bright, Kayes, Worrall \& McPherson, 2015), which can emerge from seeing progress and feedback, and intrinsic factors such as one's awareness of rehabilitation importance for their own good, or enjoyment gained from the process of rehabilitation (Kowal and Fortier, 1999).

\section{Digital games}

Digital games can provide players with immediate feedback and self-reciprocity in response to their actions in the game. This feedback loop, together with adaptive gameplay to maintain the skill-challenge balance, can lead to self-efficacy (Backlund, Engstrom, Johannesson, Lebram \& Sjoden, 2008). Showing players they are progressing on their way to achieve their goals, which can promote engagement, and further, immersion and the optimal experience. (Nacke \& Lindley, 2008; Csikszentmihalyi \& Csikzentmihaly, 1991).

\section{Immersion}

Ermi and Mayra recognize three types of immersion (Nacke \& Lindley, 2008):

\section{Sensory immersion:}

Sensory information is influenced by the audiovisual elements of games such as compelling graphics and sounds.

\section{Imaginative immersion:}

According to Brown and Cairns (as cited in Nacke $\&$ Lindley, 2008) imaginative immersion includes empathy through absorption in the narrative of a game or connection with a character. Neural studies show that the feeling of empathy will be more likely to occur in third person perspective rather than in a first person perspective (Heenzen et al., 2015).

\section{Challenge based immersion:}

Challenge based immersion describes the flow experience recognized by Csikszentmihalyi (1991). Flow is an optimal psychological state that requires concentration and leads to pleasure. In this state the person is totally involved in the activity and experiences positive effects such as freedom from self-consciousness 
and enjoyment of the process. It is an intrinsically enjoyed state that includes clarity of goals, knowledge of performance, concentration, feeling of control and feelings of being completely in tune with the performance (Jackson \& Marsh, 1996; Sharafi, Hedman \& Montgomery, 2006).

\section{The optimal experience}

In their qualitative study, Jackson and Marsh (1996) explored Csikszentmihalyi's (1991) flow theory with athletes. This optimal experience includes the following characteristics:

\section{Challenge-skill balance:}

In order to facilitate the flow state, the balance between challenge level and players' skills needs to be maintained. Athletes report this state as challenging and automatic. The balance between challenge and skill has also been described by game researchers as a consequence of "Ludic optimization" (Tanenbaum \& Bizzocchi, 2009).

\section{Clear goals:}

The goals are clearly defined, letting the players know exactly what they are going to do.

\section{Feedback:}

Immediate and clear feedback is necessary in order to inform players whether their efforts will lead them to accomplish their goals. It is unclear how and what kind of feedback should be provided, but according to Csikszentmihalyi (as cited in Jackson \& Marsh, 1996), all feedback types should allow the players to know they are succeeding in reaching their goals.

\section{Concentration:}

Total concentration is one of the most frequently mentioned flow dimensions by athletes. However, this may be a problem as some stroke survivors may suffer from cognitive impairments that may damage their concentration abilities.

\section{Action-Awareness merging:}

The activity becomes spontaneous and automatic and induces freedom of selfawareness. It may be that promoting the action-margin-awareness element of flow through RAS in the game, could overcome the concentration limitation patients may be affected by, and promote the intrinsically rewarding flow experience. However, more research is needed in this area.

\section{Sense of control:}

The sense of exercising control is a significant part of the flow experience, even though the person is not trying to exert control. Athletes report that they feel like they can do anything in this state and that they can not imagine anything going wrong.

\section{Loss of self consciousness:}

The self disappears during the flow state as the person becomes one with the activity. When time is not necessary for the activity itself, a transformation of time can occur, where time either changes or absent from the person's awareness. In addition, an autotelic experience can take place when the activity is done for its own intrinsically rewarding experience of enjoyment rather than external rewards. 


\section{Game design for rehabilitation}

This research identified the following design elements from literature on engaging rehabilitation games:

\section{Feedback}

Feedback is an important part of both games and rehabilitation (Burke, McNeill, Charles, Morrow, Crosbie \& McDonough, 2009; Burke et al., 2009; Flores et al., 2008). Stroke rehabilitation and motor learning require patients' engagement, and measurable progress is often only seen after long-term practice (Krakaver, 2006). Stroke survivors report they feel more motivated when they receive positive feedback (Eng et al., 2014).

Clinicians report it is hard to measure small steps of progress and there is a risk for non-engagement when stroke survivors do not see the results of their hard work. Games can offer the facilitation of feedback, even for small steps of progress, while designed appropriately for the aims of the therapy.

\section{Balance between challenge and skill}

Challenge is also required to facilitate an engaging experience (Alankus et al., 2010; Burke et al., 2009; De Schutter 2010). However, the balance between challenge and skill is important for engagement and, furthermore, to reach the optimal experience (Csikszentmihalyi \& Csikzentmihaly,
1991). The level of difficulty in the game should be tailored to players' ability, allowing enough positive feedback and enough challenge, while reducing the risk of boredom from not enough challenge, and preventing the feeling of frustration from too much challenge, which can influence players' engagement. These are especially important when designing for stroke survivors as they are already suffering from loss of function and might relate their difficulty in the game to their impairments (Alankus et al., 2010; Burke et al., 2009; Csikszentmihalyi \& Csikzentmihaly, 1991; Flores et al., 2008). Alankus et al. (2010) analyzed six games according to criteria they developed. Their testing revealed that cognitive challenge combined with physical challenge created an overload for the stroke patients, and a risk for non-engagement. Many stroke survivors suffer from cognitive impairments in addition to their motor deficits. However, redevelopment of these skills is necessary and can improve neuroplasticity and as result; function (Cramer et al., 2011). 


\section{Focus}

The focus needs to be diverted from the repetitive exercises (Flores et al., 2008). It has been suggested that the audio, visuals and narratives can maintain players' focus in the game. The context can be designed to fit to patients' goals in rehabilitation. In addition, the interface should be tailored to users, considering their limitations in the auditory, visual and motor systems (ljsselsteijn, Nap, de Kort \& Poels, 2007).

\section{Social}

Social aspects in the game can also increase engagement. (De Schutter, 2010; Flores et al., 2008). Even sharing progress, achieved goals and frequency of engagement with clinicians, family and peers can increase extrinsic motivation.

\section{Strategy and chance}

Strategy and chance (Harley, Robertson, Gandy, Harbert \& Britton, 2011) were revealed following testing as promoting engagement with rehabilitation. Strategy can be beneficial for the promotion of neuroplasticity. This should be carefully designed as frontal stroke survivors suffer from cognitive impairments that may limit their cognitive planning ability (Andrews, Halford, Chappell, Maujean \& Shum, 2014).

\section{Games can offer the facilitation of feedback, even for small steps of progress, while designed appropriately for the aims of the therapy.}




\section{Rehabilitation methods}

The literature on games for rehabilitation expands the knowledge on how to design an engaging experience. However, there is a gap in the literature on how to integrate effective rehabilitation methods in the design framework.

The second aim of this research is to facilitate Rhythmic Auditory Stimulation and motor learning in the game design to enhance the effectiveness of the upper limb rehabilitation provided by Able-M.

\section{Rhythmic Auditory Stimulation}

This research suggests a solution to maintain the balance between cognitive and physical challenges and abilities, and therefore increase engagement with effective rehabilitation, using Rhythmic Auditory Stimulation (RAS). RAS was found to be effective for upper and lower limbs rehabilitation following a stroke. It is often practiced using a metronome, or music to synchronize motor movements with auditory cues and maintain repetitive exercise (Ford, Wagenaar \& Newell, 2007; Malcolm, Massie \& Thaut, 2009; Thaut, Mclntosh, Prassas \& Rice, 1993; Thaut, Mclntosh \& Rice, 1997; Whitall, Waller, Silver \& Macko, 2000).

Auditory cues can control the motor system directly, without the need of cognition (Thaut, Miller \& Schaver, 1998; Molinari, Leggio, Martin, Cerasa \& Thaut, 2003). When stroke patients' motor planning ability is impaired (Andrews et al., 2014), RAS has the potential to support the motor system directly in a challenge. This research suggests that the use of RAS in the game design can maintain the balance between cognitive and physical challenges offered by the game and players' abilities, and therefore increase engagement with effective rehabilitation.

Performing rehabilitation exercises with RAS is more effective than performing them without the rhythmic cues (Thaut et al., 2007). RAS stimulates the motor system to modify motor movements in synchronization with the rhythmic cues (Thaut, 1993). Rhythmic patterns allow the motor system to anticipate, plan and execute the next moves (Thaut, Kenyon, Hurt, Mclntosh \& Hoemberg, 2002). Constant cues ensure the movements are repeated, and motor learning is promoted since matching movements with rhythm gives patients an attentional goal, and the auditory cues provide them with feedback (Molinari, Leggio, Martin, Cerasa \& Thaut, 2003).

Nevertheless, research shows that emphasized rhythmic cues may reduce compensatory contributions (Malcolm, Massie \& Thaut, 2009). Whitall et al. (2000) found that functional gains in a chronic paretic arm can be achieved 


\section{Rhythmic patterns allow the motor system to anticipate, plan and execute the next moves. \\ Constant cues ensure the movements are repeated, and motor learning is promoted.}

with the use of RAS, after six hours of training.

Therefore, RAS can promote rehabilitation outcomes and make the activity more automatic, enhancing players' experience and promoting engagement. The rhythmic patterns can be both visual and auditory in the game world. Furthermore, the patterns can change according to players' needs and abilities, in order to balance between physical and cognitive challenges and patients abilities.

Hence, The facilitation of RAS in the game design may affect players' engagement with the rehabilitation exercises.

\section{Rhythm games}

Music games, in general, were identified into the following categories by Pichlmair and Kayali (2007):

1. Rhythm games: Rhythm games can facilitate RAS as they require following a rhythm within a game. The success means that the players' actions are as close as possible to fit the rhythm. Progression in the game can be facilitated through increased rhythm speed and rhythm complexity.

2. Electronic instrument games: In this genre melody is generated by the player, providing freedom of expression. The game may provide background rhythm that the player can fit the melody to.

3. Musical puzzles: In these games the player needs to play certain tunes that will affect the game world.

Common features of music games include: active scores, rhythm actions, quantisation, synaesthesia, play as performance, free form, and sound agents (Pichlmair \& Kayali, 2007). Rhythm games can facilitate RAS for upper limb rehabilitation. Guitar Hero, Cyrus, Tap Tap Revenge and Vib Ribbon are examples rhythm games available. However, these rhythm games have not been designed specifically for stroke survivors, nor for upper limb rehabilitation with the use of Able-M. Also, in order to promote long-term effects following rehabilitation, the games should integrate motor learning elements. 


\section{Motor learning}

Motor skill is defined as the ability to plan and execute a movement towards a goal.

Research recognise ways to improve long-term effectiveness of performance and learning, such as introducing rest between repetitions, variety of tasks, and random order of tasks.

These may show fewer performance improvements in the short term, however (Krakaver, 2006).

Implementation of motor learning principles in the game is necessary to increase improvements in the long term. In addition, providing feedback can increase engagement. However, it should be designed appropriately to facilitate motor learning.

\section{Feedback provision}

Feedback is sensory information provided during or after a performance of a task (Winstein, Pohl \& Lewthwaite, 1994). Feedback provision affects the learning of motor skills and can enhance the retention of motor learning, as recognized by Herbert and Cirstea (as cited in Subramanian, Massie, Malcolm \& Levin, 2010). Generally, feedback can be either extrinsic or intrinsic. Augmented feedback is extrinsic and can replace and enhance the effects of intrinsic feedback (Van Vliet \& Wulf, 2006; Eng et al., 2014).

\section{Extrinsic feedback:}

Differences in feedback provision have been classified in research into the following categories:

\section{Knowledge of results}

Similar to Terminal feedback (Rosati et al., 2011), is given after the task performance (Sigrist, R., Rauter, G., Riener, R., \& Wolf, P. 2013), and defined as goal related extrinsic feedback (Subramanian et al. 2010). This type of feedback provides information about the results of the performance in the task - success or error. The use of KR can improve the accuracy of goal achievement. 


\section{Knowledge of performance}

Similar to Concurrent feedback (Rosati et al., 2011), is given during the task performance (Sigrist et al. 2013), and defined as extrinsic feedback on the nature of the performance to achieve the goal and provide information about the movement quality. This feedback type is known to improve movement quality.

\section{Error feedback}

Error feedback can provide information about errors and how to correct them to improve learning (Sigrist et al. 2013).

\section{The Guidance Hypothesis}

Although feedback can enhance motor learning (Winstein, Rose, Tan, Lewthwaite, Chui, \& Azen, 2004 ; Sigrist et al., 2013; Subramanian et al., 2010; Cirstea, Ptito \& Levin, 2006; Van Vliet \& Wulf, 2006; Rosati et al., 2011), the Guidance Hypothesis (Winstein, Pohl \& Lewthwaite, 1994; Subramanian, Massie, Malcolm \& Levin, 2010; Sigrist et al., 2013) suggests that consistent feedback during learning can lead to dependency on feedback (Sigrist et al., 2013) by forcing the learner to ignore their intrinsic feedback, internal processing and problem solving which can be beneficial for learning (Winstein, Pohl \& Lewthwaite, 1994). However, the subjects in this study were healthy and not affected by the cognitive impairments that stroke survivors may experience. Research suggest that fading or summary feedback can reduce the risk of dependency on feedback. And even though it may reduce task performance, in the long term it can enhance motor learning. However, more research is needed on the implementation of summary or faded feedback in 2D virtual realities (Subramanian et al., 2010; Cirstea et al., 2006; Van Vliet \& Wulf, 2006; Winstein et al., 1994; Rosati et al., 2011). Hence, implementation of feedback provision may increase performance quality and accuracy, reduce dependency on feedback, and as a result may increase the possibility of movements generalization.

Feedback provision

affects the learning of

motor skills and can

enhance the retention of

motor learning. 


\section{Able-M}

Able-M is a system that facilitates upper limb rehabilitation exercises after a stroke. The device works like a computer mouse, and is designed to support the affected arm in controlling a game that can show users how to perform their rehabilitation exercises.

\section{The device facilitates two movement types:}

1. Moving the forearm around the table. These movements can promote neuroplasticity.

2. Lifting the fingers from the hand rest to press a button attached to the boom. There are three possible boom positions corresponding with different hand movements, such as lifting fingers or extending thumbs. This is important for involuntary-flexion posture (Rodriguez, Chan \& McCarthy, 2015).

Rodriguez et al. (2015) analyzed the Able-M according to the universal design criteria of the Centre for Universal Design. They found the device to be simple and intuitive as it resembles a mouse, suitable for a wide range of people with affected upper limbs following a stroke, can be used at home, and is relatively low cost, flexible in use and can be beneficial for people suffering from cerebral palsy and brain injury as well. The device is lightweight and has low-friction, non-marking feet, allowing movements with minimal resistance. It is reasonably compact, however, requires some room to move compared to an ordinary mouse. The data of the upper limb movements is accurate and reliable and can be presented in the game, allowing the players to control the game, and receive feedback on their movements and progress. Overall, the Able-M facilitates a digital or tangible experience that is easy to understand.

\section{Able-M digital games:}

The device connects wirelessly via Blvetooth to a screen-based game that can prompt the player to make the two movements described.

Current Able-M games are designed to guide players to perform certain upper movements required by their rehabilitation programme, and include three steps:

1. Preparation (warm up and calibration exercises): The games start with simple and intuitive levels to introduce low cognitive and physical barriers to new players.

2. Pace (appropriate challenge tailored to players' abilities according to calibration phase): The game progresses in difficulty according to the player's ability, requiring the player to go further and faster.

3. Payoff (reward to encourage the player to repeat the feedback loop): Clear visual and audio feedback provided during the game and following the game the player receive historical graph to represent their efforts all through the gameplay. 


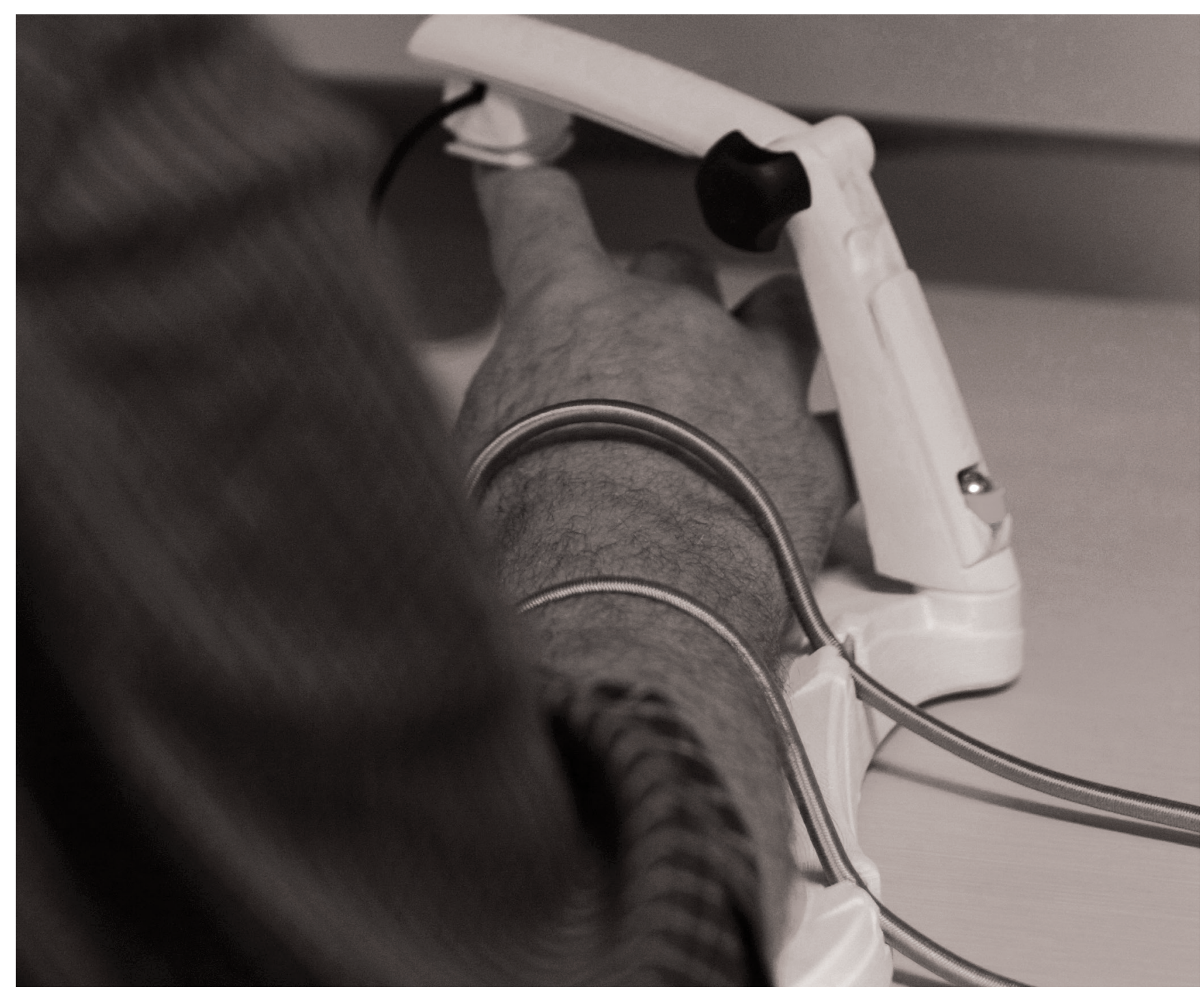

Figure 1: Using the Able-M

For example, one game mentioned by Rodriguez et al. (2015) describes a virtual insect swatter controlled by the player using the Able-M. The players are required to swat an animated mosquito by moving their forearm and making contact with the button. The game can be tailored to users' abilities (e.g. no button press needed for players with no finger mobility).

The game informs players how to perform the rehabilitation exercises through audio and visual stimulation that encourage diversion from the repetitive movements. In addition, the game provides clear feedback (swatting the mosquito). The balance between skill and challenge is facilitated through the adaptation of physical challenges to players' abilities.

The cognitive challenge was designed to stay simple; this is beneficial to prevent a cognitive and physical challenges overload. However, the game itself is repetitive and does not include a variety of tasks to promote motor learning and neuroplasticity. This can also influence players' experience and may reduce engagement over time. 


\section{Methodology}

This research will use human-centered design methodology in order to develop the design criteria and the game to facilitate an engaging experience of upper limb rehabilitation for stroke survivors. Human-centered design and participatory design (Khaled, Vanden Abeele, Van Mechelen, Vasalou, 2014) are becoming common approaches in serious game design. These methodologies can provide ways to reveal the needs of the users. The design should provide the facilitation of both the users' needs and the rehabilitation needs, in order to sustain patients' engagement and enhance the positive effects on the therapeutic outcomes. However, more research is needed on how to implement the rehabilitation considerations in the design process.

According to Norman (2005) even though human-centered design puts importance on the needs of humans, focus on the human only might interfere the support of the activity. Therefore, attention should be given to the activity as well, in this case, the rehabilitation. Same as the ludic experience that might reduce ease of use, but can increase engagement in the long term.

PAT model also suggests a useful approach for design by focusing on the person, task and artifact (Finneran $\mathcal{E}$ Zhang 2003).

\section{Methods}

This research achieves this goal through human-centered design methods together with literature review and discussions with clinicians. Considering both of the rehabilitation needs (activity or task), the users' needs (human or person) and the Able-M requirements of use (the artifact). The humancentered design methods include personas generation (Gothelf \& Seiden, 2013), field observations (Johnson, Johnson \& Zhang, 2005), and iterative design process. The research identifies design heuristics (Nacke, Drachen, \& Göbel, 2010; Nacke et al., 2009) of game design for rehabilitation and for engagement through a literature review. Further literature review informed the research on ways to integrate effective rehabilitation methods in the design framework, together with field observations in a private clinic for rehabilitation, and discussions with neuro-physiotherapists, music therapist, and a health psychologist.

The development process includes establishing design criteria, paper prototypes, game model (Fullerton, 2014), and the development of digital prototypes to be played with the Able-M.

Throughout the development process, the researcher used an iterative design process based on qualitative studies with healthy individuals, in order to test the playability of the game, recognise usability issues, and improve the 
prototype before testing it with patients. The participants were students at Victoria University of Wellington (VUW). Ethics application was approved by VUW. The testing involved participants at ages 20 to 30 . It included user observation while the participant played the game and informed the researcher on their experience by "thinking aloud" (Alan, Janet, Gregory, \& Russell, 2004 ). Following the gameplay, a semistructured interview was conducted by the researcher (Nacke, Drachen, \& Göbel, 2010). The interview included questions that aimed to prompt the participants to share information about their experience and inform the researcher on usability issues (Brooke, 1996). Observations and interview notes were collected, organised into themes, and informed the researcher on needed features and changes in the game. The level of importance of each feature was suggested by the number of repetitions amongst participants.

Following the data analysis of the qualitative studies, appropriate iterations were made. These are described in the development chapter. The final prototype was investigated by a neuro-physiotherapist, followed by qualitative studies (Creswell, 2009) with stroke survivors to explore their experience of the game. The studies included user observations and semistructured interviews. Ethics application was approved by the Health and Disability Ethics Committees.

\section{The design should provide the facilitation of both the users needs and the rehabilitation needs, in order to sustain patients' engagement and enhance the positive effects on the therapeutic outcomes.}




\section{User Personas}

The research began by developing user personas in order to gain an understanding of the stroke survivors' perspective.

In order to do so, the researcher went through qualitative studies about patients' motivation to engage with rehabilitation (Eng et al., 2014; Maclean \& Pound, 2000) and generated graphical personas to reflect the data. This way, the researcher could resonate with the person behind the data and have some understanding of their needs. 

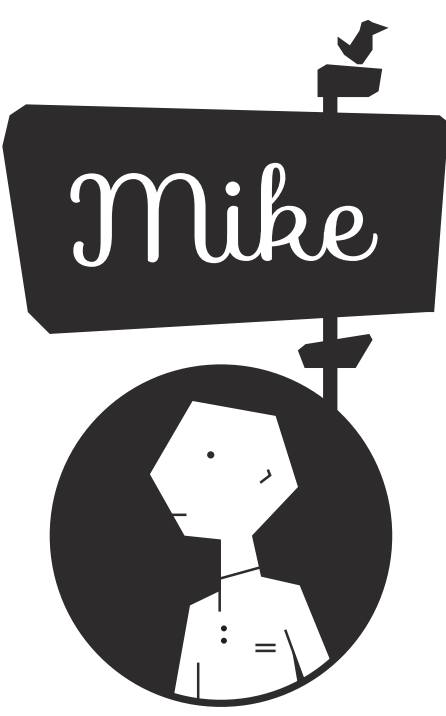

\section{WHAT'S FEELING}

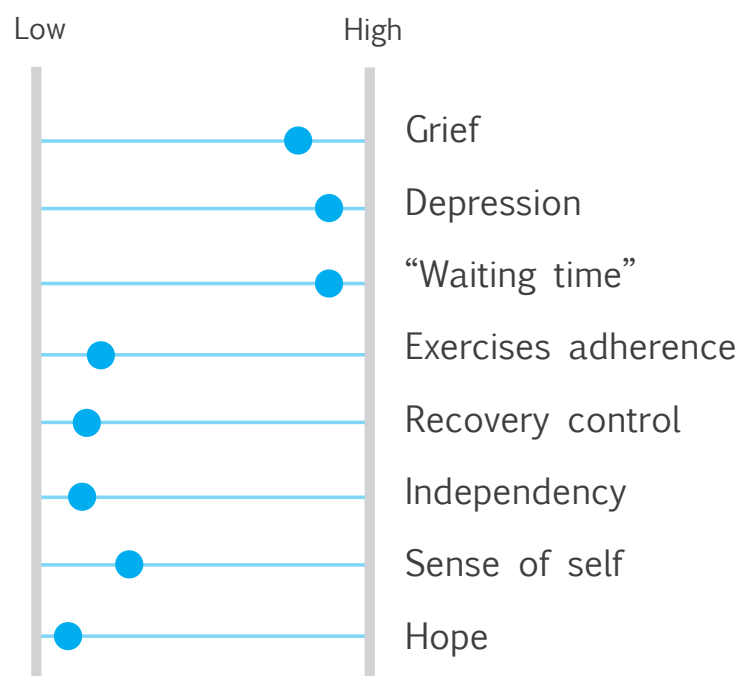

Mike is in grief for his loss, feels stuck in his body and powerless. Mike's therapists told him that therapy will help, and he is aware of it, but doesn't think he could accomplish the goals his clinicians set up for him, or that his condition is getting any better. Mike spending most of his time in bed, waiting for the next therapy or for his family to come back home.

\section{NEEDS}

- Another place to go to.

- Progress records.

- Peers support.

- Self-management.

\section{WHAT'S HAPPENING}

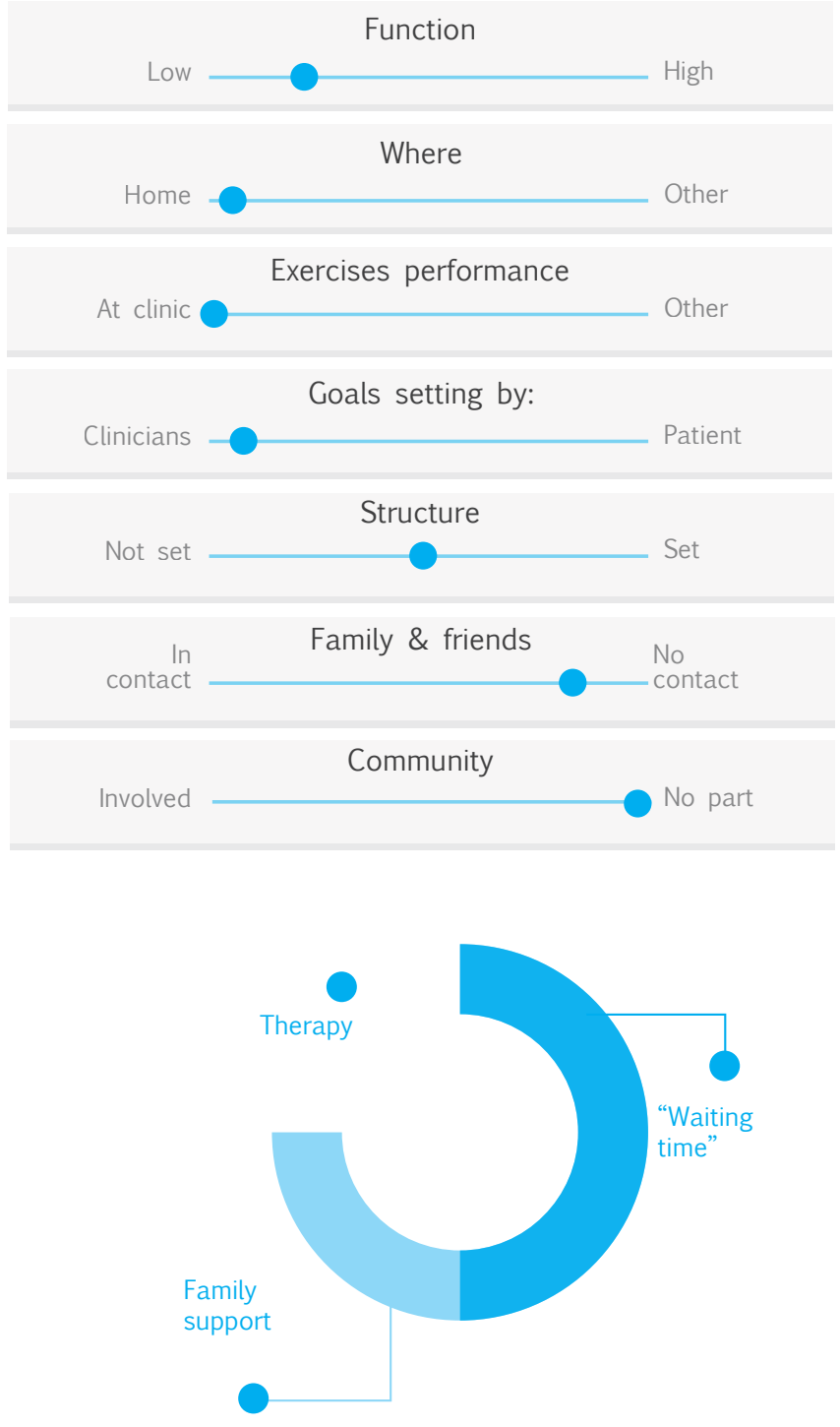

Figure 2.1: personas 


\section{2 Rose}

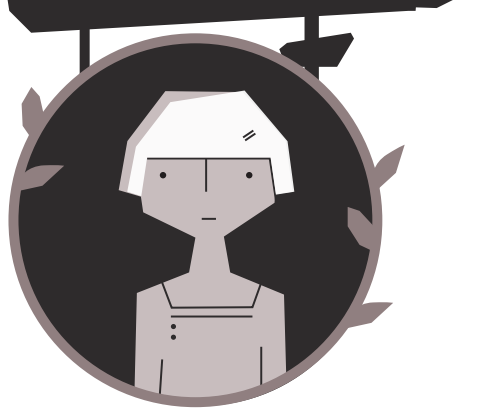

\section{WHAT'S FEELING}

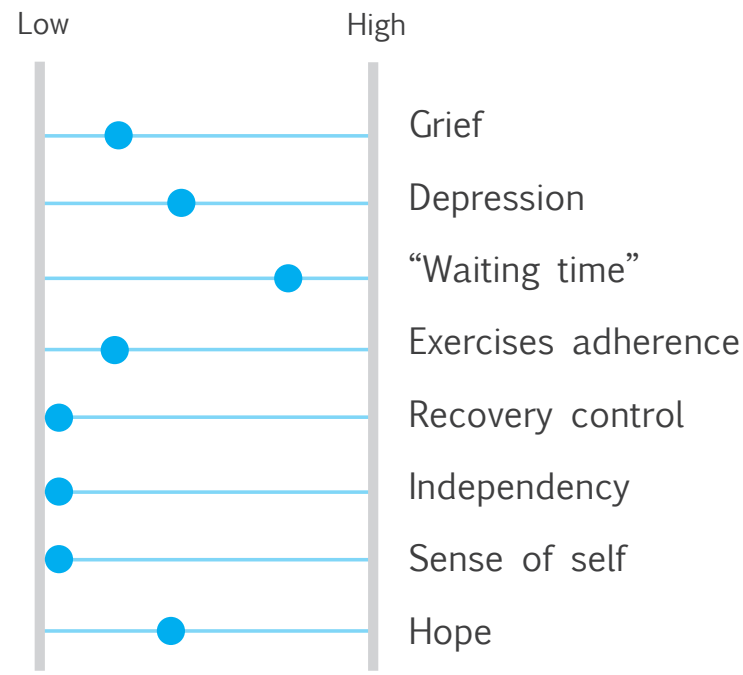

Rose is supported by her son. Her clinicians set goals and schedule for her therapy and club sessions. Feeling mostly overwhelmed and powerless, Rose says she is losing her sense of self, finding it hard to adjust to her new situation. Rose blames her clinicians for not providing enough assistance for her recovery. Rose feel she has no control of her own recovery, she is fully depended on her clinicians and son, and can't do anything by her self anymore. Without knowing what she is doing and why, between sessions she just waits at home for people to tell her what to do.

\section{NEEDS}

- Self-management

- Goals \& Values.

- Emphasis on her character.

- Another place to go to.

\section{WHAT'S HAPPENING}
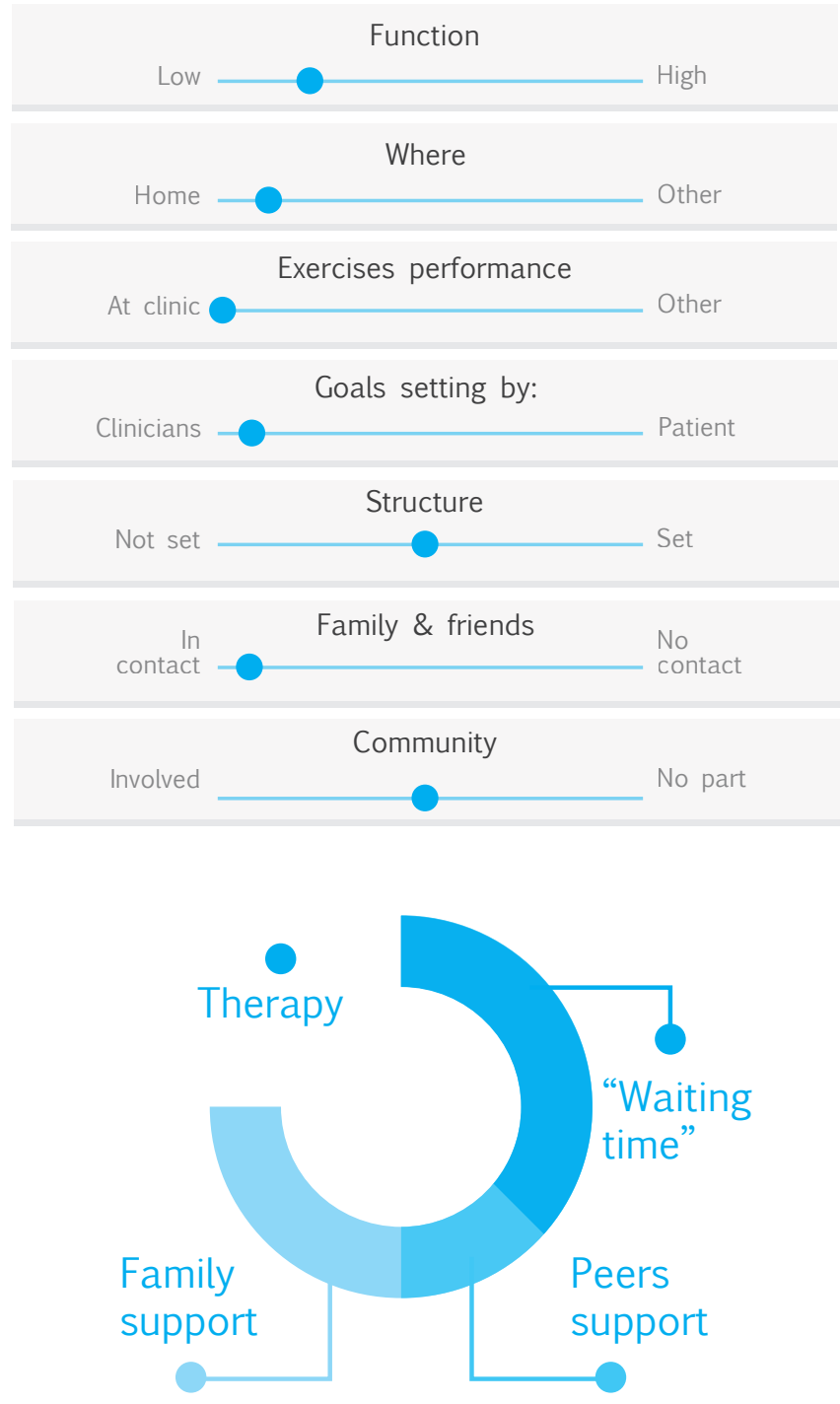

Figure 2. 2: personas 

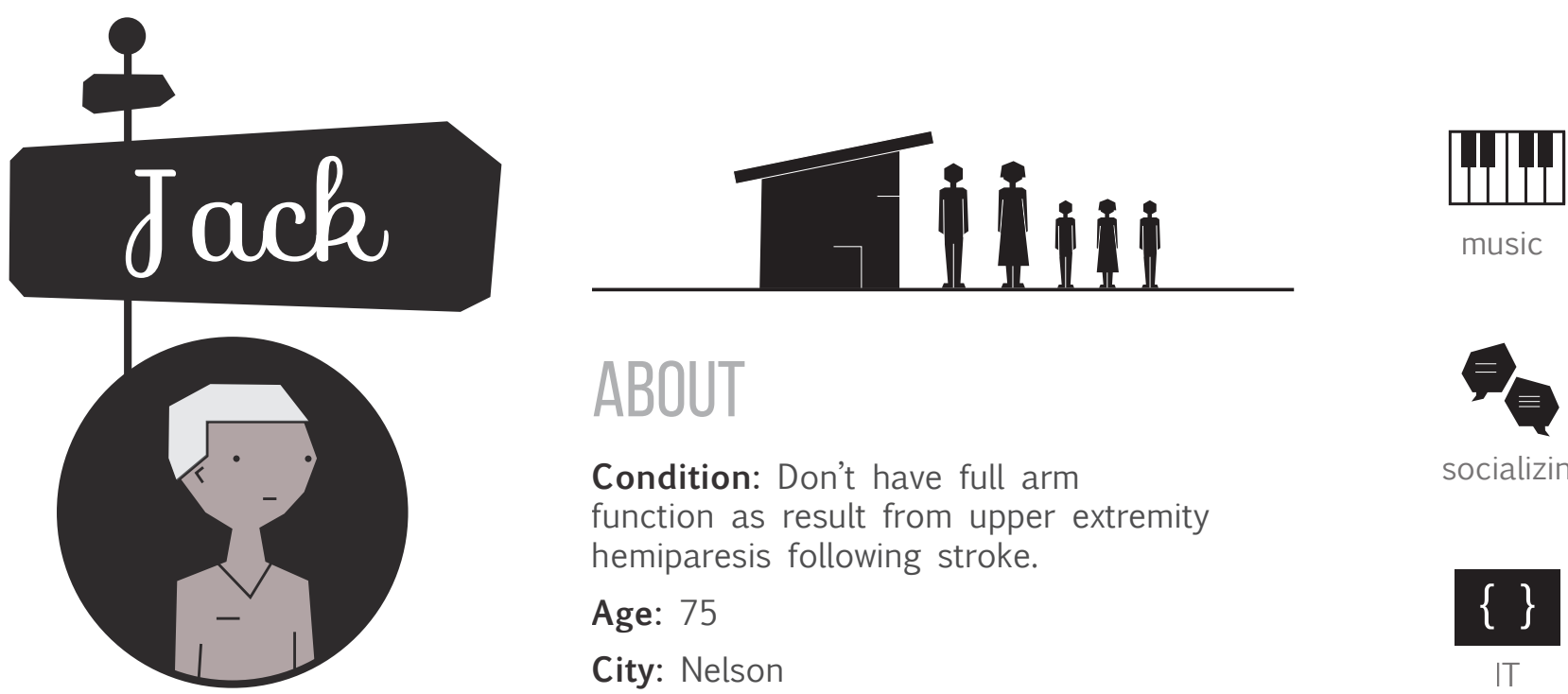

music

Condition: Don't have full arm

function as result from upper extremity hemiparesis following stroke.

Age: 75

City: Nelson

\section{WHAT'S FEELING}

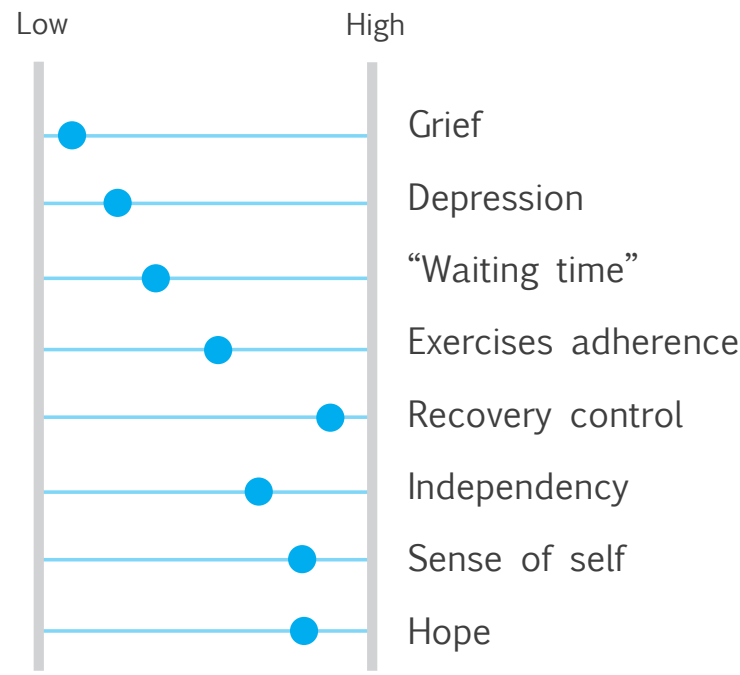

Jack set his goals and he is taking full responsibility for his progress. Jack's intrinsic motivation is very high and he performs the exercises at home as well. But still, the exercises are very repetitive and boring, bringing Jack to give up before he performed the amount of exercises he planned to. Because Jack is taking full responsibility for his progress, he is often disappointed with himself, not fully aware for his progress, Jack can get depressed and in danger of losing hope.

\section{NEEDS}

- Better rehabilitation experience.

- Progress records.

- Increase exercises engagement.

- Rewards / appreciation.

\section{WHAT'S HAPPENING}

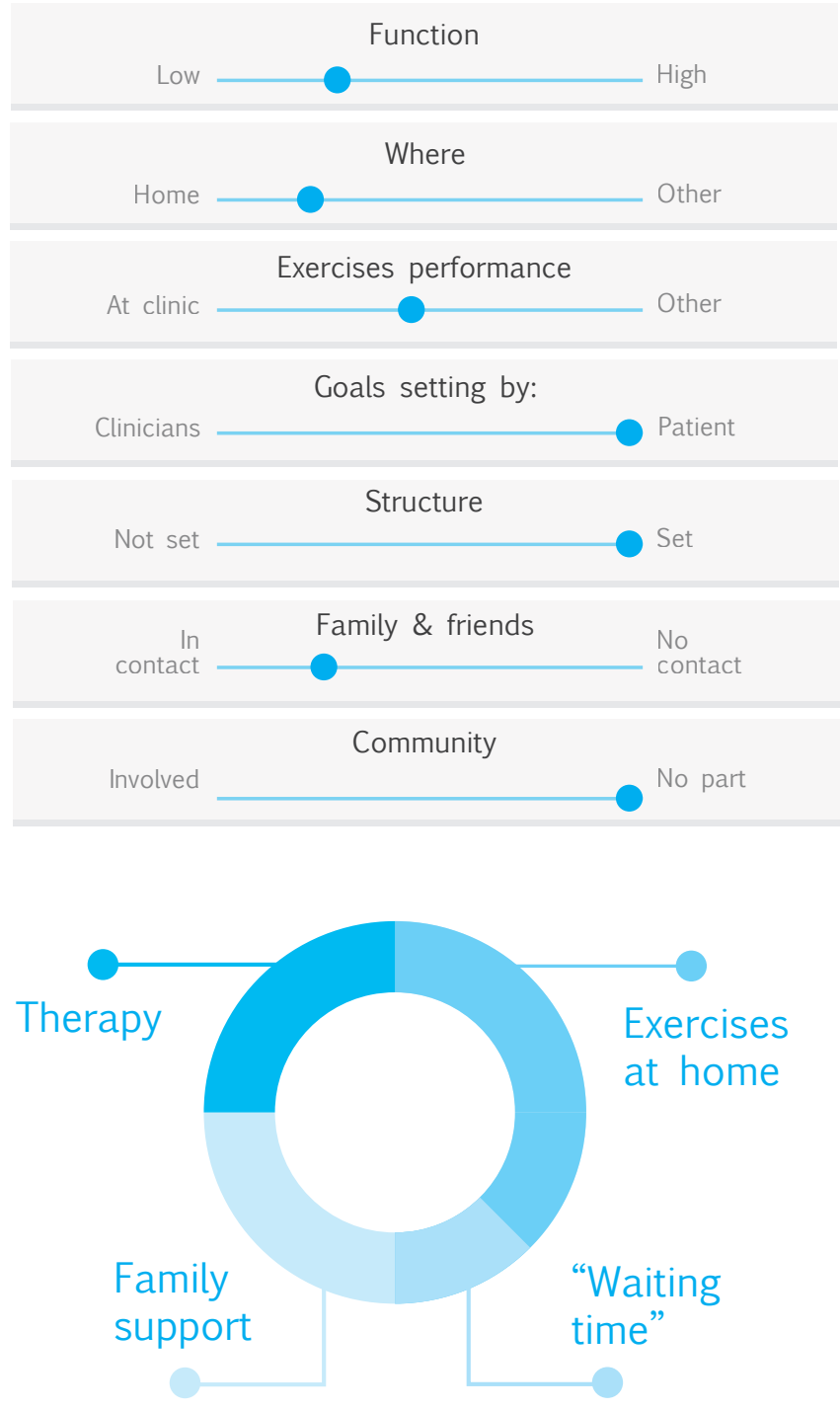

Figure 2. 3: personas 

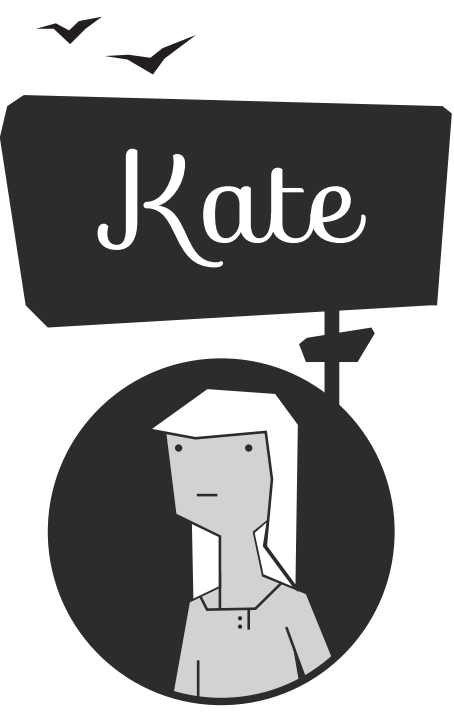

\section{WHAT'S FEELING}

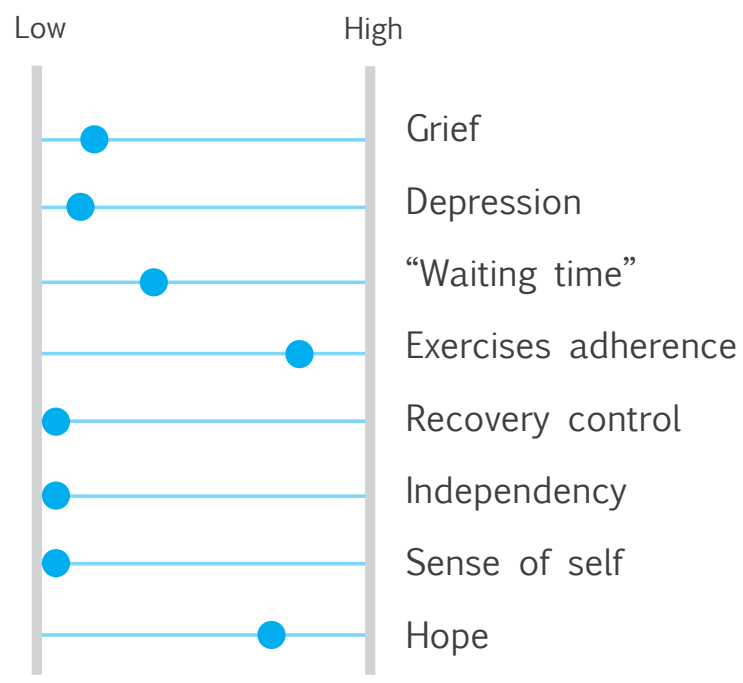

Kate performs her exercises only when the clinicians or nurses are in the area, or in the club. But outside of therapy or the club, she is waiting for the next session. Kate suffer from cerebral damage. In result her motivation is influenced by external factors only, such as others presence.

\section{NEEDS}

- Sharing progress records.

- Others presence.

- Rewards / appreciation.

\section{ABOUT}

Condition: Don't have full arm

function as result from upper extremity hemiparesis following stroke.

Age: 81

City: Wellington

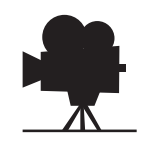

film

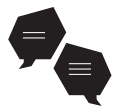

socializing

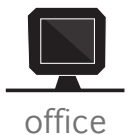

\section{WHAT'S HAPPENING}
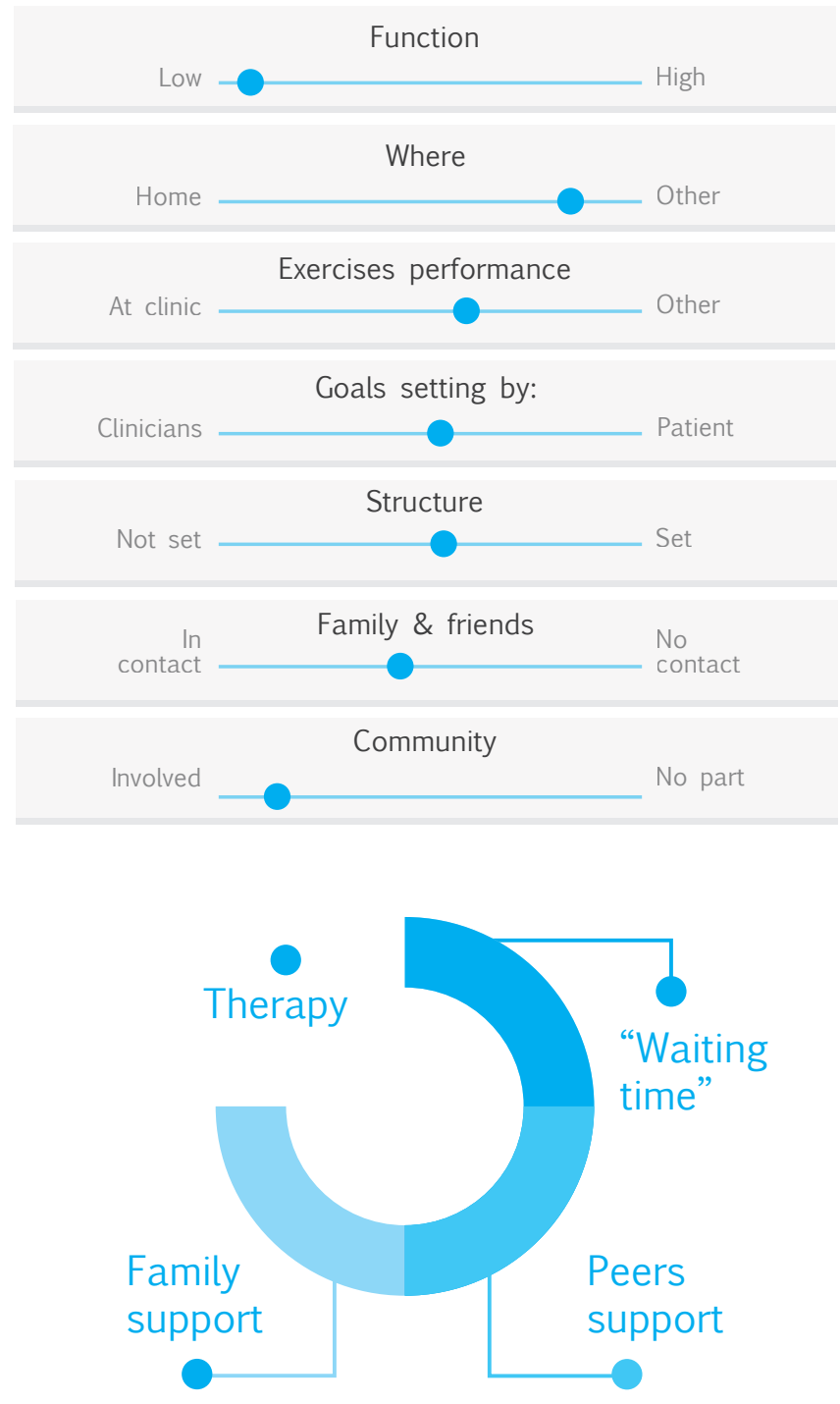

Figure 2. 4: personas 


\section{NEEDS}

- Improving rehabilitation experience. $x 3$

- Another place to go, or something else to do outside of therapy.

- Increase exercises adherence through games.

- Progress records. $x 3$

- Sharing progress records.

- Rewards / appreciation. x3

- Others presence.

- Peers support.

- Self-management x2

- Goals \& Values

- Emphasis on patient's character. 


\section{Identifying Needs}

Through this process, the researcher identified the main needs of stroke survivors:

\section{Another place to go to}

Patients spend a great deal of time alone, waiting for someone to tell them what to do or for the next therapy session, while in need of another place where they can be engaged with rehabilitation.

\section{Progress records}

It is hard to see progress in rehabilitation, but awareness of progress, even of the smallest steps, can help stroke survivors to maintain hope.

\section{Rewards}

Patients report the need for rewards, and these can facilitate the necessary feedback.

\section{Self-management}

Self-management can help stroke survivors to gain a sense of control over their own recovery. Many stroke survivors lose their sense of self after a stroke since they lose their functional body and need to depend on the people around them.

\section{Proposed solution}

A game based rehabilitation environment can provide stroke survivors another place where they can manage their own rehabilitation with the support of augmented feedback. In this place, they can progress and redevelop their sense of self through their connection with the avatar, their actions, goals, accomplishments and values in the game world.

\section{It is hard to see progress in rehabilitation, but awareness of progress, even of the smallest steps, can help stroke survivors to maintain hope.}




\section{Meetings with therapists}

\section{Meeting with a music therapist}

Music therapy naturally facilitates the use of RAS as it requires patients to play music according to a rhythm. We met with a music therapist who presented the musical instruments she uses with her stroke survivors patients and described the music therapy process. The session usually takes around 30 minutes, until the patients experience fatigue. Different musical instruments allow the use of different body parts. Usually, the therapist will strum the ukulele, or play the piano, at a tempo that would fit the ability of the patient.

The patient will play along according to the rhythm, and gradually, the therapist will increase the speed in order to challenge the patient. The therapist reported that some patients find the high-speed rhythm to be fun and playful (Robinson, 2014).

This informed the design criteria for the game, as the game can facilitate adaptive rhythm that would suit the patient's ability while challenging them and provide enough feedback.

\section{Meeting with Neuro- Physiotherapists}

Furthermore, meeting with neurophysiotherapists confirmed the use of RAS in game design, and the game concept described later in the development chapter. In addition, the neuro-physiotherapists suggested looking into integrating motor learning and feedback provision in the game.

\section{Velocity}

Another topic that came up was that of velocity; it is not about how fast the player reaches the target, but how well can they control the movement velocity. Therefore, there is a need to provide the player a reason to control their movement velocity.

A possible solution will be the use of feedback provision principles or music games design elements, such as playing different musical notes during a movement performance and according to a given tempo.

\section{Motor learning and Engagement}

To facilitate both motor learning and an engaging experience, the game should facilitate:

1. Adaptation and progression.

2. Change of tasks.

3. Allow breaks.

These elements may reduce performance in the short term, but will have better effects on rehabilitation in the long term, this is why an ongoing feedback is needed to maintain engagement. However, an ongoing feedback may cause feedback dependency.

A possible solution to prevent conflict of engagement feedback with motor learning feedback is to reduce and slowly remove feedback and RAS with players progress, or provide a replacement for the feedback.

Additional aspects that should be 
integrated into the game design are goal attainment, and personalisation: The game should provide the player with an opportunity for an emotional connection with the character.

\section{Meeting with a health psychologist}

The health psychologist gave importance to the difference between

\section{adherence and engagement:}

Adherence, like compliance, applies that the person or patient is a recipient, they are following recommendations and doing what they are told as opposed to being active, committed, and engaged in the process.

To get the optimal benefit from the rehabilitation, patients have to engage. Adherence is not enough, they can turn up to rehabilitation and go through the motions but that is not going to have the same benefit if they are not active, committed, and engaged in the process.

\section{Connectivity}

The therapeutic connection between patient and practitioner: In order to facilitate a therapeutic connection, the game can provide a narrative through visuals and audio, these will promote avatar connection and the development of personal goals of players in the game world. "Aspiration leads to goals in rehabilitation, that leads to therapy tasks". According to the health psychologist, if the focus of the technology is on the tasks, then we need to somehow allow a connection to the broader picture of goals and aspiration, which is an important component.

It is important that the patients will be able to see their progress and experience progress, see that it connects to the task that they performed, while knowing why doing the task is important and how it connects to their goals and aspirations.

The narrative in the game can offer a metaphoric world of the patients' aspirations, where they can focus on their goals in the game and gain a sense of achievement while making progress in rehabilitation as well. According to the health psychologist, the sense of progress will keep patients engaged with rehabilitation. However, even clinical assessment tools do not provide connectivity, as they can not measure small changes. Games could provide a solution as they can provide an immediate feedback and sense of progress, showing patients they are on their way to achieving their goals.

Furthermore, the health psychologist identified a few characteristics that practitioners should sustain in rehabilitation, such as:

\section{Investing}

The practitioner should have an emotional investment in the process.

\section{Entrusting}

Providing the patient with trust in their skill and competence.

\section{Adapting}

Adapting is probably the most relevant 
aspects for game design. Being able to respond to the person's needs and preferences, while also to move them forward and challenge them more when they are ready, knowing they are in the right place to be challenged. Or pull back to let them experience some success before you challenge them further.

Adapt, tailor, respond to a person's needs in the moment as they progress through rehabilitation is one of the key things.

\section{Reciprocating}

The clinician is as engaged and reciprocating emotionally so the patients feel the person is as invested in the process as them. Again, feedback comes as an important mechanism to facilitate this characteristic. Virtual characters and worlds can provide this feedback. However, the distinction between feedback for engagement and feedback for motor learning is of importance.

\section{Knowing}

You have to really know who this person is and who they are as a human being in order to adapt and be responsive. It's important in order to know how to connect the aspirations.

\section{"Adapt, tailor, respond to a person's needs in the moment as they progress through rehabilitation."}

Dr. Nicola Kayes 


\section{Field Observations}

The researchers observed the session in the clinic while neuro-physiotherapists explained to them what is happening.

The group framework of the session contributed to the social aspect and peers support which has been mentioned by Eng et al. (2014) as a positive reinforcement for patients. However, each patient participated in individual activities, tailored to their own needs and abilities.

One patient suffered from upper limb hemiparesis and spasticity. His aim was to hit the pins with a rubber ball using his affected arm. After every attempt, the patient picked the ball with his unaffected arm and then placed it in his affected arm to throw it again. A staff member stood beside him, chatting with him and providing positive feedback on successful attempts. After a few minutes, the facilitator called the patient to change his activity.

Another patient suffered from traumatic brain injury (TBI). The patient's goal was to transfer a bucket from point $A$ to point B (see figure 3). A staff member walked beside the patient, chatting with him to distract his awareness. The first attempt was successful. In the second attempt, the staff member added a challenge. She placed one mat on top of the other on the floor in the second half of the patient's walk. When the patient reached this point, he said he can not continue and was about to give up and fall down. The staff member caught him and supported him throughout the rest of the walk. In the third attempt, the staff member reminded the patient about the challenge coming, in order to help him plan his steps ahead. Two steps before the challenging step the staff member clapped her hands twice, synched with the patient's steps rhythm, providing an auditory cue to help the patient plan his third move unconsciously. The patient passed the challenging part in his third step and reached the goal successfully.

Many stroke survivors do not have access to these clinics due to financial and transportation limitations, and even when they do, research show many patients spend a lot of time waiting between appointments, or for someone else to tell them what to do, in need for more opportunities for physiotherapy exercises at home settings, which can be fulfilled with digital games.

The field observations confirmed the research assumption derived from the literature on the use of RAS. Furthermore, the observation showed how RAS can support patients through challenges. And so, this research recognises RAS as beneficial design criteria for rehabilitation game design, and as a possible solution for the problem faced by rehabilitation game developers; the frustration that can be caused by the both physical and cognitive challenges overload. 


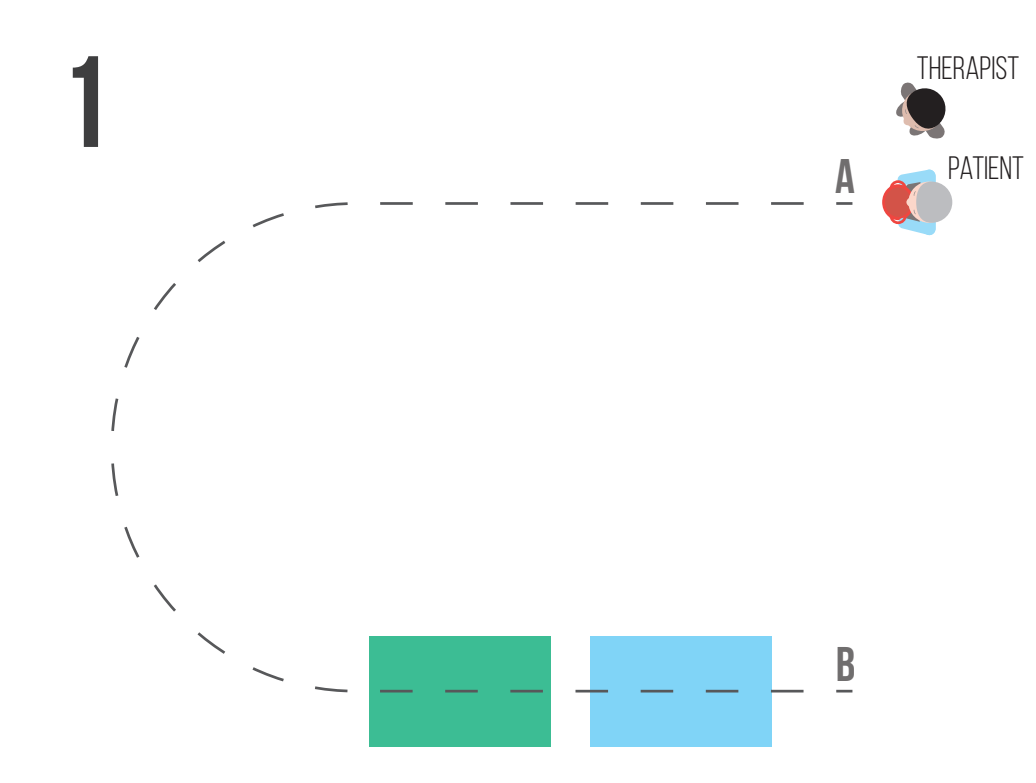

The goal of the patient is to transfer the red bucket from $A$ to $B$, following the path. The therapist is guiding and supporting the patient through the path while chatting with him so he will be less conscious about his movements.

The mats facilitate a balance challenge

Mats placed on top of each other, increasing the challenge. When the patient arrived at this point, he stopped and said he can not do it. He wanted to give up and almost fell down. The therapist caught him and told him he can, then supported him physically, and they went through the challenge together.

The therapist prepared the patient ahead to the challenge, in an aim to visualize and plan his next actions.

This time, the therapist was not supporting the patient physically. Instead, the therapist clapped his hand twice, and in the third cue, the patient made his step and passed the challenge.

Figure 3: Field observations 


\section{Design criteria}

Based on these findings, the research proposes the following design criteria for an Able-M upper limb rehabilitation game:

\section{Game controller: Able-M}

We identified a game controller that was designed specifically for upper limb rehabilitation following a stroke, provides accurate information about the user's movements, supports the arm in a safe manner, and provides exercises for patients who may suffer from spasticity as well.

In this case, the design should investigate how to engage users with the two interactions that the Able-M was designed to facilitate:

Arm movements across a surface and lifting finger movements to click.

\section{Engagement:}

Second, we identified design elements that can enhance engagement. We found that the elements that are known as significant by most researchers are:

1. Feedback to promote engagement and optimal experience.

2. Skill-challenge balance to promote engagement, challenge based immersion and optimal experience.

3. Narrative for focus diversion and imaginative immersion.

We also identified two gaps in the research about with these elements:

1. How should feedback be provided in rehabilitation games to promote both engagement and motor learning?

2. How to maintain both the cognitive and physical challenges in rehabilitation games while preventing frustration?

\section{Rehabilitation:}

Third, we identified rehabilitation methods that can increase the effectiveness of the rehabilitation intervention and promote the retention of motor learning.

1. Feedback provision.

3. Rhythmic auditory stimulation.

\section{Questions:}

1. Can feedback provision mechanisms also facilitate feedback for engagement?

2. How can RAS be implemented in the game, and can the rhythmic cues support players in cognitive challenges?

3. What will be the suitable level of cognitive challenge?

\section{Assumptions:}

1. The game prototype will facilitate the design criteria.

2. The design criteria will achieve the aims for Able-M interactions, engagement, and rehabilitation . 


\section{Design process}

In order to facilitate the criteria in the game, the development process was based on iterative design methodology, where the researcher generated prototypes, tested them with healthy individuals and iterated according to the data gathered from user observations and semi-structured interviews with participants. Later prototypes were presented to therapists in order to confirm the rehabilitation criteria facilitation in the game. Iterations made accordingly.

In the following chapter, the development process will be described, concluding with the final prototype. 


\section{Concepts}

Based on the benefits of Rhythmic

Auditory Stimulation recognised by previous research, two strong concepts were identified, and from them, two questions:

\section{Experiment 1:} Paper prototype

Can the player follow the rhythm?

This question implies that the meaning of success is the accuracy of synchronisation with the rhythm. The aim can be this success in the form of points, or in the means of how this success helps the player to accomplish his/hers goals in the game.

\section{Experiment 2: Paper prototype}

2. Will the players follow the rhythm when they are creating music in the game world?

Success is determined by the player, as music can be a subjective form of free expression. The creations can be shared amongst friends, family and peers. Social recognition and appreciation can encourage patients to keep going and create more music. This may work well with some people who have a high intrinsic motivation to create music, experience with music composition, or willingness to express themselves freely. However, some stroke survivors may lose their ability to understand music (Stewart, von Kriegstein, Warren, \& Griffiths, 2006), which can influence their creations, or their ability to enjoy the experience. Hence, In order to retrain patients rhythmicity, a combination of choice for musical expression and a rhythm challenge could be more suitable. 

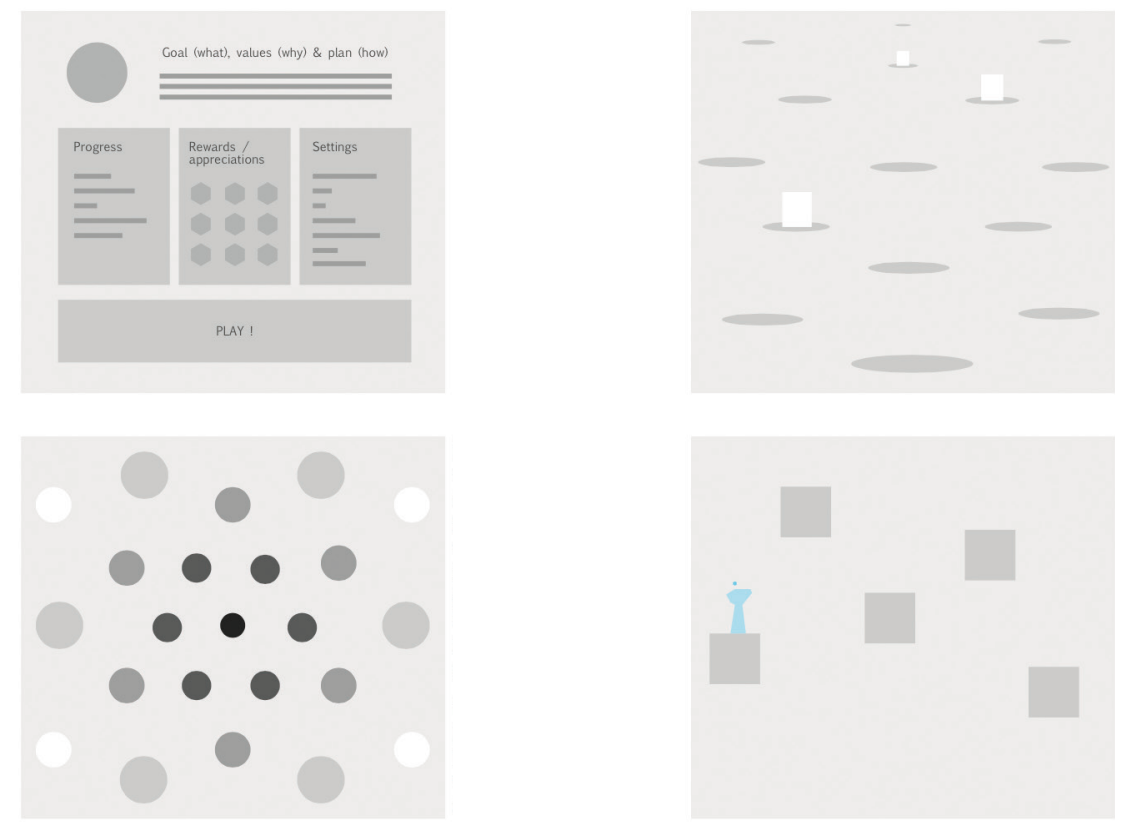

Figure 4: Concepts
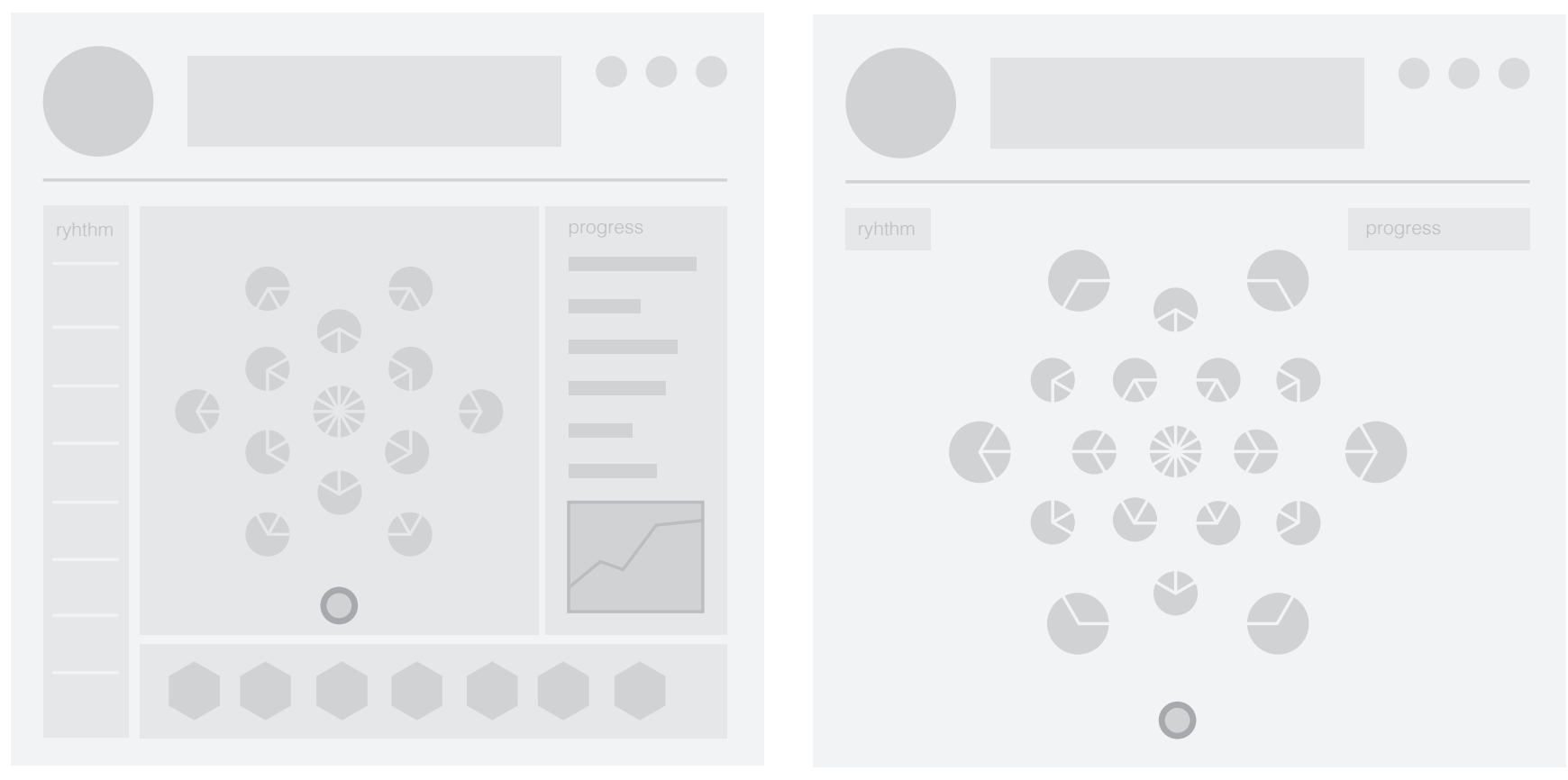

Figure 5: Music app concept 


\section{Game model}

\section{Experiment 3: \\ Game model using gestures}

Two or more players are needed to play this game. While sitting in a circle, all the players clap their hands according to an agreed beat. Players can give treasures to each other to increase points, or shoot players and remove them after three hits. Players clap twice according to the beat, and in the third cue, they can either catch a treasure, protect themselves, give a treasure, shoot another player, or just clap. The aim of the players is to stay in the game as much as possible and to get extra points for treasures. After testing the game we revealed that the social aspect of the game can be fun and engaging. While it's a competitive game, it can also promote a form of social currency through giving treasures to each other. However, maintaining the challengeskill balance for all the players involved when designing for patients with different abilities can be a problem. The most significant design elements were the rhythm emerging from players engagement while keeping everyone on the same beat, feedback, and the challenge facilitated by the need to stay on beat, avoiding obstacles, and gathering rewards from the right person at the right time. 


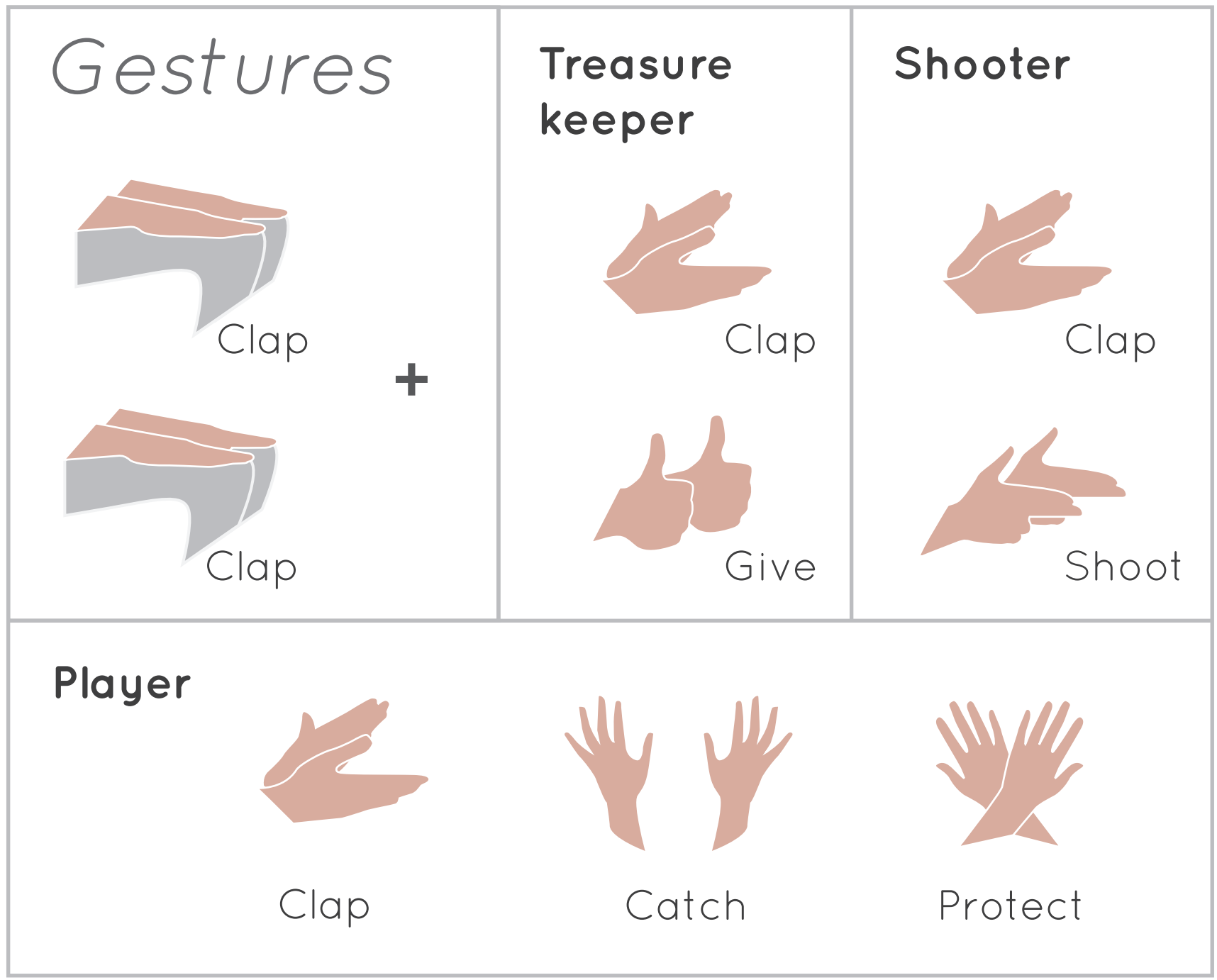

Rules

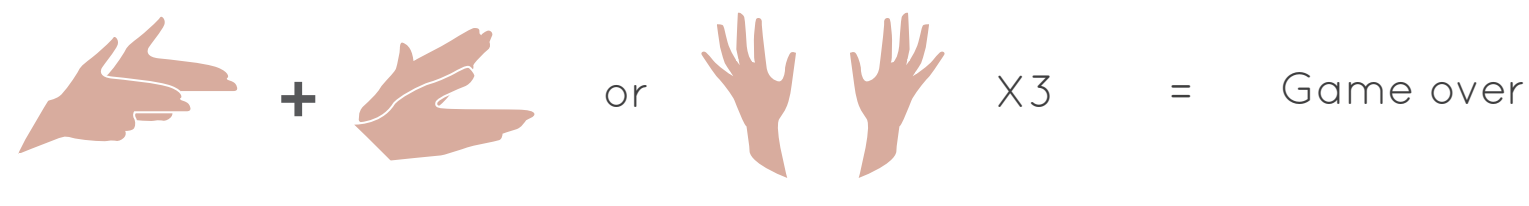

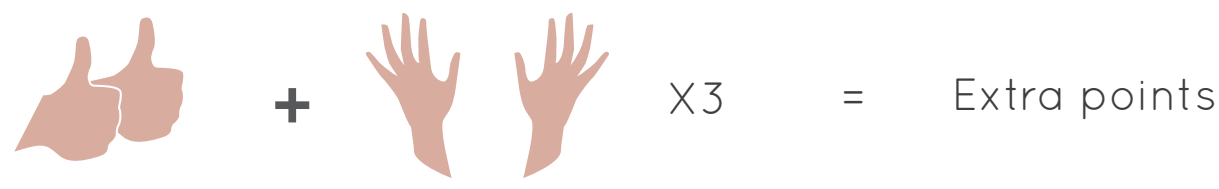

Figure 6: Game model 


\section{Development}

\section{Experiment 4: \\ First person rhythm game}

The first prototype used a first person perspective and integrated RAS to engage players with certain movements. The rhythmic stimulation was both visual and auditory, aimed to motivate navigation through the game world using rewards and obstacles that appear at a certain location relative to the player position, and at certain times according to a consistent beat. The players aim was to avoid obstacles that may reduce their level of health, and collect rewards that could increase health. Facilitating a negative punishment and positive reinforcement system to shape the players' upper limb movements, which can be both challenging and rewarding to the player. The rhythmic pattern of the elements may help the player to anticipate their next moves automatically. The environment contained natural elements such as green mountains and trees surrounded by water. The space allows the player to explore and find new places. After testing, we recognised that first person perspective will be less appropriate for stroke survivors' cognitive abilities, third person perspective may be perceptually clearer. Third person perspective can show the players how their movements influence their avatar movements, enhance character empathy (Heinzen et al., 2015) and divert players' focus to the character's needs. However, more research is needed on this subject, as it might be that practice can improve first person usability and enhance immersion. For the scope of this research, it will use the perspective that is known as most usable for stroke survivors. 

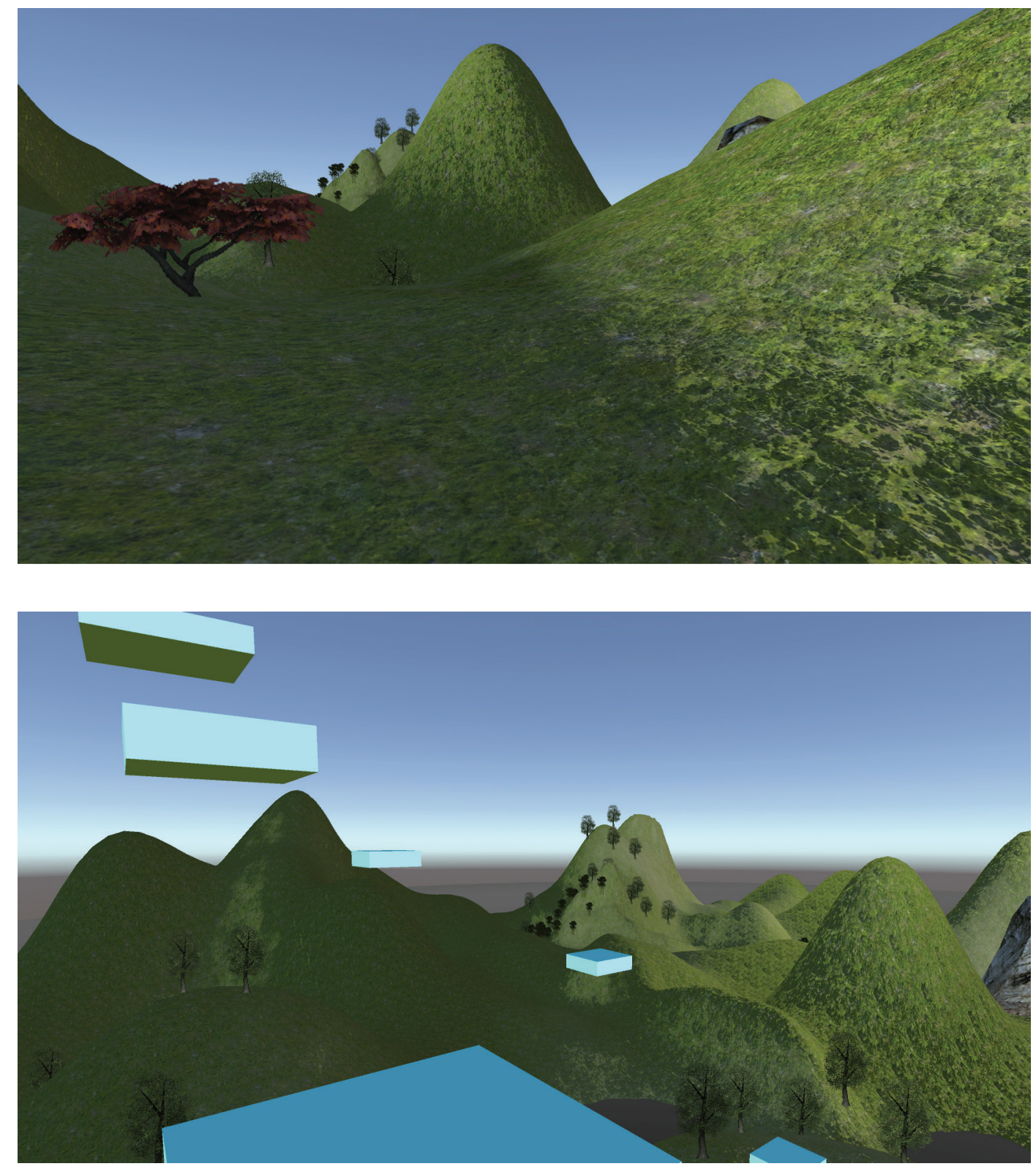

Figure 7: First person rhythm game 


\section{Experiment 5:}

\section{Third person rhythm game}

Hence, The researcher proceeded to another prototype with a third-person perspective, where the camera follows the avatar controlled by the players' upper limb movements. In this case, the world was built as a maze. However, something was missing, a meaning and a goal to contain the purpose of avoiding obstacles and increasing health. 

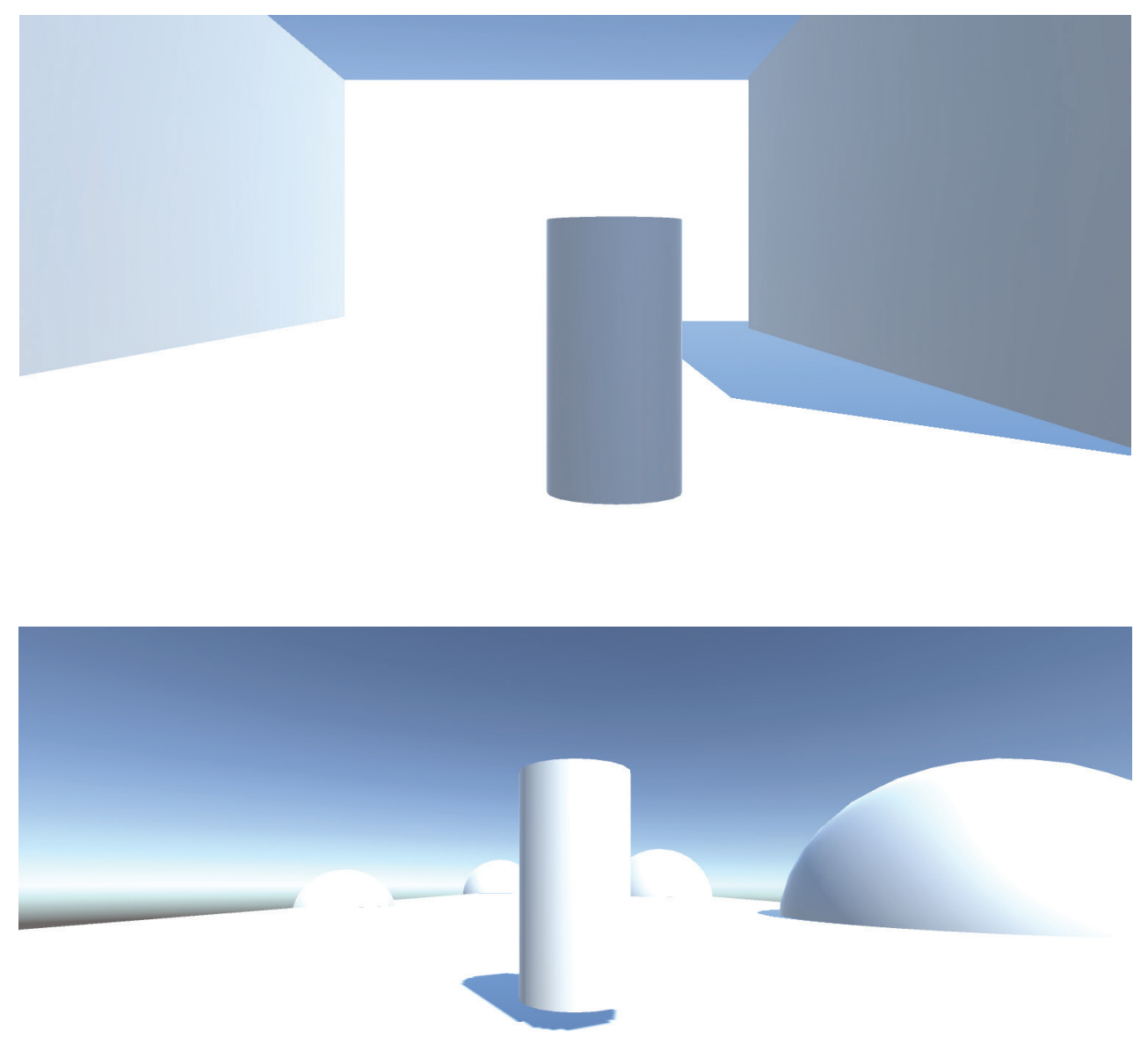

Figure 8: Third person rhythm game 


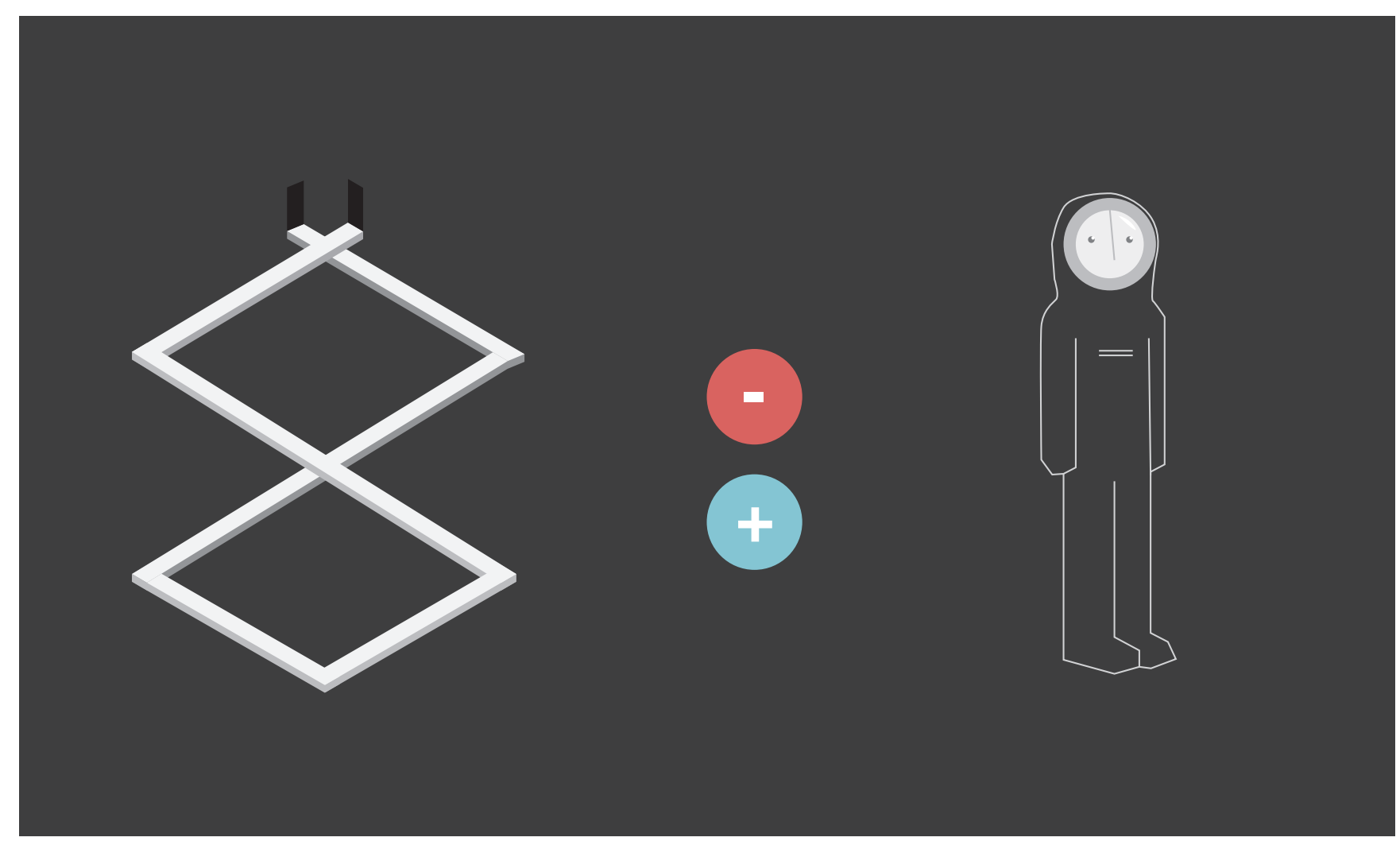

Figure 9: Narrative concept

\section{Experiment 6:}

\section{Narrative}

The researcher developed a story for the character in the game world.

The rehabilitation process has been referred to as the way back home in a qualitative study on patients motivation to perform their rehabilitation exercises outside the clinic (Eng et al., 2014).

This metaphor describes the process patients need to go through to get back to their functional body while struggling through the unknown condition following a stroke. The hopeful mention of "home" emphasize the purpose of their journey and asks for an action. The researcher used this metaphor to develop the narrative of the game. The story is about an astronaut who is flying through space in his spaceship. The astronaut is on a mission which can be discovered and defined by the players as the gameplay progresses, this provides the

players the ability to choose their own goals in the game which is recognised as important for their motivation (Eng et al., 2014). In addition, the narrative brings the players to land on a new and unknown planet, where they can find fuel needed by their spaceship to get back home, to planet earth. While looking for fuel, the players need to sustain their avatar's oxygen level by collecting oxygen along the way and avoiding rhythmic obstacles such as asteroids that may harm the avatar and cause loss of oxygen. The player's upper limb movements control the avatar navigation through the planet on the $X$-Axis while click (lifting the finger up) would influence the avatar's movements on the Y-Axis. 


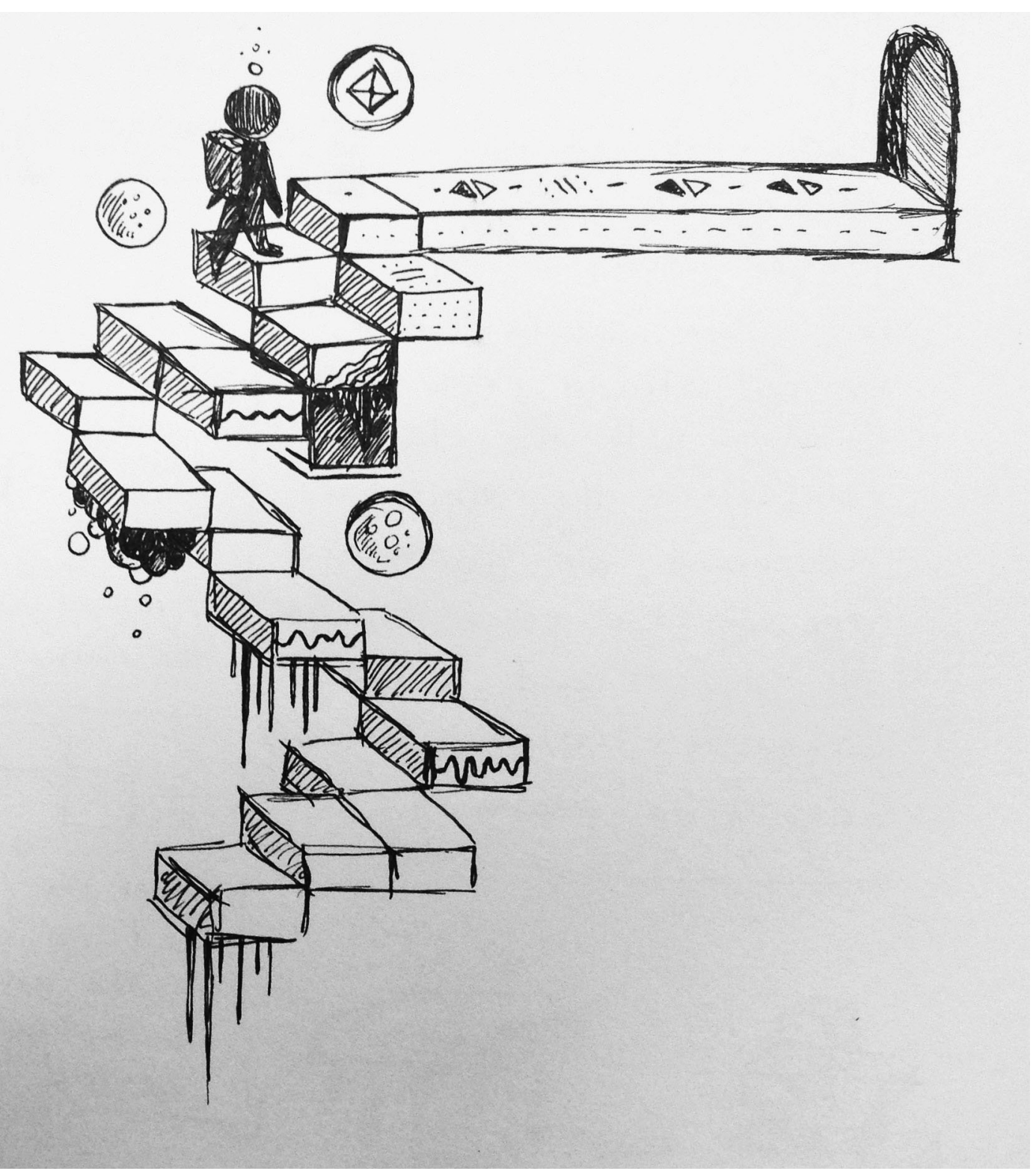

Figure 10: Concept development sketch 

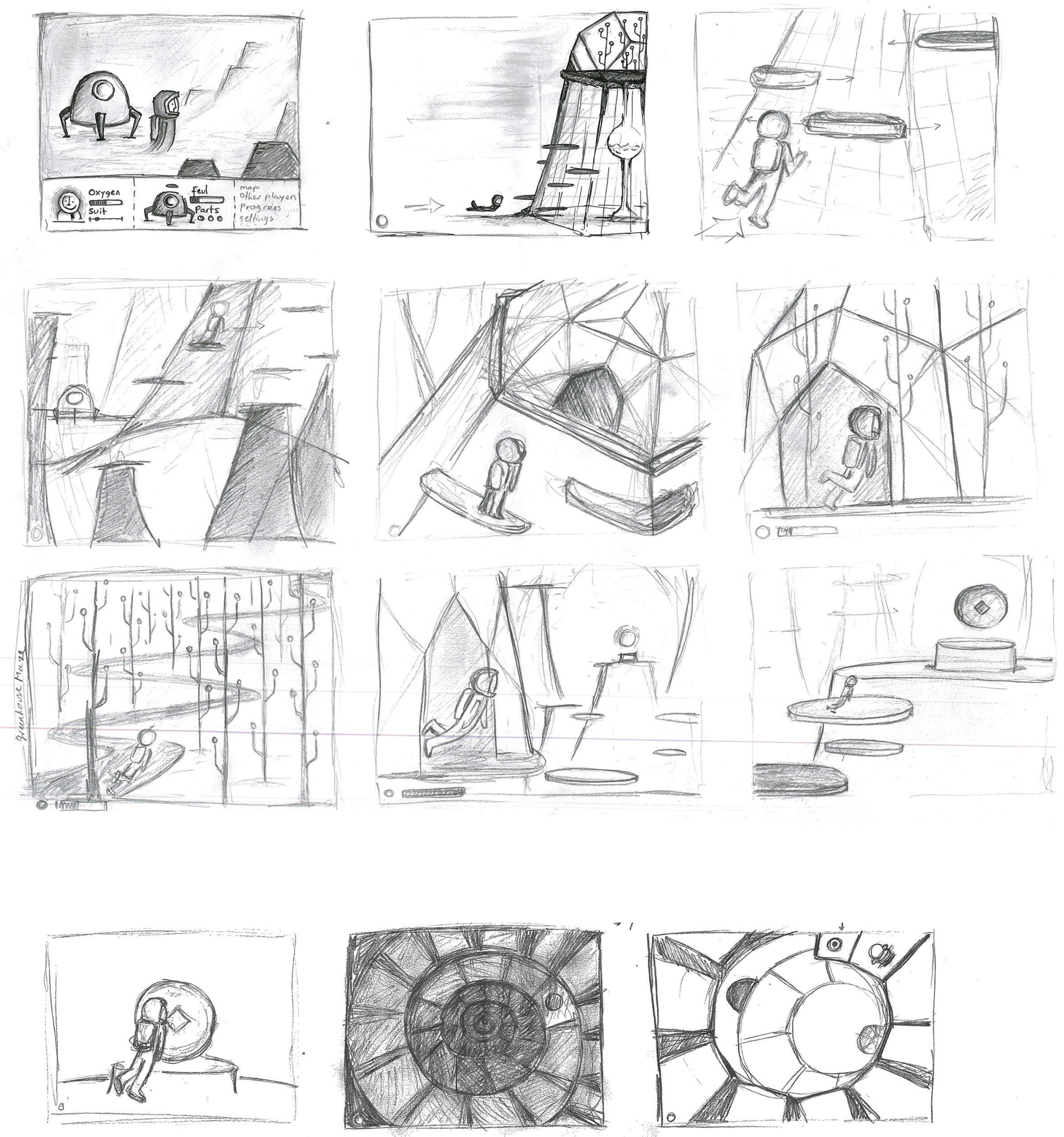

Figure 11: Concept development through storyboarding 

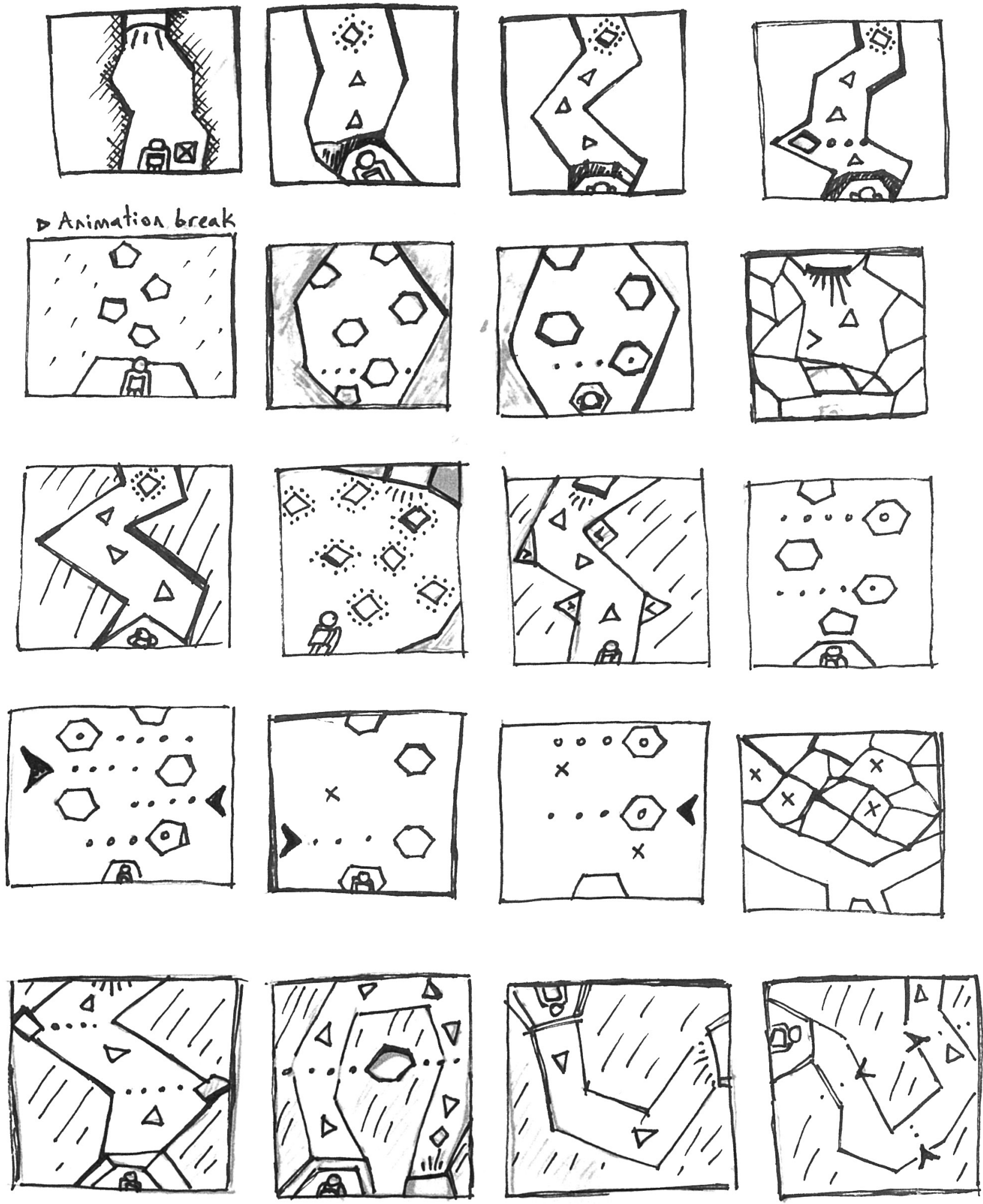

Figure 12: Level design through sketching 
Throughout the design process, the researcher developed several prototypes of different game mechanisms. These have been tested and iterated into a final prototype with different levels. The game is in a birds eye view to provide the player a good perspective on the game world.

\section{Experiment 7:}

\section{Calibration}

The game starts with a calibration phase where data on the player's range of motion and speed is been collected in order to tailor the next levels to the players needs.

1. The first prototype was questioning the player "how far can you go?" In order to prompt an action. The player controlled a centered element and was required to move it around to activate further elements that represented steps in the player's range of motion. Every time the player reached a step, the element would change color and generate a sound.

\section{HOW FAR CAN \\ YOU GO?}

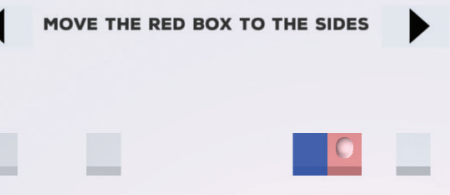

Next

\section{HOW FAR CAN YOU GO?}

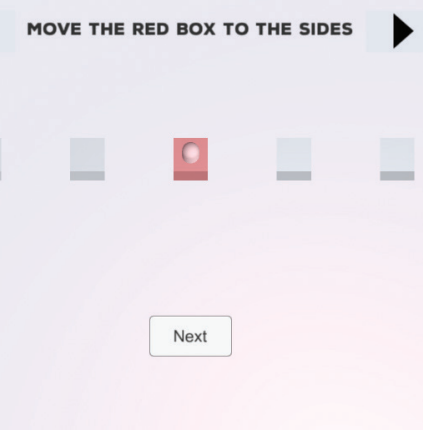

Figure 13: Calibration prototype 1 
2. The second prototype had more elements all around the player, these produced different notes in a collision, acting as a musical instrument. This prototype relays on the player's need to explore the different notes while the game is detecting the player's range of motion.
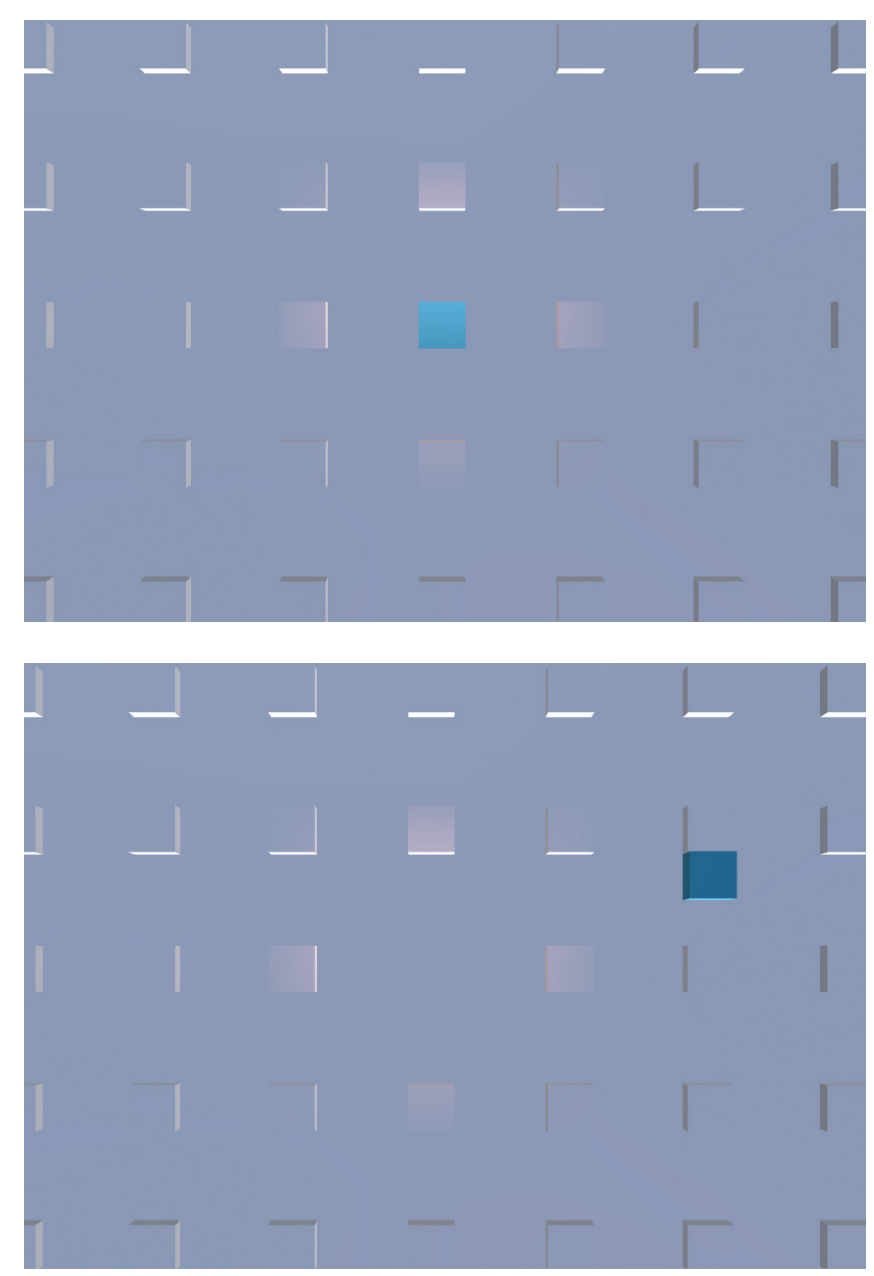

Figure 14: Calibration prototype 2
3. In the third prototype, the elements were ordered around the player. Some generating notes in a collision and some elements generated loops of rhythmic patterns in a collision. This prototype acts as a musical instrument as well, while providing the player rhythms to play along to. The aim of this phase is to collect data about the range of motion of the player while the players' motivation to continue moving their upper limb will be to create music. 

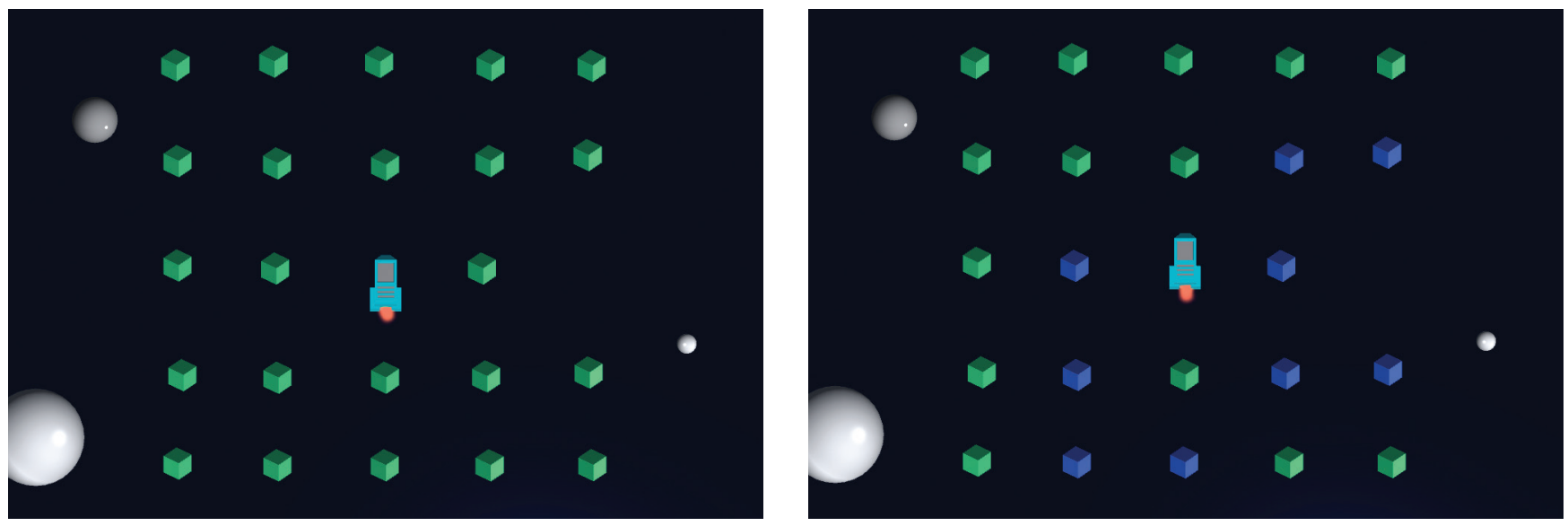

Figure 16: Calibration development

The problem with the instruments prototypes is that some stroke survivors may lose their ability to make and enjoy music as a result from their loss (Wilson, Pressing \& Wales, 2002) as many areas in charge of pitch, timbre and rhythm are in the right hemisphere (Stewart, Kriegstein, Warren \& Griffiths, 2006).

Therefore, the ability to understand music within right hemisphere stroke survivors may be affected. However, some areas in the left hemisphere are also responsible for rhythm (Stewart, Kriegstein, Warren \& Griffiths, 2006), and it's been found that a bilateral network of motor areas is activated when a rhythm is perceived, even if no movement is being made (Grahn \& Brett, 2007).

4. The fourth prototype integrated the narrative requiring the players to fly a spaceship around the space until landing on the planet. Boxes positioned between the spaceship and space and were destroyed by collision with the spaceship, revealing the space behind and introducing the players a new world. The boxes are divided into levels of range and different sides in order to detect the range of motion and side neglect. This phase displays the players the building blocks of the game like in story theater, letting the players be part of the creation of the next to come. When the players discovered enough, they can land on the planet, and proceed to the next level, tailored to their ability or effort in the calibration phase.

A problem recognised with testing was that it was too easy to move the spaceship around without needing to move the upper limb too much. Thus, the researcher used steering behaviours to make the spaceship seek the upper limb movements in slower speed, requiring the player to move further in order to get the spaceship to points in the space. The speed can also be tailored to the players' needs.

5. Iterations were made after testing the prototype with a therapist, and as result, in the fifth prototype of the calibration, the players are to lead the spaceship to different planets. The players are asked to click on the planets, which are seen in the space only for limited amount of time. The players must reach the planets at a different location at the right time. 


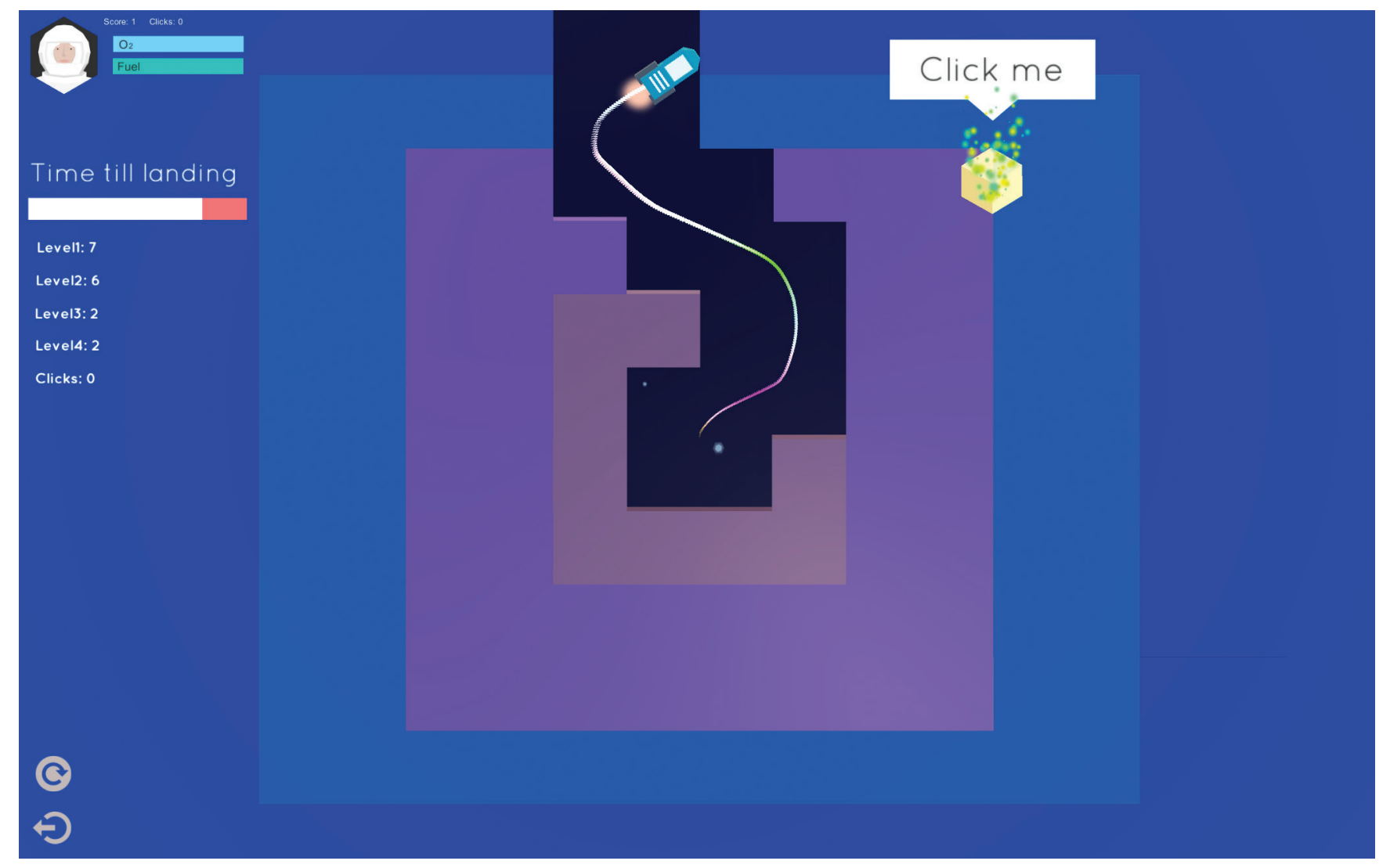

Figure 17: Calibration prototype 4

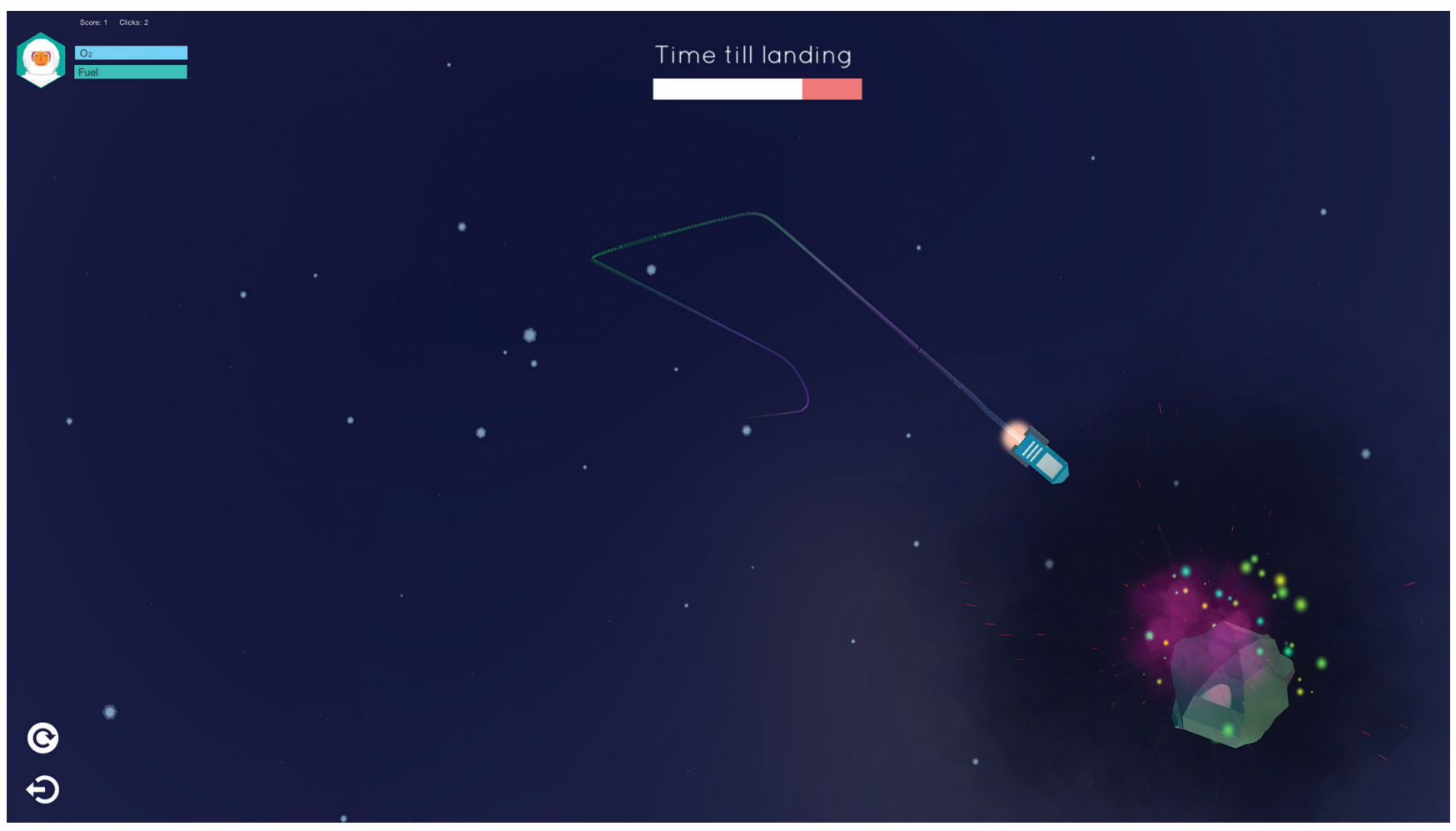

Figure 18: Calibration development 5 


\section{Experiment 8: Going forward}

Following the calibration phase, a short animation describes the landing of the spaceship and the players can begin to explore the planet. This level is designed to be easy and clear, yet the astronaut's path is tailored to players' ability and needs, based on the calibration phase.

The mechanism is familiar to the players as it uses the steering behaviour used in the calibration phase. The aim of the players is to space walk through the path till the end where the next level begins.

Along the way, there are structures positioned to define the players' path. So the players can know how to navigate to the next level.

Open-ended games or sandbox games where players can explore and define their own gameplay are known to

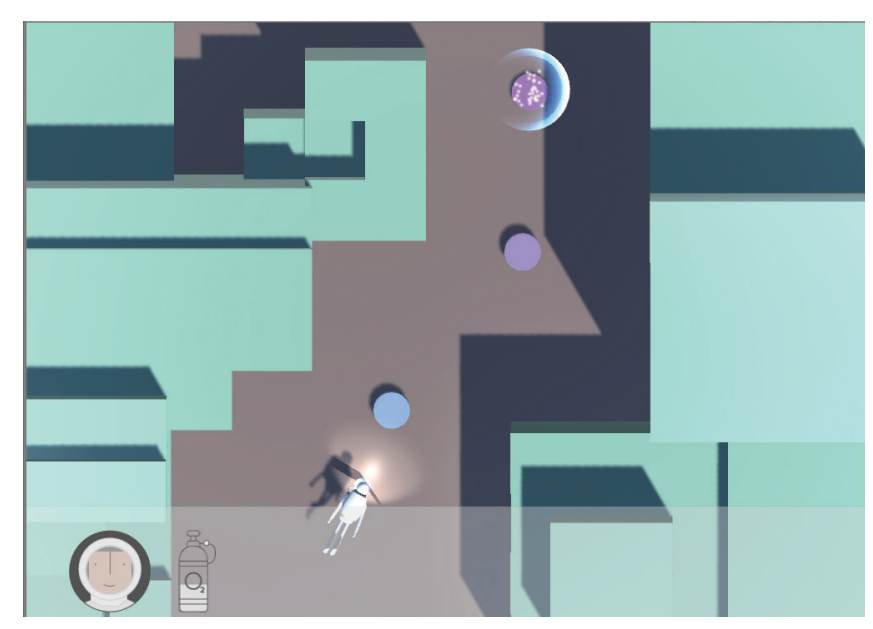

Figure 19: Blocks frame the path be engaging (Squire, 2008). Hence, the researcher decided to keep the box elements from the calibration phase to define the path and provide the player the opportunity to shape the structure along the way. These can also contain the fuel the players need to dig in to find. However, when the researcher tested the game with healthy individuals, players spent time destroying the boxes and shaping structures, sometimes until there were no boxes at all.

The problem is that once the player shapes the structure, the path to the next level is not clear anymore. In addition, this free mode might be engaging, but it is unknown if the player performs the movements needed by the rehabilitation program.

This level could be at calibration phase, in order to familiarise the players with the controller.

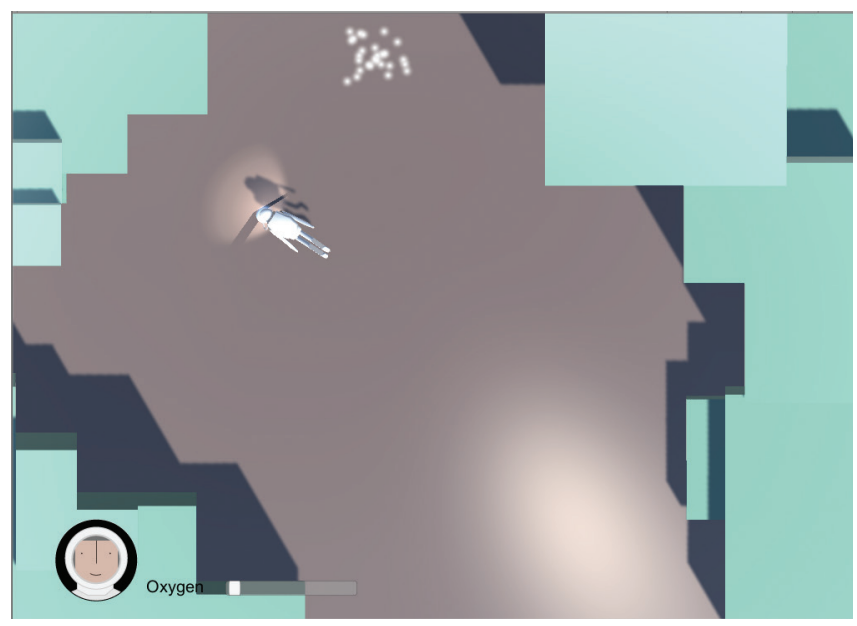

Figure 20: Blocks removed 


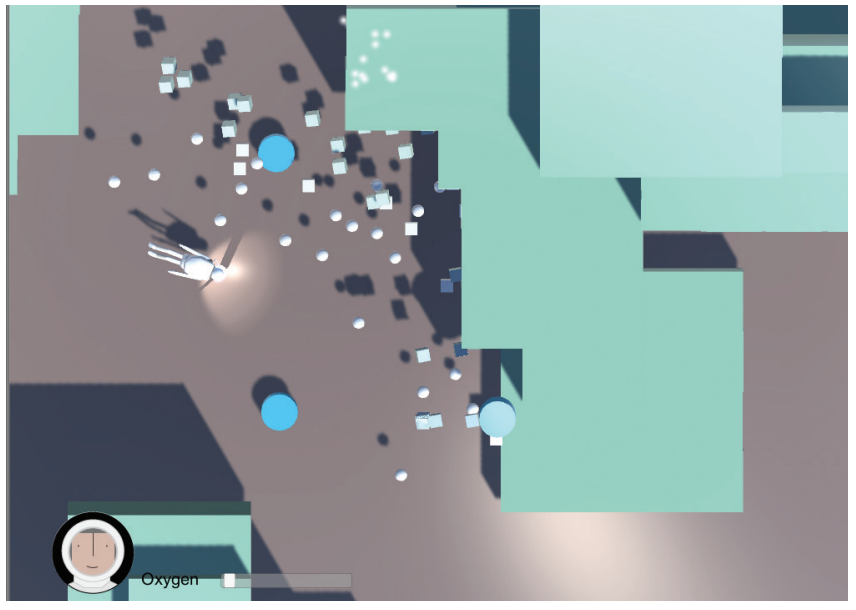

Figure 21: Generating objects

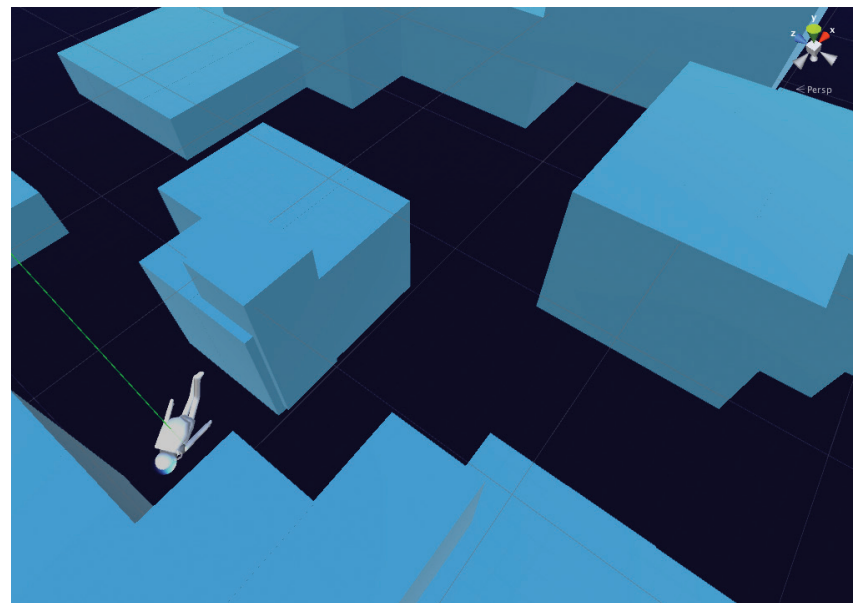

Figure 22: Exploring the world

And so, the next iteration contains structures that can not be destroyed.

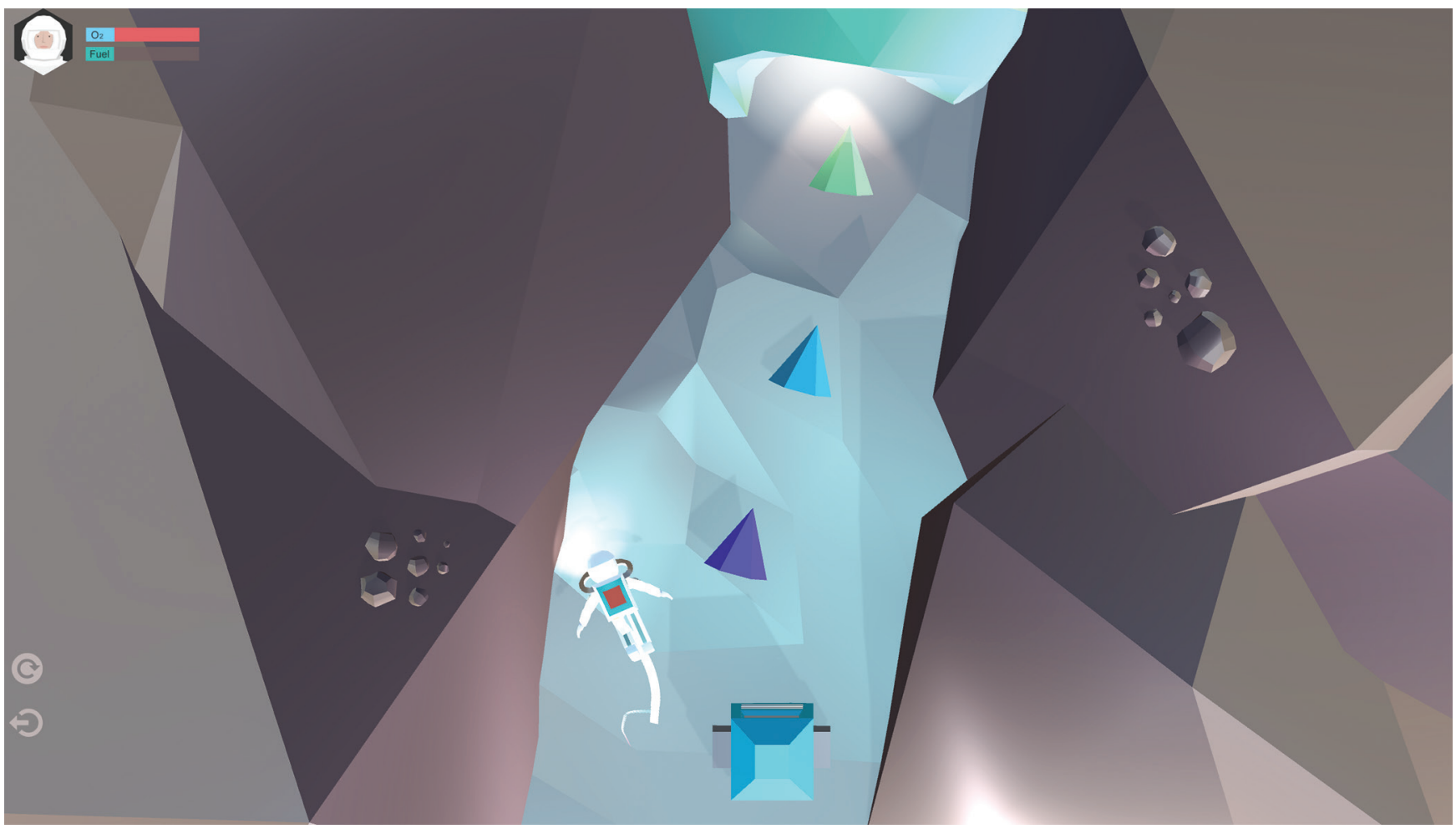

Figure 23: Clear path forward 


\section{Experiment 9:}

\section{Feedback provision}

In the second prototype, the players are to follow knowledge of performance (KP) signs that lead to oxygen

(knowledge of results - KR). Every KP step generates a musical note once collided with the avatar. Once the avatar collides with the oxygen, a final sound that completes the melody is generated as a reward, and the avatar's oxygen level is increasing. The feedback provision along the game is summary in order to reduce dependency on feedback.

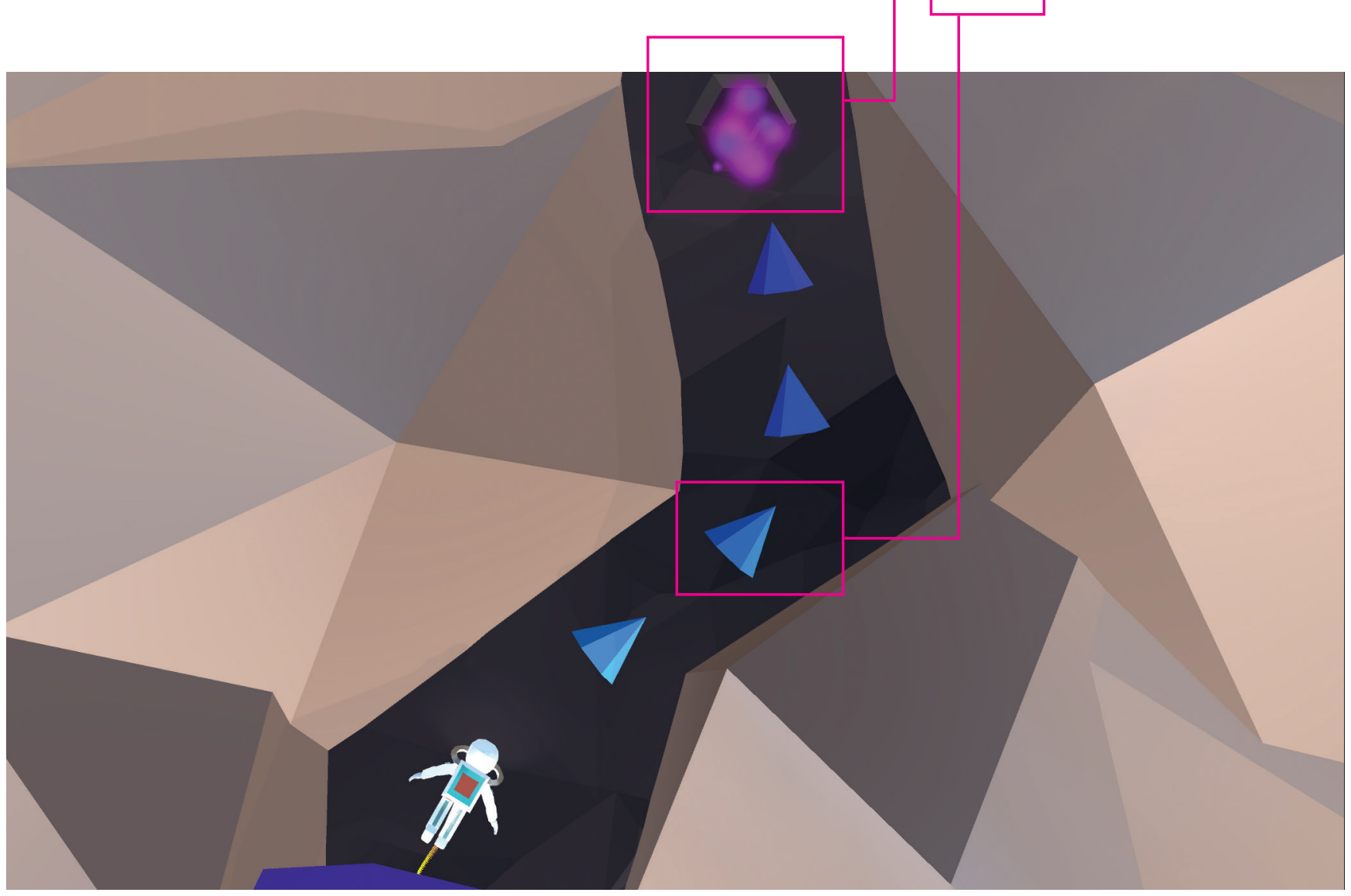

Figure 24: Feedback provision 


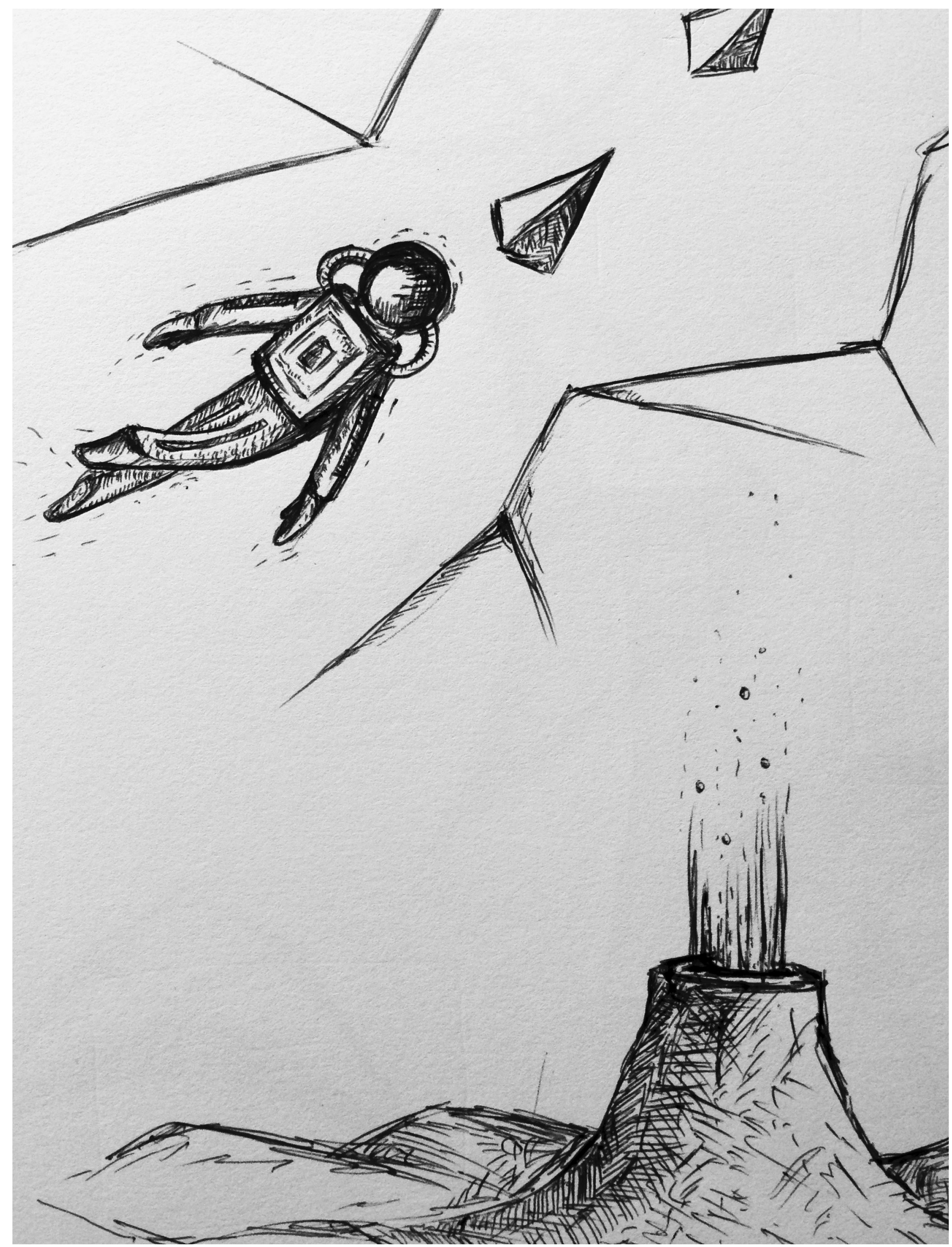

Figure 25: Elements sketch 


\section{Experiment 10: Rhythmic obstacles}

The third prototype introduces the players to the obstacles, at first asteroids, and later on, these became flying aliens. The characters of the aliens were more interesting to players in testing, and in order to keep the consistency in the game, the asteroids were removed. The aliens move across the avatar's path and create auditory and visual rhythmic patterns that players can anticipate ahead and plan their next moves accordingly. It may be that this condition will require more use of cognitive resources as was mentioned in testing by a healthy individual who was listening consciously to the rhythm in order to know when to make his next move. Cognitive impairments may influence patients ability to perform at this level in the same way. However, the rhythmic cues may support the upper limb movements. The use of rhythm can adapt to players' needs and abilities, in order to increase or reduce the use of cognition.

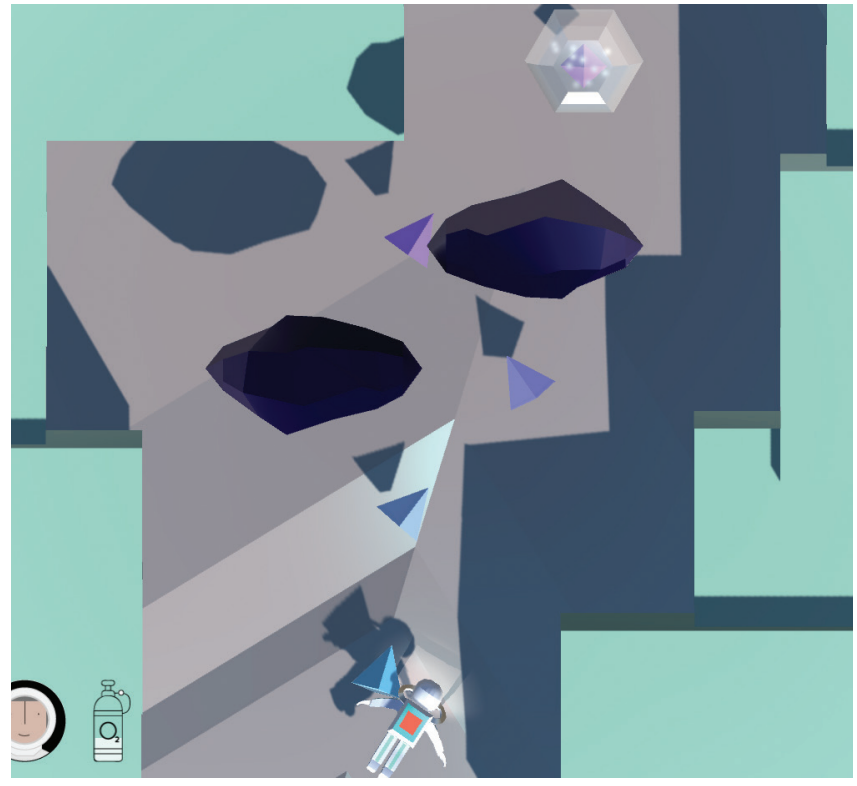

Figure 26: Rhythmic astroids

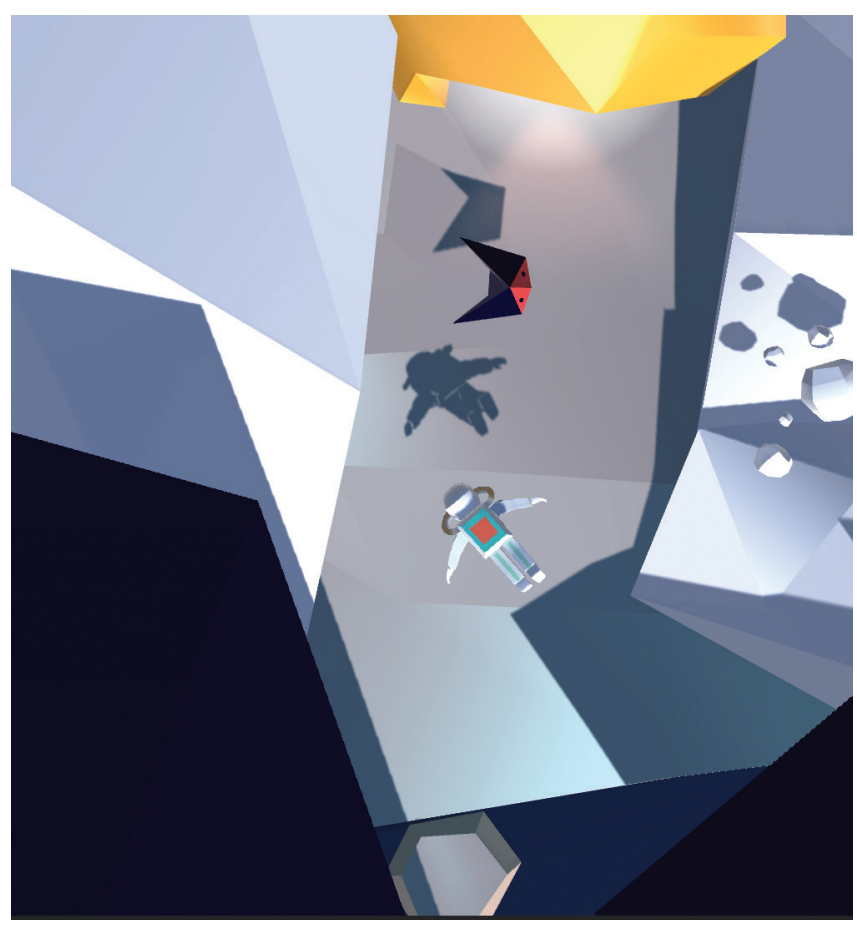

Figure 27: Rhythmic aliens 


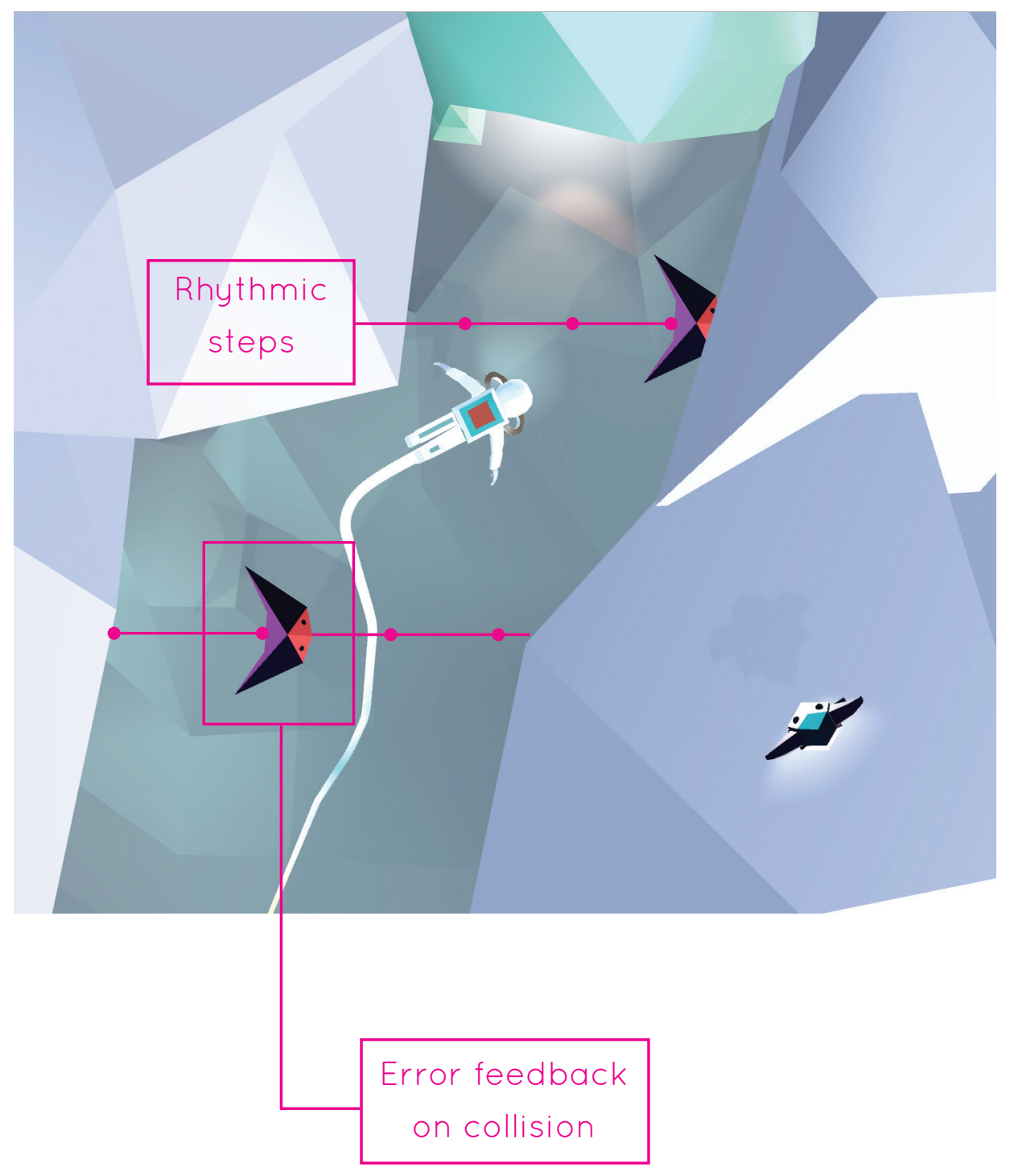

Figure 28: Rhythmic obstacles 


\section{Experiment 11: Musical steps- Feedback provision}

In this prototype, a short animation describes to the players the need of the avatar to continue to the next mountain through a series of floating elements. The players must move within the constraints of the elements, introducing the players a new mechanism to learn. The players can only move the elements from side to side when the avatar is standing on them. In order to proceed forward to the next element, the first element needs to be positioned in line with the next one. Then the players can move the avatar to the next element and continue their journey. This condition requires planning (Andrews, Halford, Chappell, Maujean, \& Shum, 2014). Every step of the elements movements from side to side creates a note on the way and provide auditory KP feedback. All the notes played on a path to success combine to a melody created by the players' movements and leading to the final note, the oxygen that facilitates $K R$ feedback.

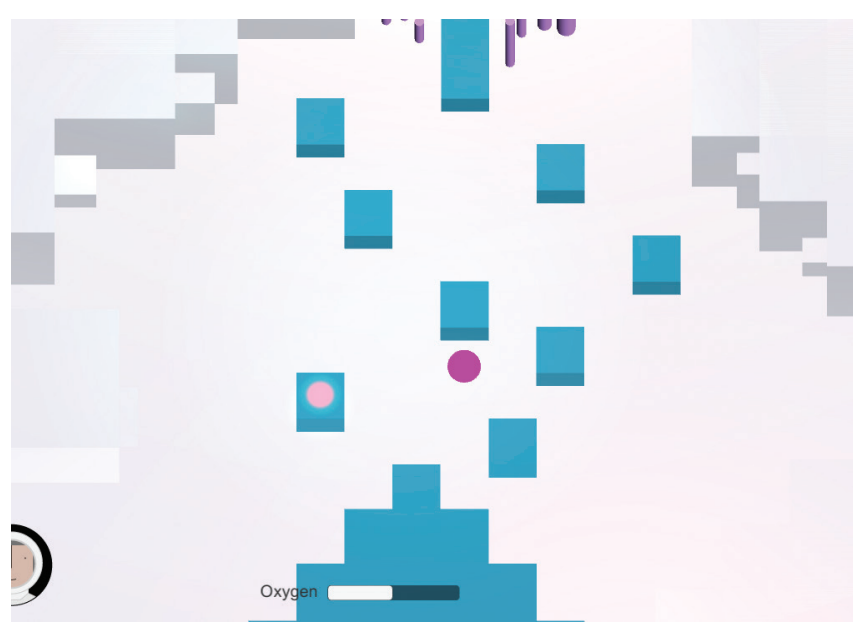

Figure 29: The steps can only move through the elements
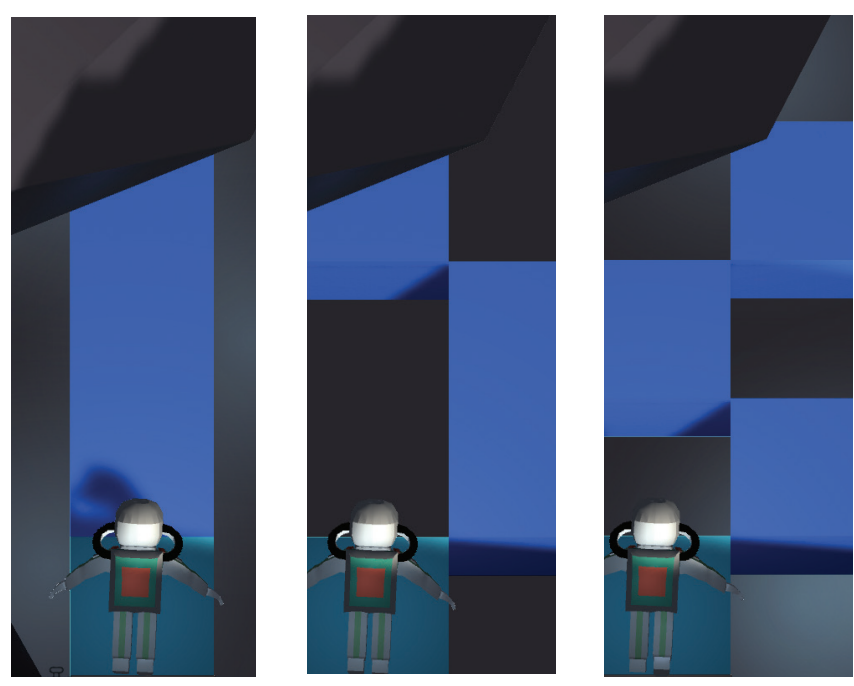

Figure 30: Generating steps at random locations according to players' ability 


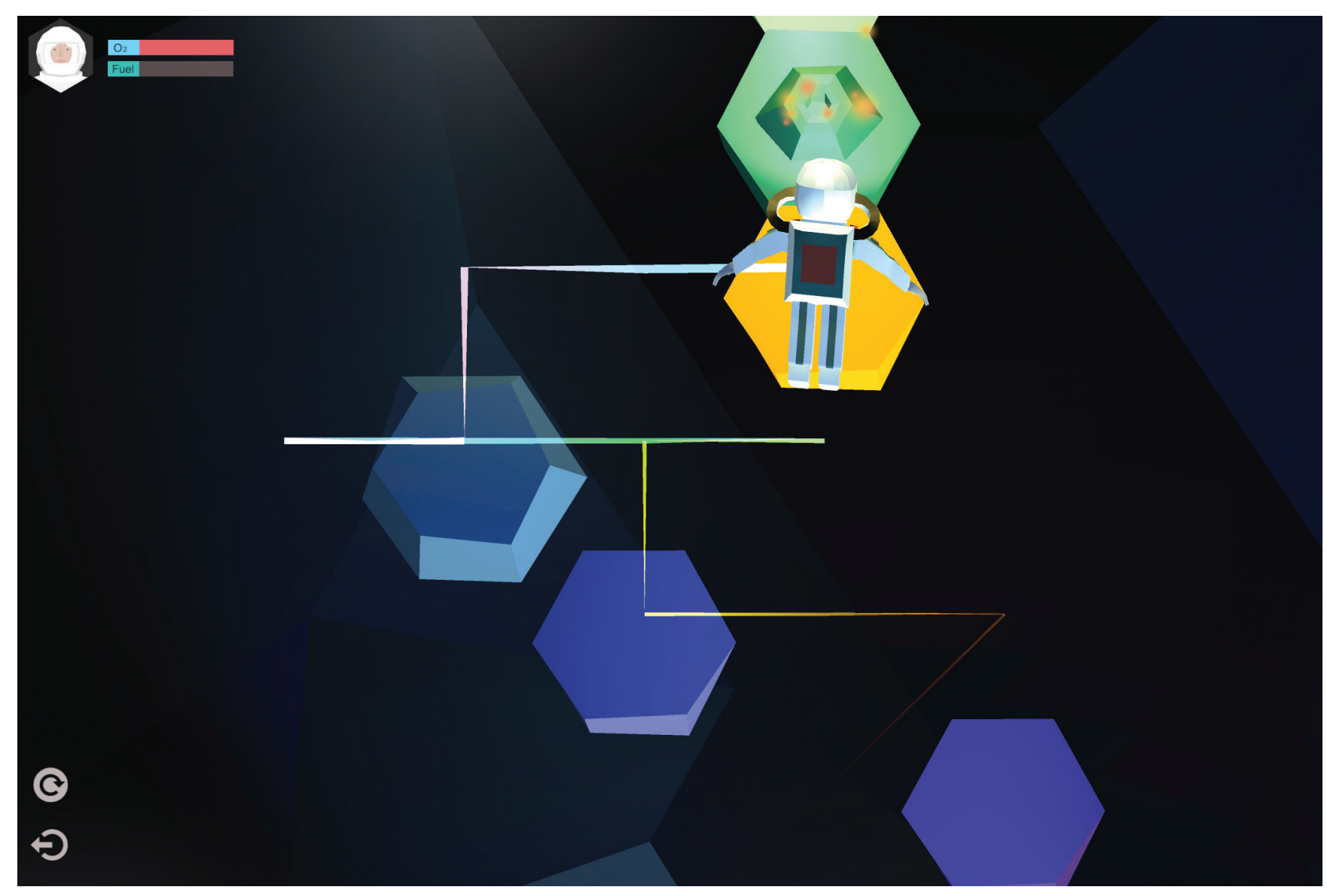

Figure 31: Rhythmic element (in yellow)

\section{Experiment 12:}

\section{Rhythmic elements-}

\section{Feedback provision and RAS}

In this prototype, the players are still walking through the floating elements. However, in this prototype, some of the floating elements constantly move from side to side, according to players' tempo, while creating auditory and visual rhythm for the players to $\mathrm{co}^{-}$ create the melody with, and to support the execution of the next steps forward through the challenges. To increase level difficulty, more rhythmic elements will increase rhythm complexity, tempo can be changed and elements positions can increase the range of motion.

Testing with healthy individuals revealed that the rhythmic elements can be challenging, and their speed needs to be matched to players' abilities. Some players focused on getting ahead as fast as possible while some reported that the rhythmic pattern encouraged them to move accordingly in order to match the notes to the beat. This condition requires planning (Andrews, Halford, Chappell, Maujean, \& Shum, 2014) and concentration, however, it may be that the rhythmic cues will support patients with cognitive impairments to go through this challenge. 

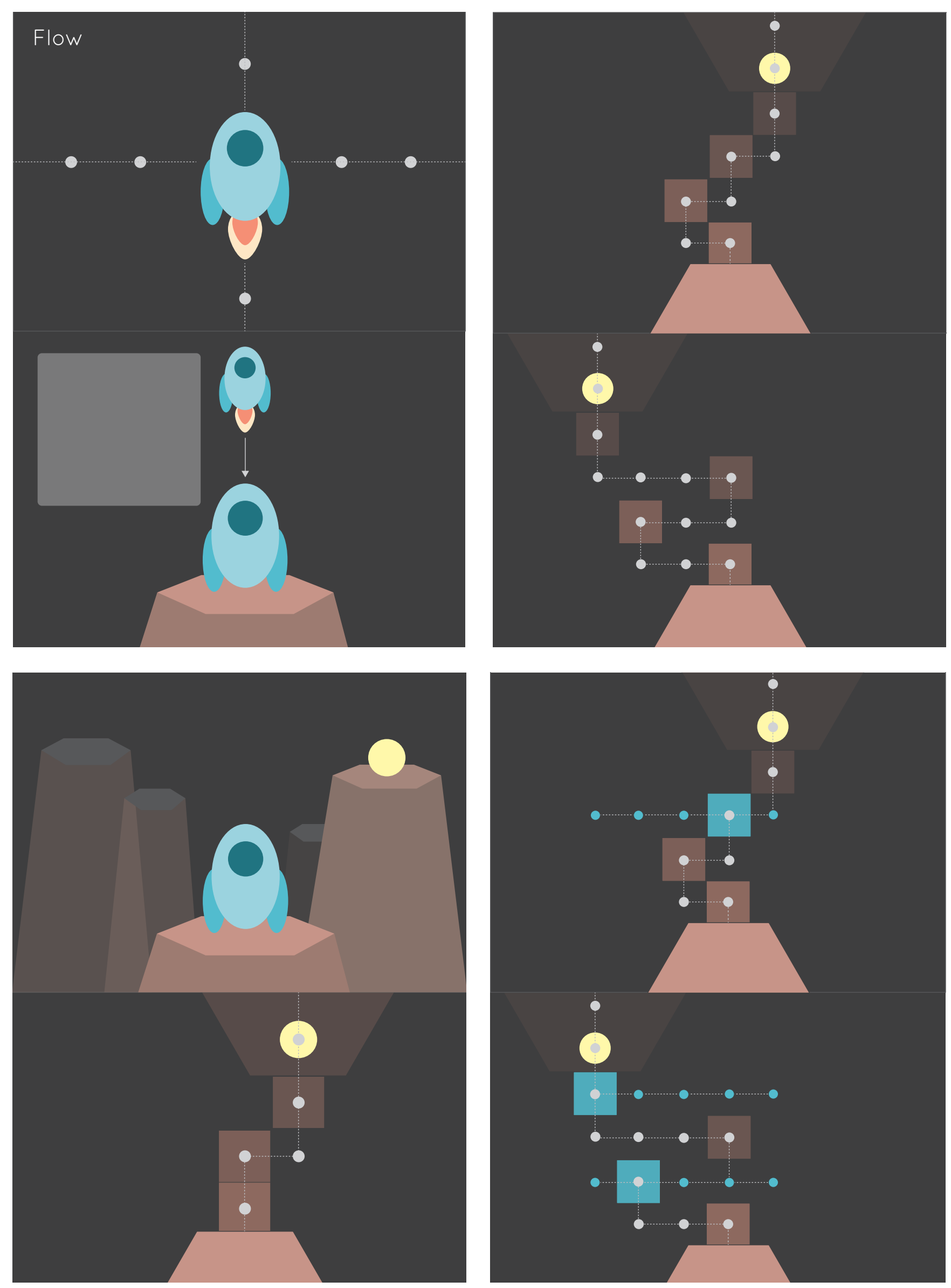

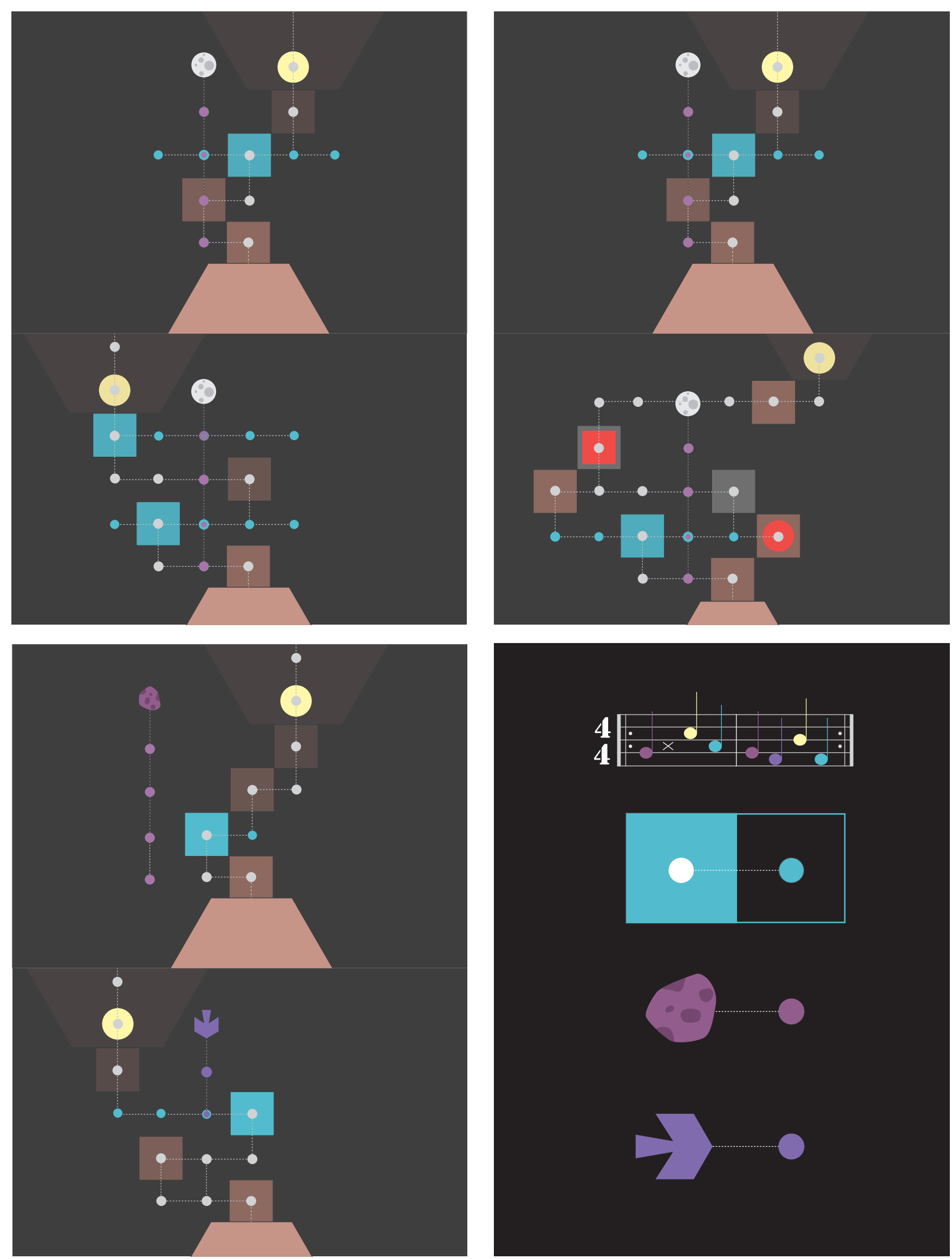

Figure 32: Flow - floating elements 


\section{Experiment 13:}

\section{Rhythmic rewards}

This prototype contains a mechanism for rhythmic auditory stimulation (RAS) integration by providing oxygen at certain locations and certain times according to a rhythmic pattern. This is similar to RAS studies where patients were to move their upper limb to certain points on a board according to the rhythm provided. Accordingly, this prototype has the most potential to provide patients with RAS. The integration of RAS was also validated by a neuro-physiotherapist.

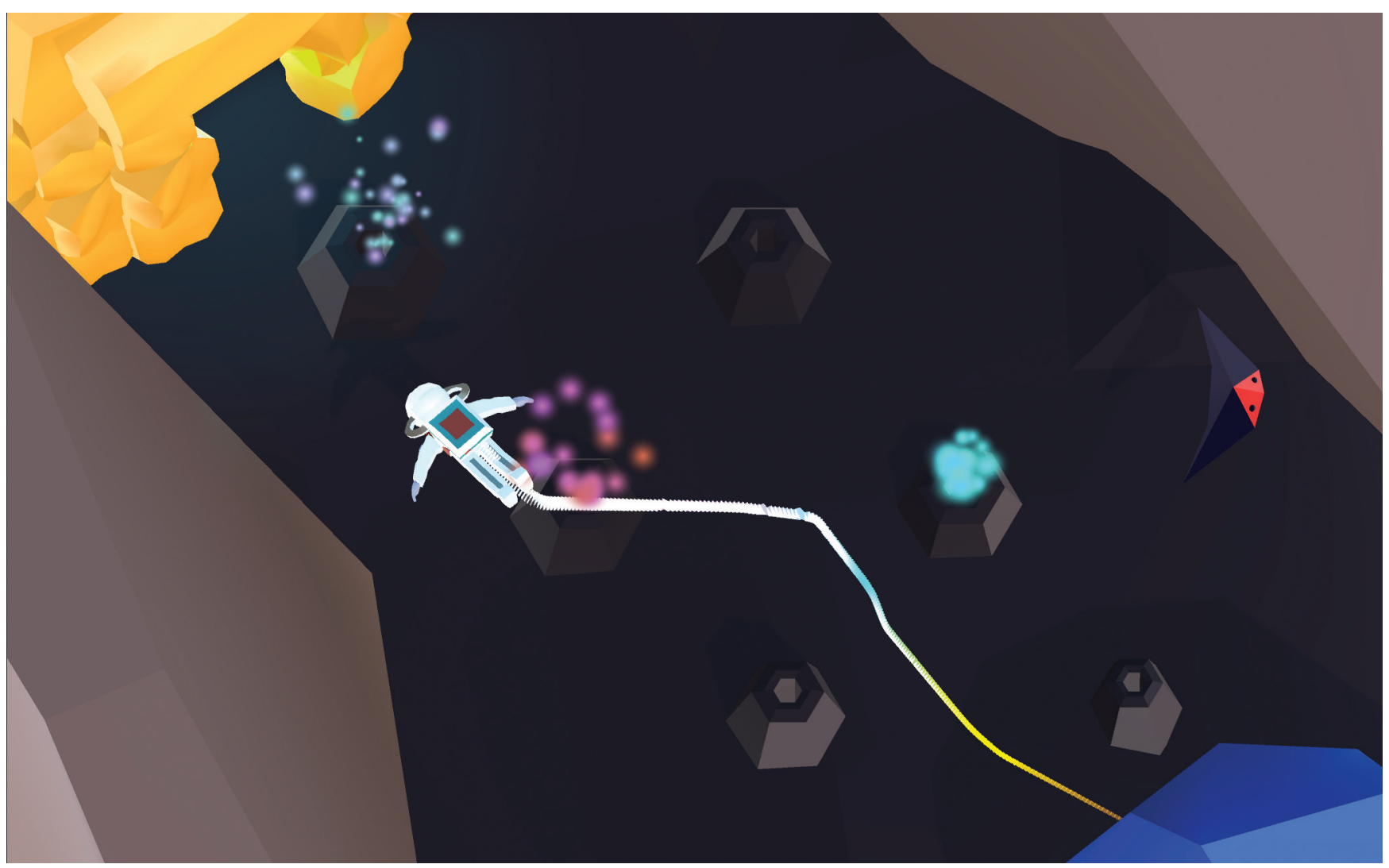

Figure 33: Rhythmic rewards 
Testing with healthy individuals revealed that players were confused about the musical steps levels, as these levels introduced a new type of mechanism they needed to learn.

This can be beneficial for neuroplasticity and the redevelopment of cognitive abilities (Andrews, Halford, Chappell, Maujean \& Shum, 2014; Cramer et al., 2011). Though it needs to be implemented carefully in order to prevent players' frustration. And so, the researcher developed a prototype where the musical steps mechanism is introduced later in the game, and the level design provides rest periods by returning to the first mechanism. In another prototype, only the first mechanism is introduced to the player throughout the full journey on this planet. After the players find fuel, they can get back on the spaceship and have three possibilities:

1. Go home to planet earth.

2. Start again in this planet.

3. Discover a new planet.

The third option will introduce the players with the new mechanism of musical steps, where they can float from object to object, co-creating music with the rhythm provided.

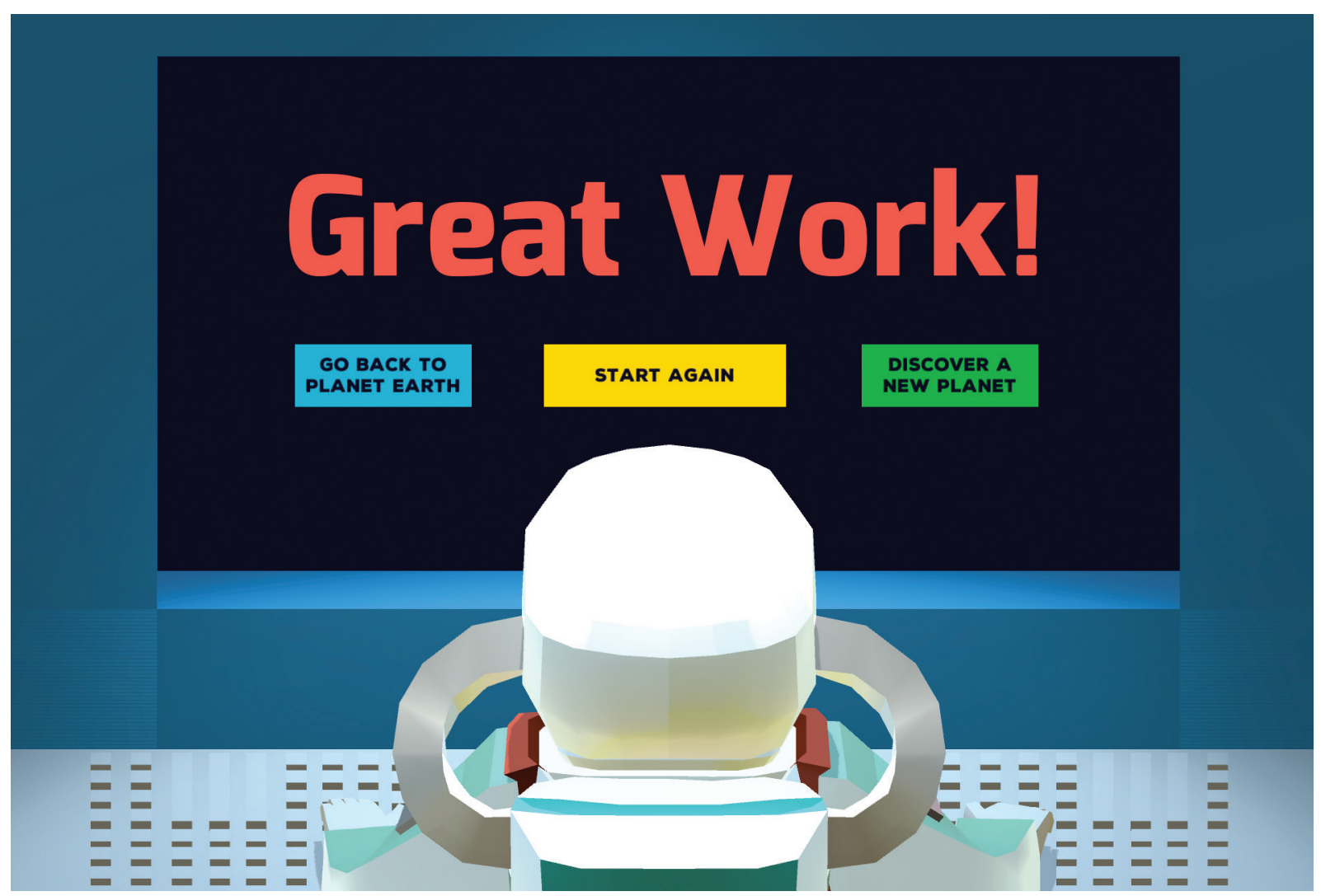

Figure 34: Back in the spaceship 


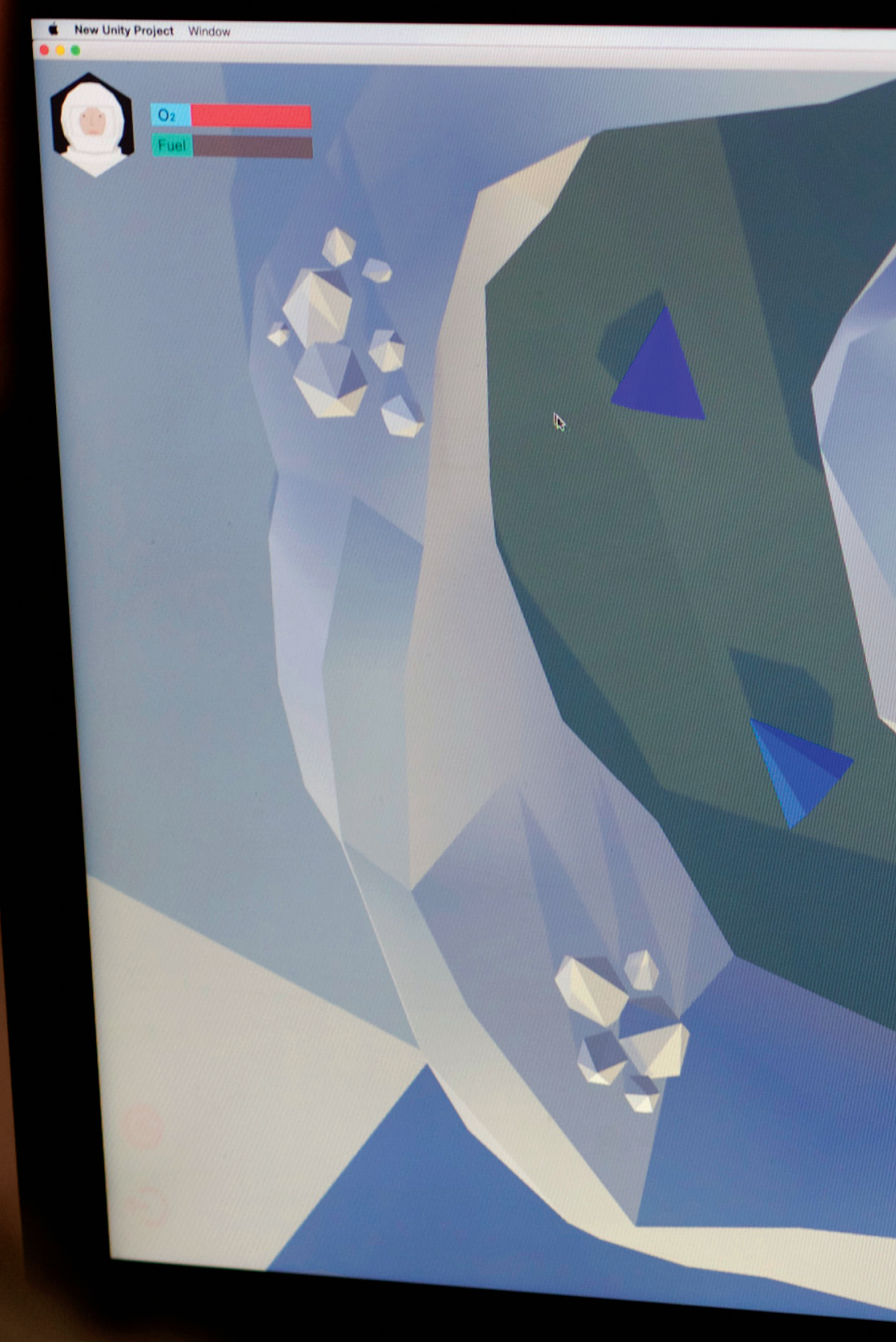

Figure 35: Playing the game with the Able-M 


\section{Final prototype}

The final prototype implemented the design criteria of the Able-M interactions for upper limb rehabilitation, narrative, feedback and challenge-skill balance for engagement, and Rhythmic Auditory Stimulation (RAS) and feedback provision for effective rehabilitation.

\section{Able-M:}

Able-M movements are implemented through navigation in the game world with the avatar, using different mechanisms, one more intuitive, and the other requires more cognitive resources. Click is implemented according to patients' ability and progress, by collecting oxygen only while holding the finger up, and jumping between elements in the second mechanism with the finger up - holding and dragging the avatar to the next step.

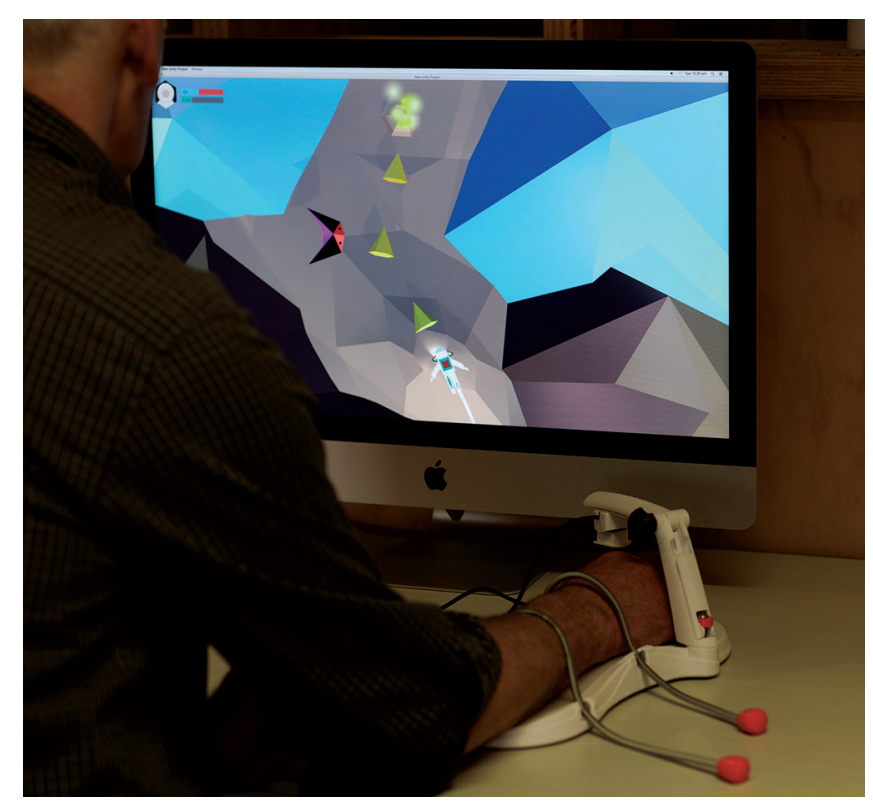

Figure 36: Playing with the Able-M

\section{Narrative:}

The narrative is discovered by the players as they progress in the game. After flying a spaceship around space, the players can land their spaceship on a planet where they can help their avatar, the astronaut, to find oxygen and fuel for the spaceship to get back home to planet earth, or continue their exploration to discover new places.

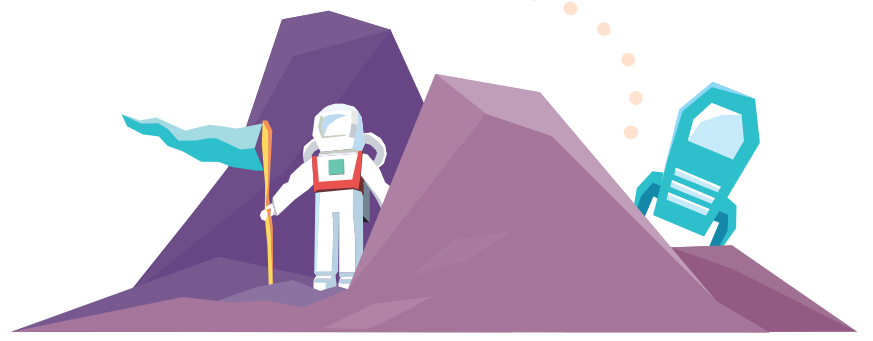

Figure 37: Narrative

\section{RAS integration:}

The researcher experimented with different ways for RAS integration:

Rhythmic rewards - This condition requires the players to collect the rewards at the right time, in the right place, according to the rhythmic pattern. 
This condition is a classic RAS that only requires players to move according to the rhythm and the visual feedback to catch the oxygen in time.

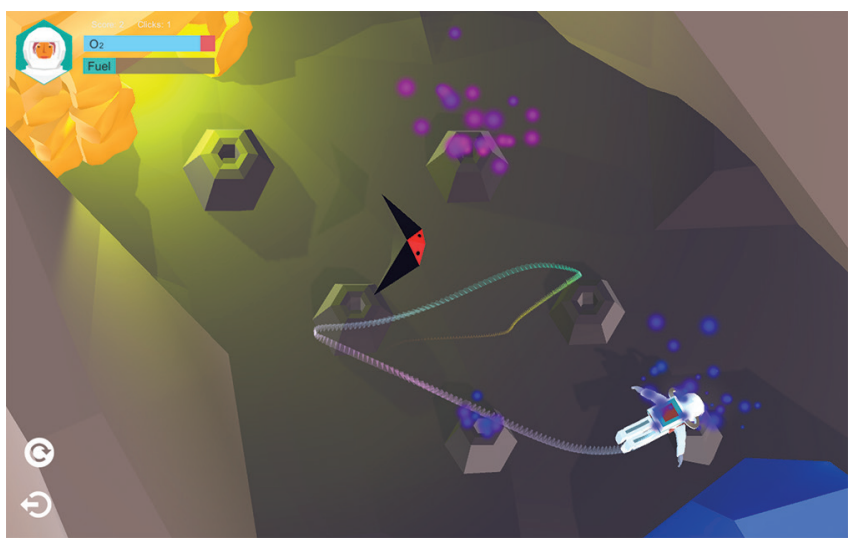

Figure 38: Rhythmic rewards

Rhythmic obstacles - The players are to avoid the obstacles by anticipating their next cue. This condition may facilitate a cognitive challenge as they need to plan their steps ahead.

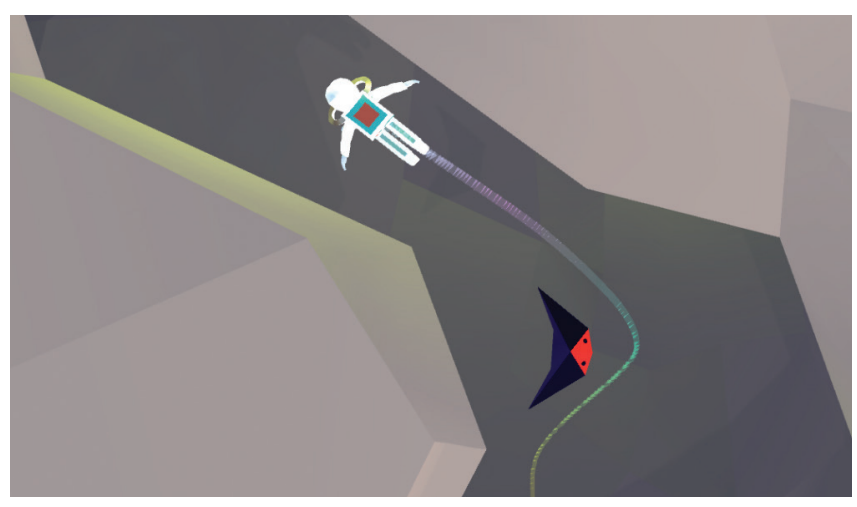

Figure 39: Rhythmic obstacles

Rhythmic elements - The floating elements are moving according to the rhythm, demanding the players to listen to the rhythm and anticipate the next move of the element to plan their steps ahead. This is a task that will demand the players' cognitive resources, however, it might be that the rhythmic cues will support them in this cognitive challenge.

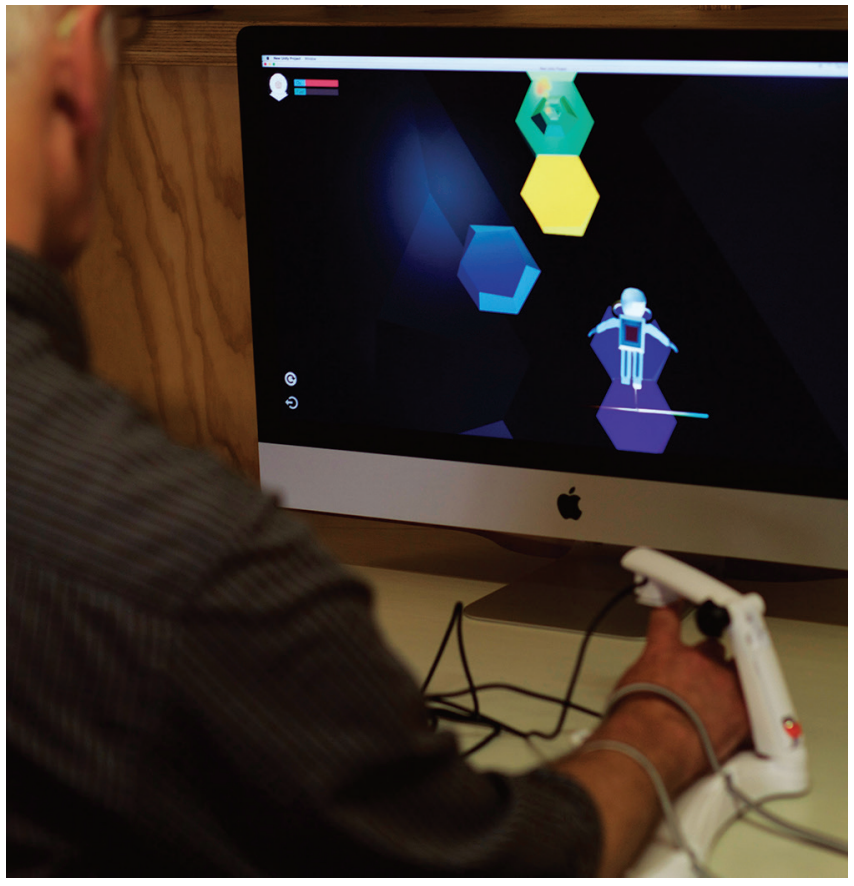

Figure 40: Rhythmic elements

\section{Rhythmic rewards and elements:}

The players need to collect rhythmic rewards, integrated as fuel while moving through the floating elements. This condition is more challenging than the rhythmic rewards condition, as the players need to manage two tasks; move at the right time and to the right location to the next step, and collect the rhythmic rewards at the right time.

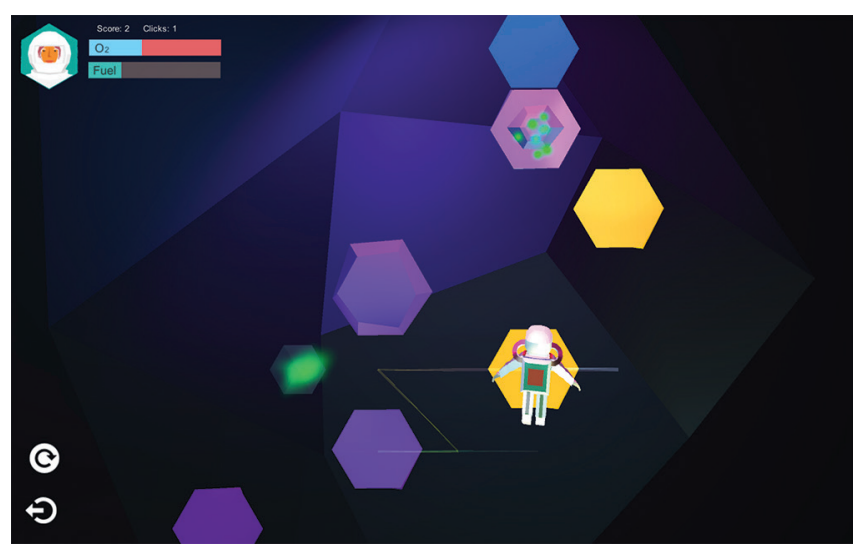

Figure 41: Rhythmic rewards \& elements 


\section{Feedback provision:}

Error feedback was implemented by providing auditory feedback and loss of oxygen if the player moves at the wrong time and collides with the alien.

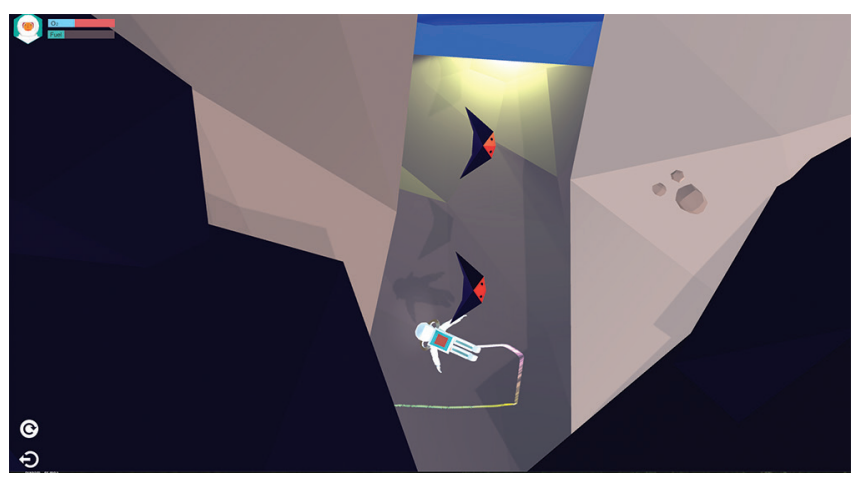

Figure 42: Error feedback

\section{Knowledge of Performance (KP)}

feedback was implemented through

objects with auditory and visual feedback that show the players their way and which the avatar need to eat on their way. The notes created with KP elements collision are the same notes that create the rhythmic pattern in later levels, letting the players learn them and add to their complexity through their progress in the game.

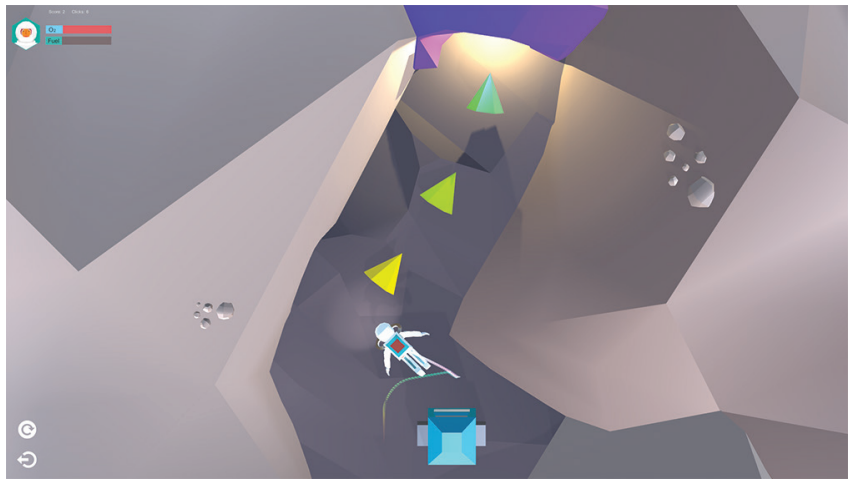

Figure 43: Knowledge of performance

\section{Knowledge of Results (KR) feedback}

was implemented through rewards such as oxygen in the end of the paths and the gates to the next levels can inform the players on their goal achievement. This can also be facilitated by global end results in the game-collecting enough fuel to get back home to planet earth or discover a new planet.

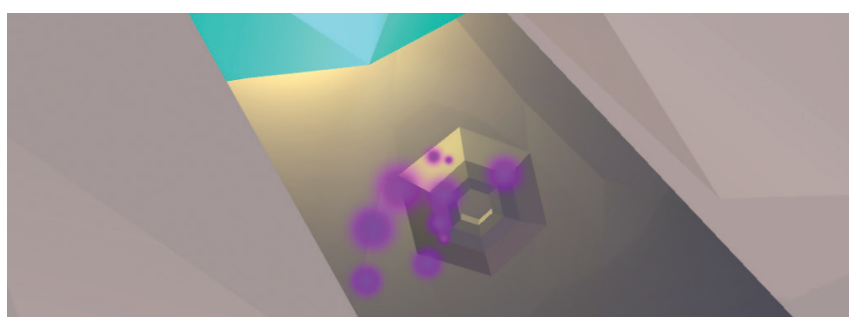

Figure 44: Knowledge of results

Summary provision - The feedback provision changes between different levels in the game to reduce the risk of dependency on feedback in the game world.

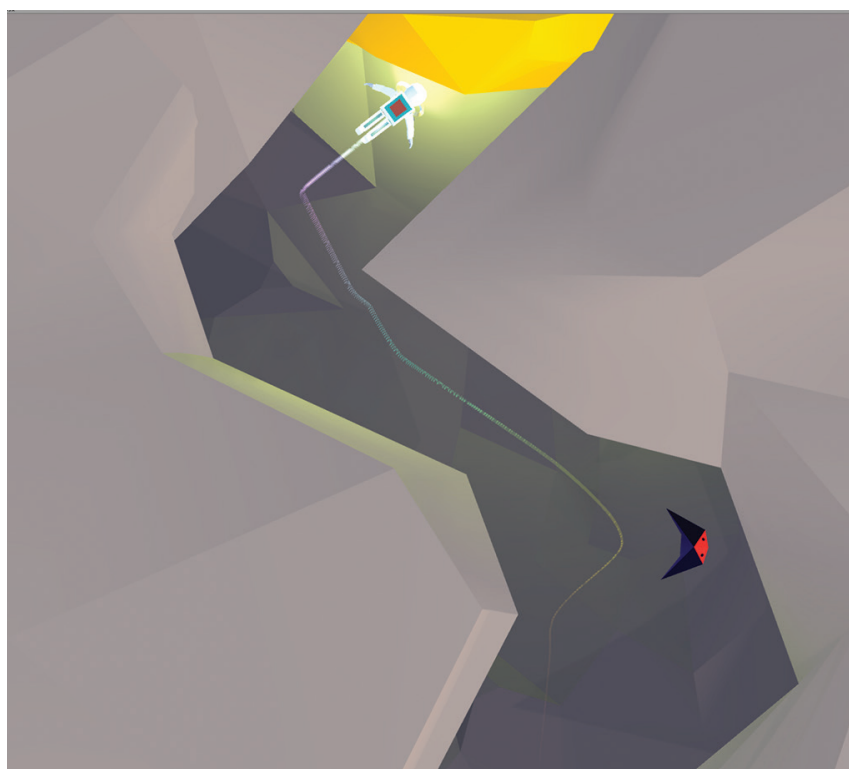

Figure 45: Summary provision 


\section{Skill-challenge balance:}

Both of the planets start with a calibration phase where the players fly their avatar's spaceship around space. The players need to reach planets in space and click them at different locations, in a limited amount of time.

\section{This is so the system will know the} players':

- Reaction time

- Time of movement to reach a target

- Range of motion

- Whether they have a side neglect

- Control of movement

- Ability to click

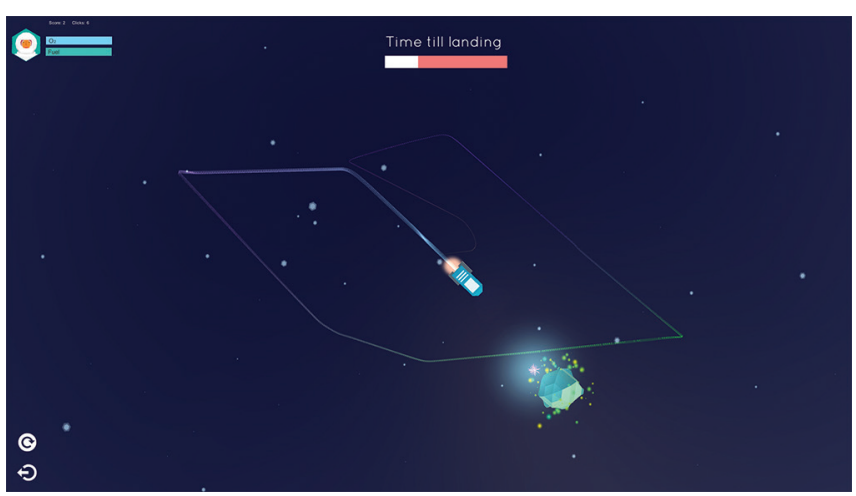

Figure 46.1: Calibration

The data will determine the following in the next levels:

- Range of motion required by the players (the path they will take to reach their goal),

- Areas of movements which the player should engage with more.

- The tempo of the rhythmic pattern

- Will the player be required to click.
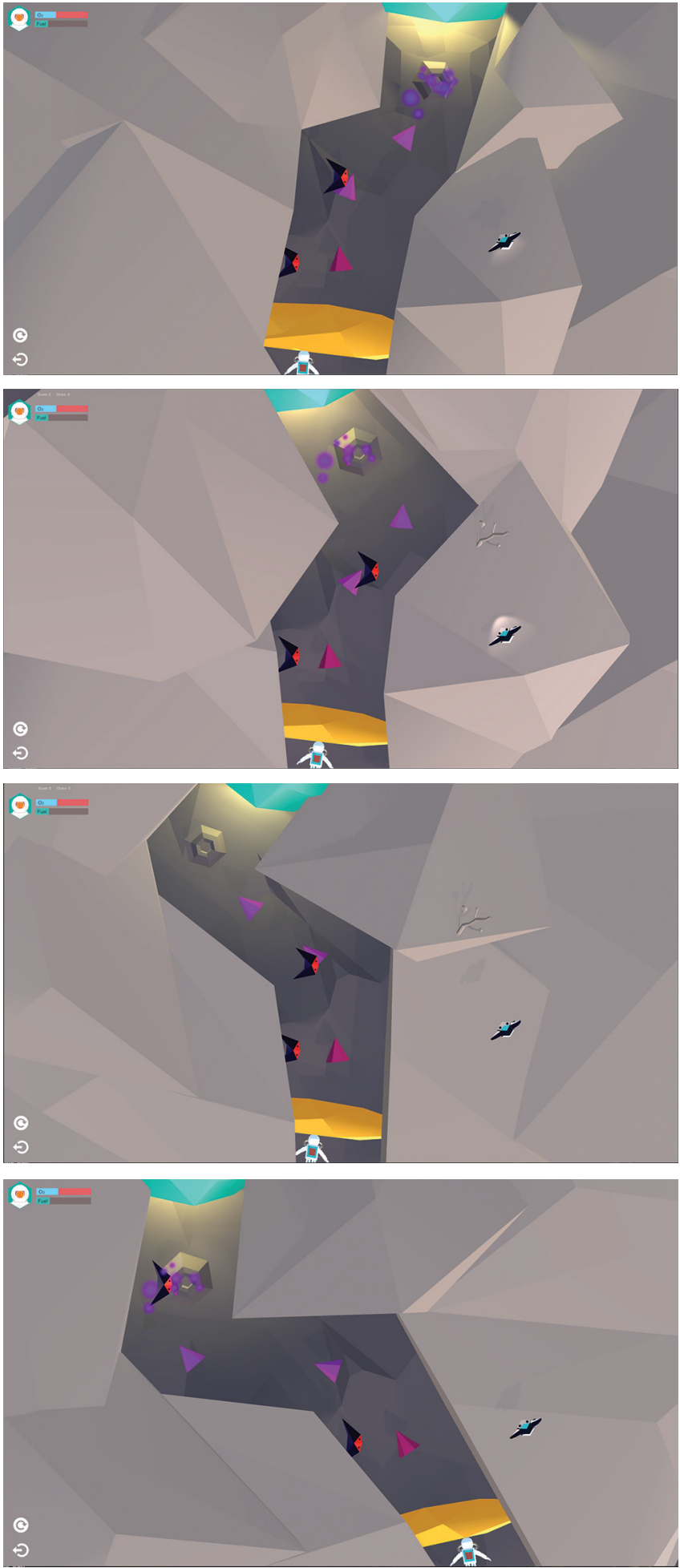

Figure 46. 2: Example- influence on path 
Following the calibration, a short animation describes the players the landing of their spaceship on the new planet.

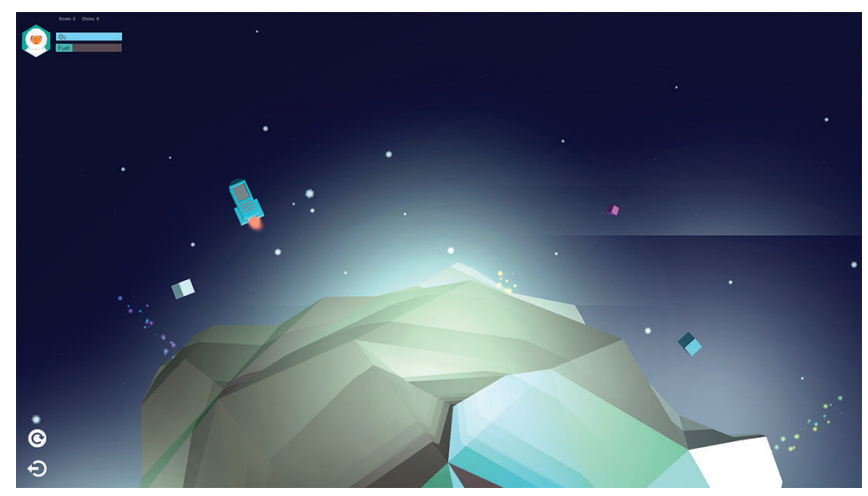

Figure 47: Landing

Both of the planets have nine levels each, and the difficulty increases in each level leading the players' to discover the game-world and reach their goals.

In addition, each of the levels have different levels of difficulty to match players' performance in the calibration phase, tailoring the game to their own individual ability.

The difference in difficulty manifests in range of motion required by generating paths with minimal to maximal range of motion needed, tempo of rhythmic elements such as obstacles and rewards for speed of reaction and movements, Avatar's speed, and finally, the need to click and hold the finger up to collect oxygen, or just pass through the oxygen to collect it.

\section{Mechanisms:}

The final prototype includes two planets with two different navigation mechanisms.

In the first planet the mechanism for navigation is based on steering behaviors. This mechanism was described as more intuitive by players, and can promote range of motion increment. The avatar follows the mouse controlled by the players' upper limb movements. The speed of the avatar to reach the mouse changes according to the mouse position, for example, the further the mouse is from the avatar, the faster the avatar will move. In addition, the speed will also change according to player's abilities. Faster players will have faster avatars.

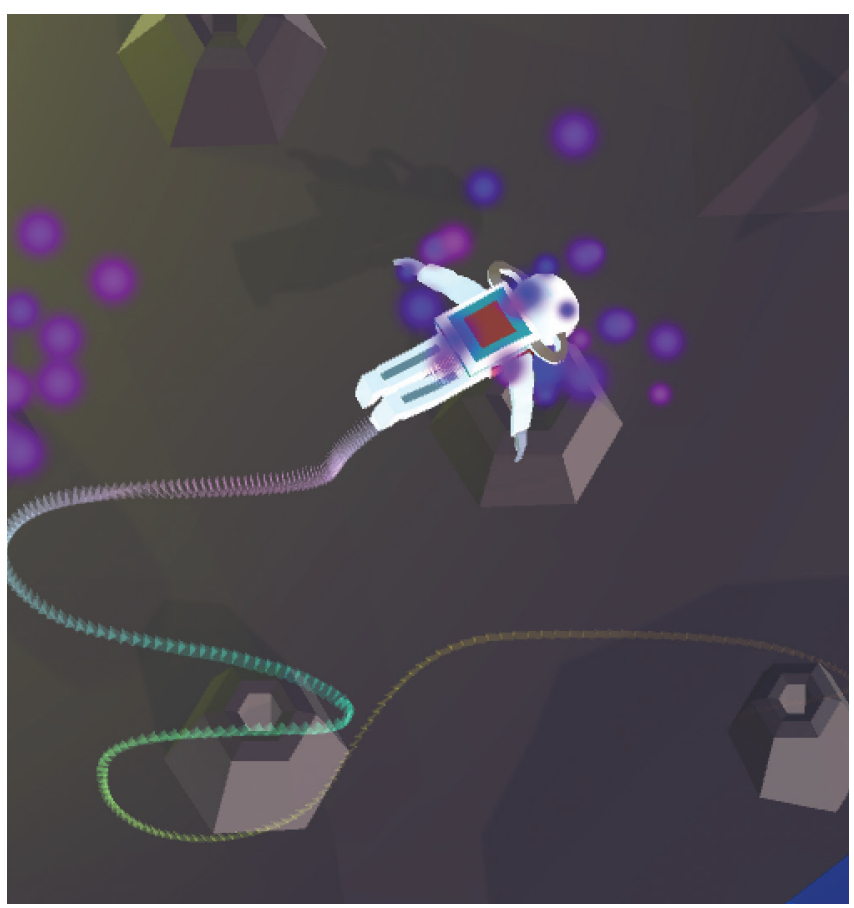

Figure 48: Steering behaviors 


\section{Planet one description}

The second planet integrated musical steps mechanism which demands more cognitive resources from players as it requires players to plan their moves ahead. This mechanism may suit patients with high cognitive abilities who would enjoy the cognitive challenge. However, it is unknown if it would suit patients with cognitive impairments as it might frustrate them.

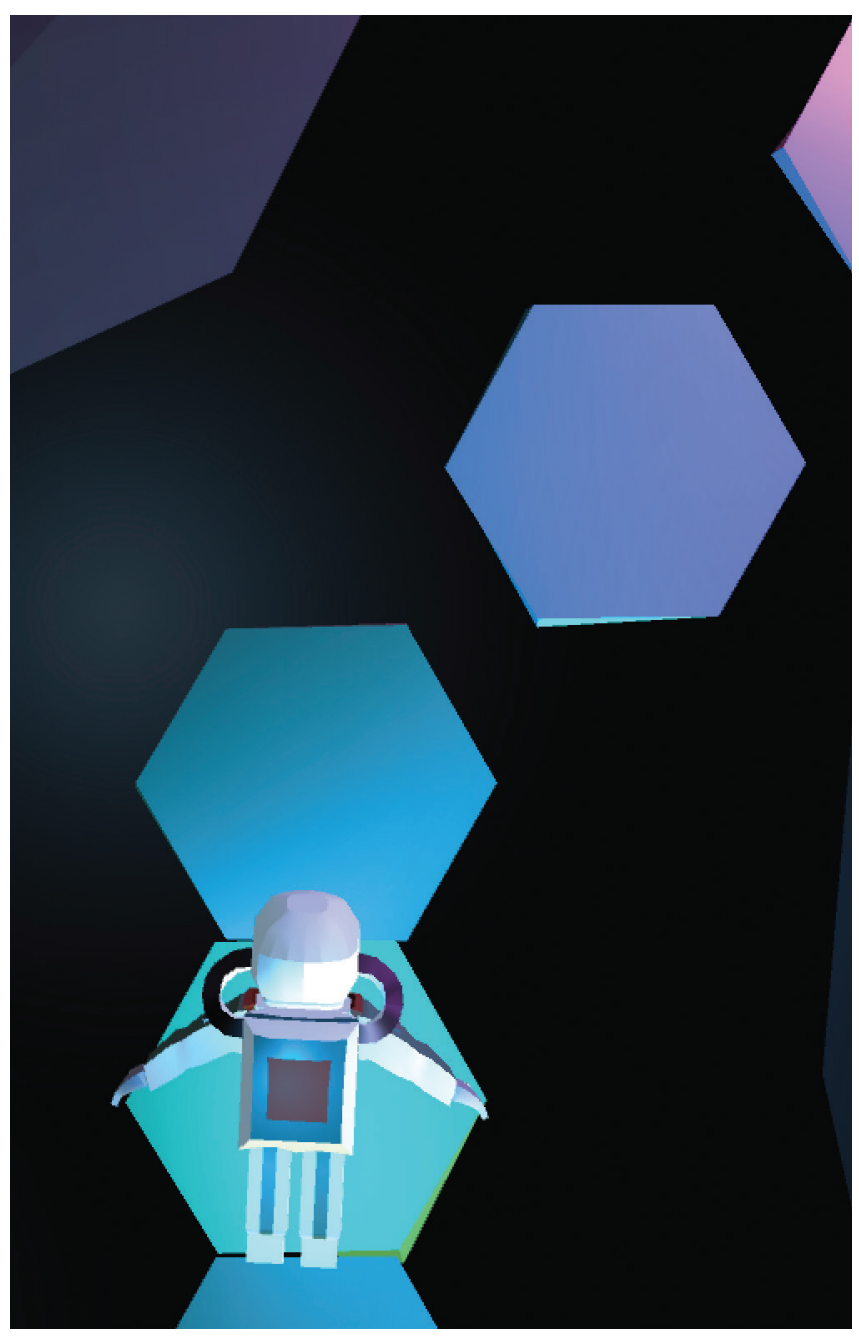

Figure 49: Drag and drop
Once landed, the players can move their avatar in the game-world. They are presented with colorful elements which the avatar can create musical notes with on the path. These elements facilitate KP feedback. The path guides the players to a gate where light shines.

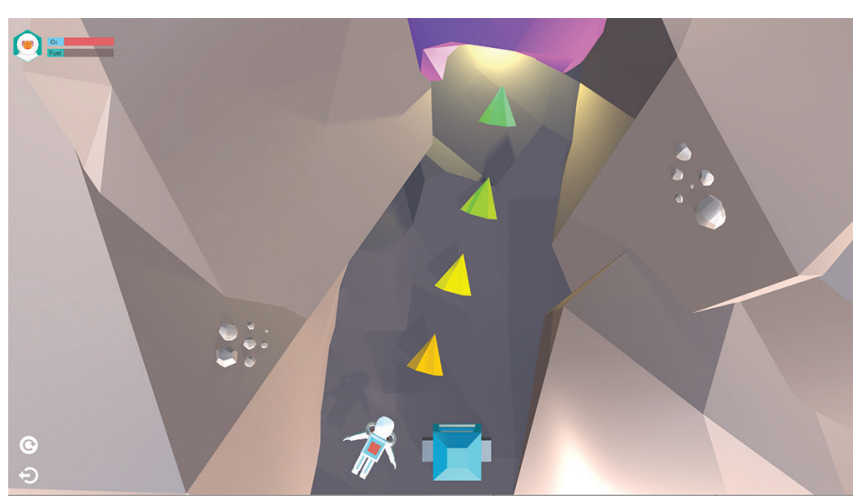

Figure 50: After landing

When the avatar reaches the gate, the players can continue to the next level which also contains KP elements. Oxygen is waiting for the players as a reward in the end of the path, facilitating a small KR feedback. This level is intended to be easy to accomplish and inform players they are on their way to reach their goals.

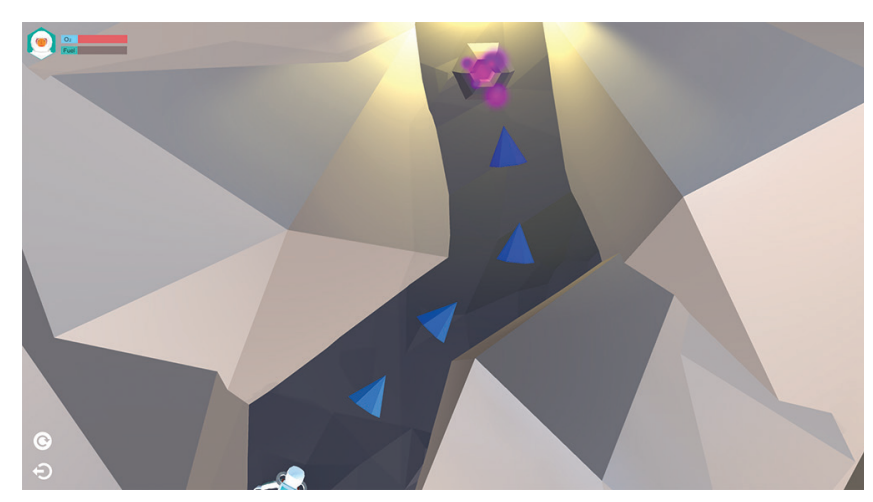

Figure 51: Following the path 
The next level introduces a new obstacle to the players, a rock blocking the path of the avatar. In order to continue, the players must hover on the obstacle and remove it. This obstacle was introduced in order to engage players in moving down with their upper limb in the start of a new level. The pointer interface changes to provide players clues on how to solve it.

After removing the obstacle, the avatar is about to meet a sound agent in the form of an alien crossing the path while
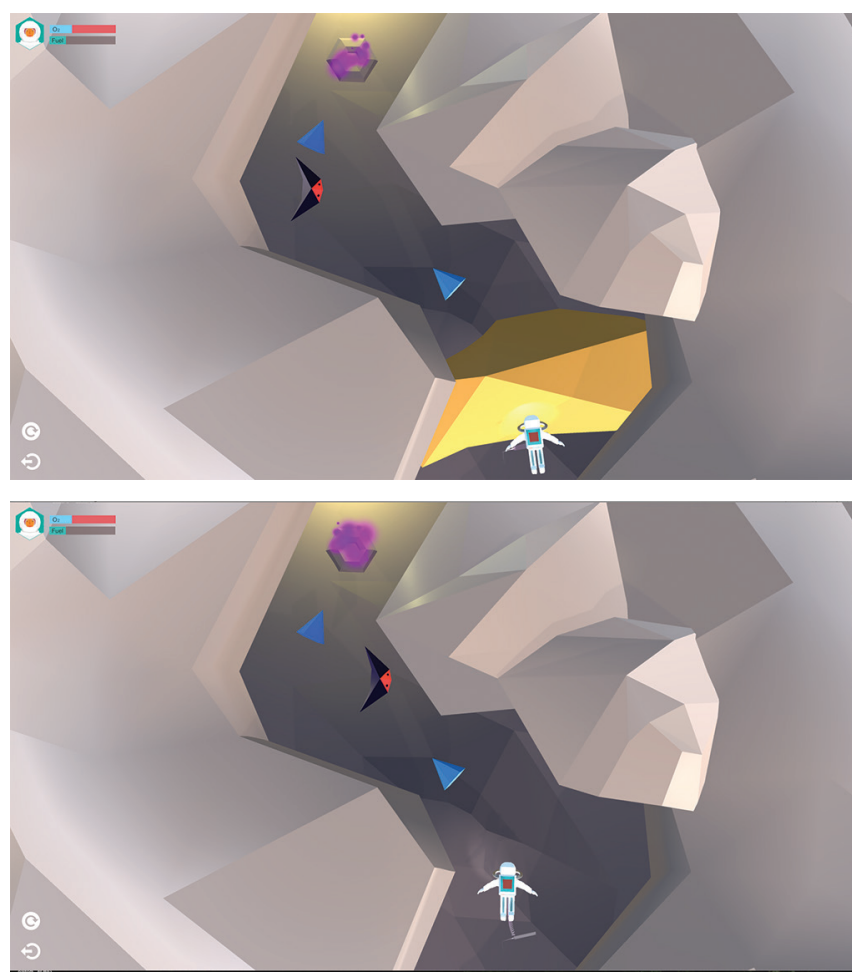

Figure 52: Removing the obstacle

providing a rhythmic cue for every step it makes. If the avatar hits the alien, the players will receive an error feedback as an auditory feedback and the avatar will lose some oxygen. The error feedback can teach players they need to avoid the aliens in order to sustain their oxygen level.

In order to facilitate a summary feedback provision, some of the levels do not always contain KP or KR feedback, for example the next level (see figure 53) have two aliens that will create error feedback on avatar collision, but this time there will be no $\mathrm{KP}$ elements along the way or oxygen in the end of the path. However, the path constraints will be presented as usual to keep consistency.

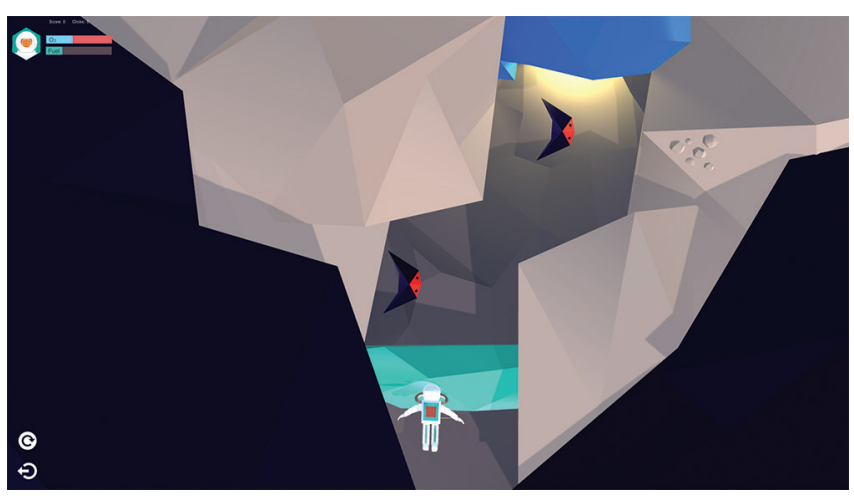

Figure 53: Two aliens

After accomplishing this level, the players arrive to a new place where oxygen is provided at different locations and times according to the rhythmic pattern that was developed during the previous levels, which the players had an opportunity to learn.

The players can now accumulate enough oxygen for the rest of their 
journey, while moving according to the rhythmic pattern to get to the oxygen on time. This level facilitates RAS, while is also a rewarding point in the game.

There is also an alien in this place to add to their challenge.

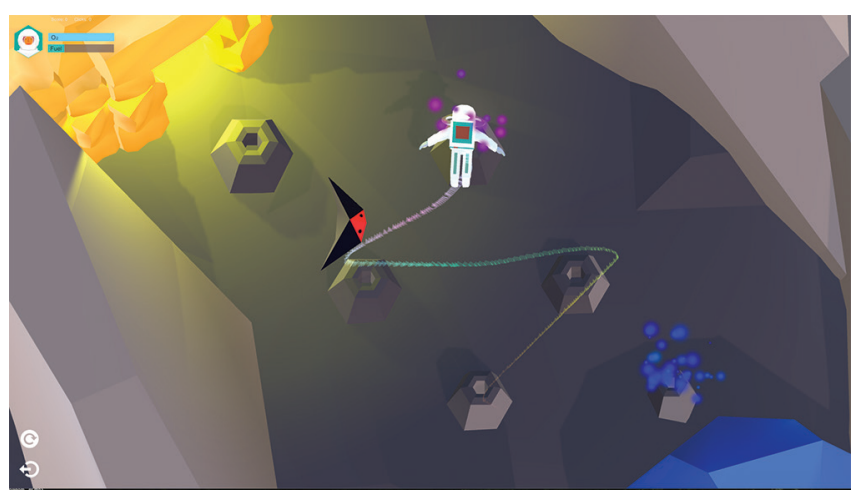

Figure 54: Collecting oxygen

Once the players collect enough oxygen, they can choose to continue through the gate back to the familiar path.

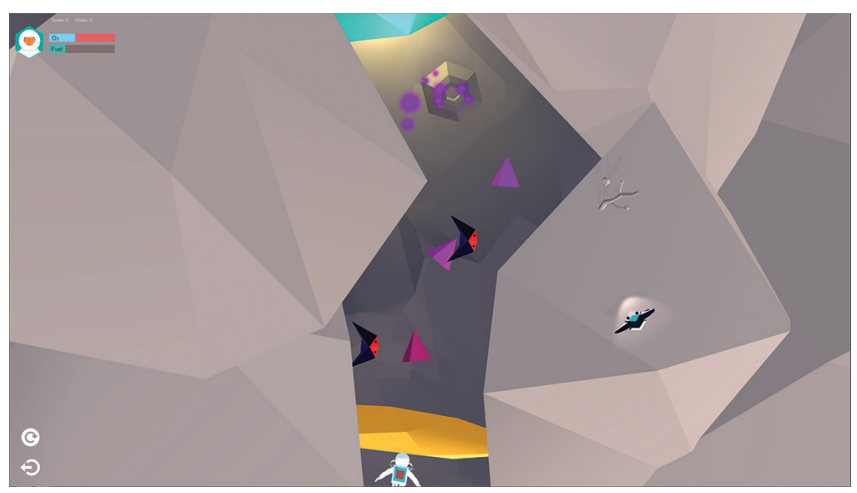

Figure 55.1: Back to the path
In each level, the range of motion required by the players increases until they get to a final spiral path where they can find fuel for their spaceship.

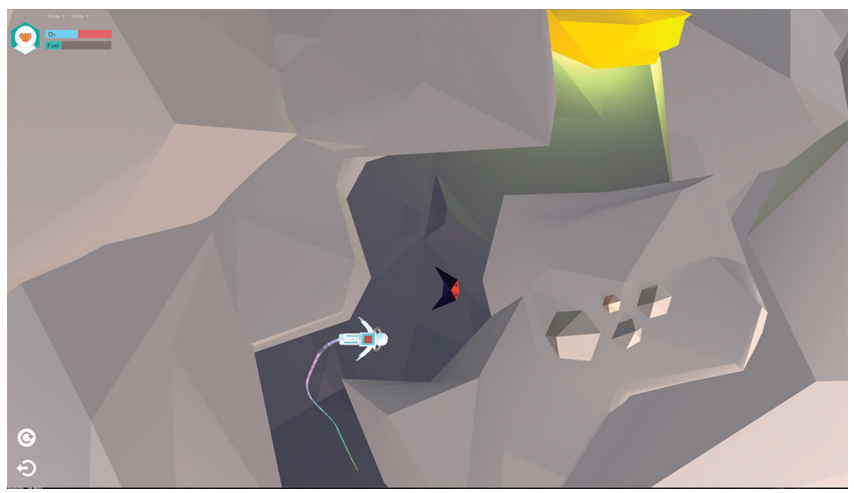

Figure 55. 2: Back to the path

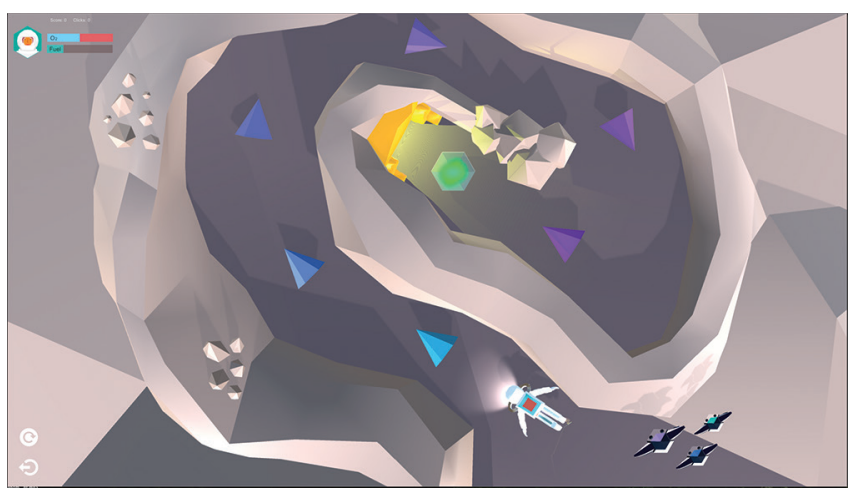

Figure 56: Spiral path

They can now lead their avatar back to the spaceship where they get to choose whether to explore a new planet, start their journey again on the planet and improve their performance, or go back home to planet earth. 


\section{Planet two description}

Like in the first planet, after the calibration phase and the landing, the players can explore the new planet by following the familiar KP elements using the same navigation mechanism introduced to them in the first planet.

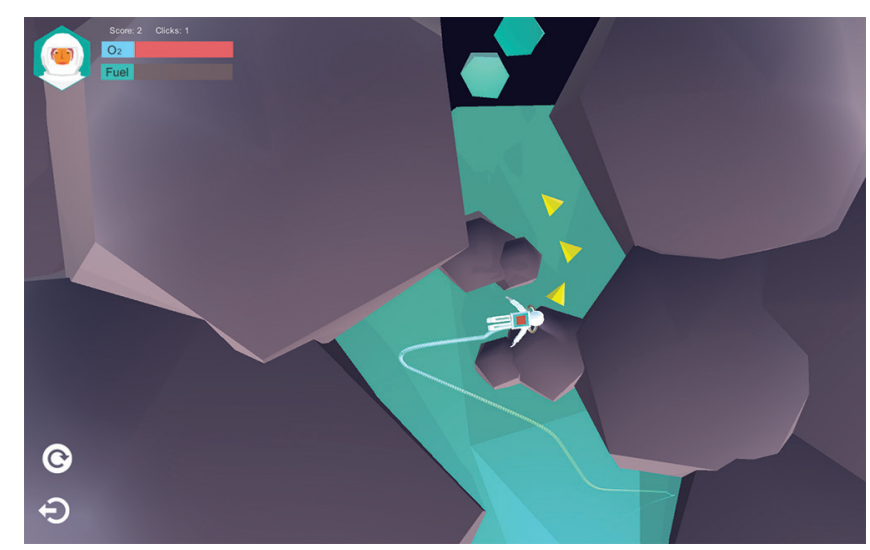

Figure 57: Following the path in the second planet

Next, a tutorial animation shows the players how the avatar is now jumping from rock to rock in order to go forward, the path of the avatar is now constrained by these steps.

Once the tutorial animation has finished, the players have a go on their own. To navigate in this planet, the players need to click on their avatar and drag it to the next element ahead. This means they need to move the current element the avatar is standing on from side to side, to the location attached to the next element, and only then move forward. Each move snaps to a grid and plays a certain musical note. The KP here between elements is auditory only. The players need to explore and find their own way between the elements. With it, the elements also provide KP feedback, leading the players to the KR feedback, the familiar oxygen in the end of the path.

The distance of each element from each other is based on the players' performance in the calibration phase, and increases with the players' progress in the game.

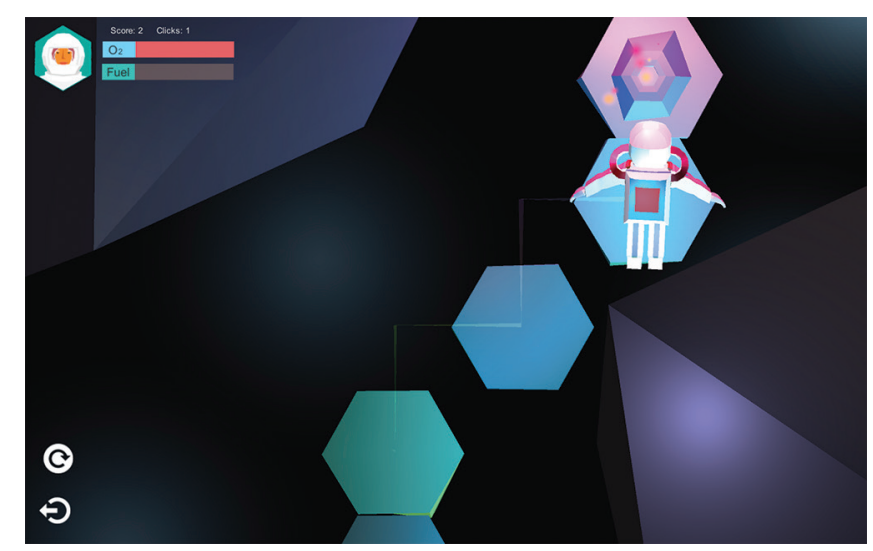

Figure 58: Floating elements

The following level becomes more challenging, as the players are introduced to the rhythmic steps. These rhythmic steps can facilitate the rhythm in which the players can play music with. However, the rhythmic steps facilitate a challenge as well, as the players need to move their avatar at the right time to proceed forward. If they miss it, they might fall and need to start the level again. As the players progress in the levels, more rhythmic steps are added, contributing to the rhythmic pattern complexity, and to the difficulty. 

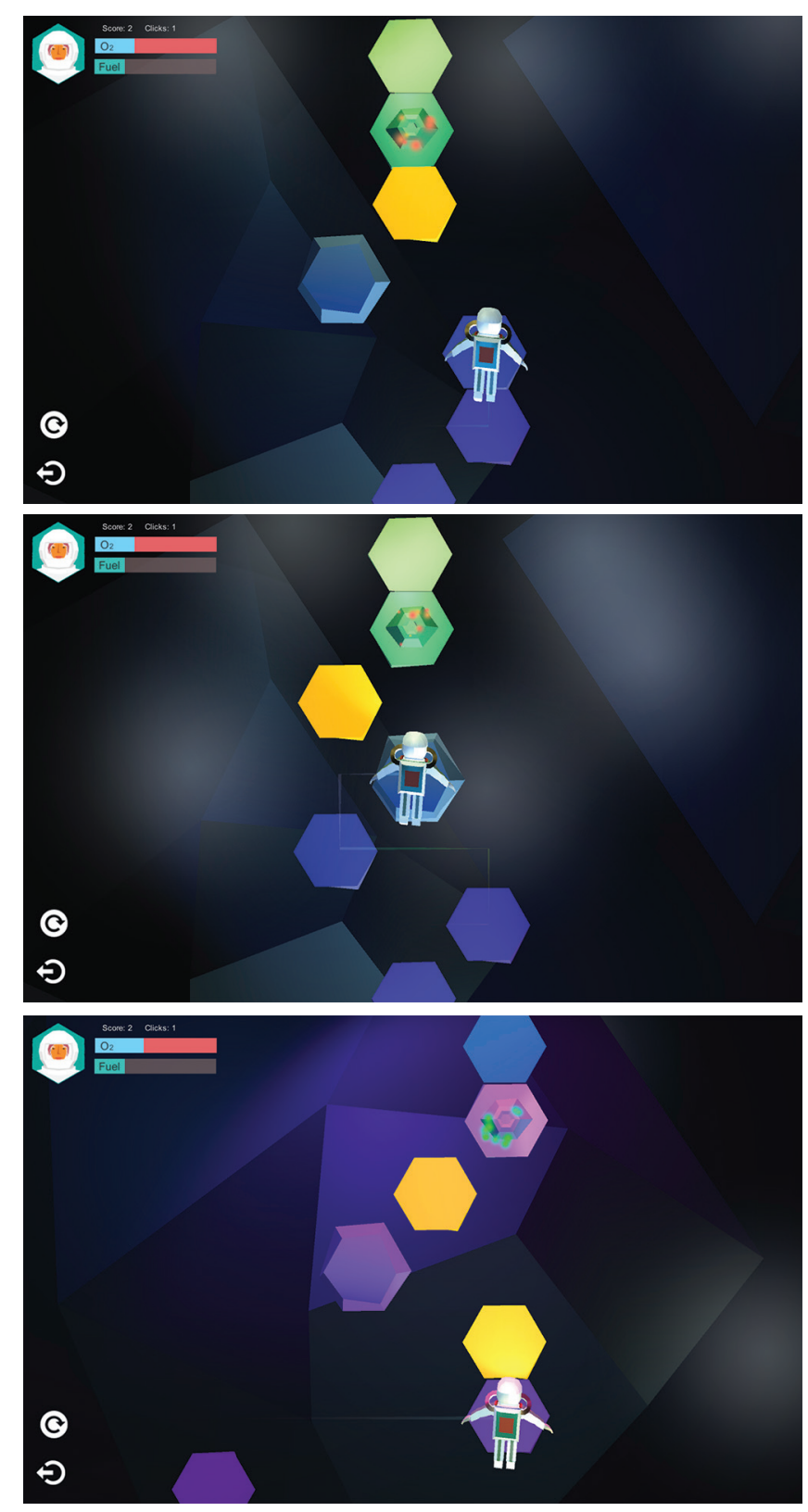

Figure 59: Rhythmic elements
In the next levels, rhythmic rewards are introduced in the form of fuel points on their way, appearing in different locations according to the rhythm. The avatar must reach these fuel points on time, before arriving back to the spaceship.

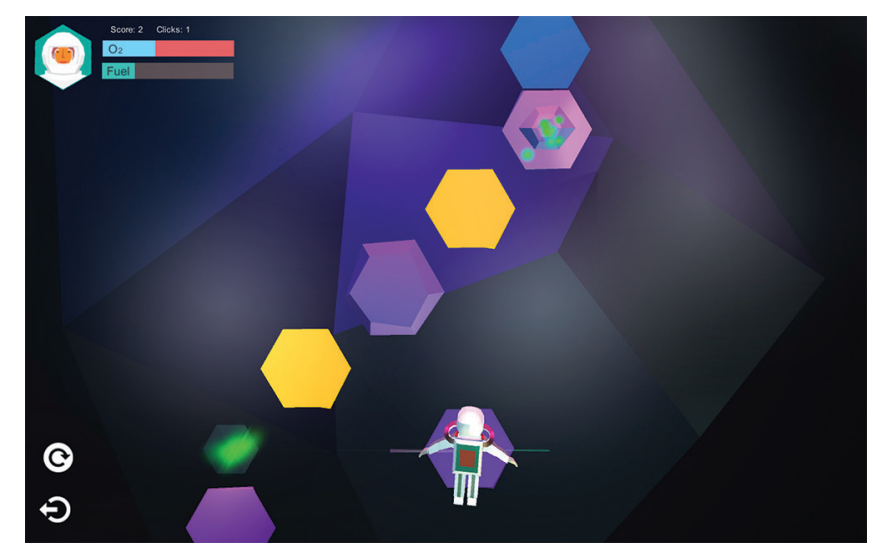

Figure 60: Rhythmic fuel

Once back to the spaceship the players can choose whether to play again and improve their performance or go back home to planet earth. Another planet could be added here in the future. 


\section{Testing}

\section{Meeting with a}

\section{Neuro-physiotherapist:}

The meeting started with an explanation on how the rehabilitation methods were integrated through different design elements in the game, followed by a game demo and a discussion with the neuro-physiotherapist who was observing and investigating if the elements facilitate what they aim to do in the game and informing the research from her practical and theoretical expertise.

\section{Qualitative studies with patients:}

\section{Recruitment process:}

The researcher contacted care providers in the Wellington and Nelson area. The clinicians informed patients who would fit the including criteria about the study, and patients who wanted to participate in the study or their carer contacted the researcher.

\section{Procedure:}

A few meetings were scheduled with the patients. After signing the consent form, the participants were asked to participate in a semi-structured interview about their experience with computers and their experience with rehabilitation.

Following the interview, the participants were introduced to the Able-M and the game and learned how to use it. The players were informed they can play as long as they like, and stop whenever they like, or if they get tired. The participants were left to play the game on their own using the Able-M while asked to "think aloud" and while their gameplay and interactions are recorded and observed. If the participants needed breaks or support during the gameplay, it was provided to them.

A one-on-one semi-structured interview was conducted with the participants after the gameplay. The questions' aim was to inform the research of their experience and changes needed in the game.

\section{Participants:}

\section{"Tom" ( 3 sessions)}

Tom is in his early 90s, who had a stroke 11 months ago. He suffered from physical impairments to the left side of his body, impaired coordination for upper and lower limb, and reduced mobility. Tom's arm got better with rehabilitation, but he still uses support to walk. Tom exercises by walking to promote neuroplasticity. Tom does not have experience with computers, and he never played computer games.

\section{"Joy" ( 4 sessions)}

Joy is in her late 50 s. She had a stroke almost three years ago, after suffering from complications with type one diabetes and epilepsy as well. After 

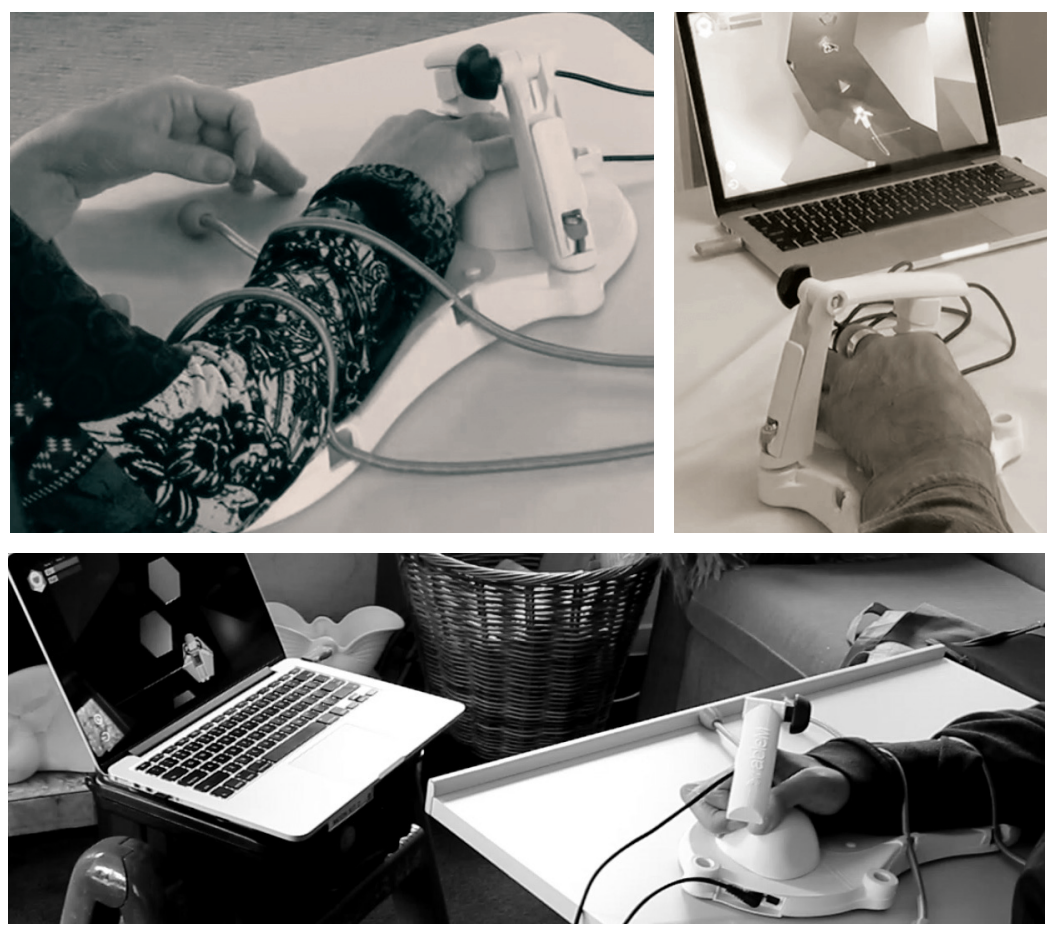

Figure 61: Testing the game with stroke survivors

the stroke Joy had moderate cognitive impairments and short-term memory damage, motor impairments in her right side of the body and tremor, the tremor started to improve in the last few months. Joy says that at first, she engaged with rehabilitation at home and saw some improvements, but after a while, she practiced less and less, until she stopped and there were no more improvements. "What you don't keep up gets harder," she said. Joy has experience with computer use, but not with computer games.

\section{"John" (1 session)}

John is in his late $40 \mathrm{~s}$. He had a stroke five and a half years ago and now suffers from right side hemiparesis, spasticity, side neglect, aphasia, and cognitive impairments. Recently John's leg got stronger, and now he uses a walking stick for support. However, he is still in need for more rehabilitation opportunities for his upper limb, foot, and speech. John has experience with computers, but not with computer games. He had one session over an hour. With a playtime of 35 minutes. John finished both of the games.

\section{Data analysis}

In order to analyze the qualitative data, the researcher used constant comparative analysis and inductive reasoning processes (Poggenpoel, 1998). Comparing between patients, different sessions, levels, and game elements helped the researcher to better understand if the criteria are facilitated and achieving the research aim through different design elements, for different patients.

In the following chapter, the results will be described in regards to each design criteria. Further users' needs that were revealed in the testing, and possible solutions, will be discussed as well. 


\section{Results}

\section{Integration of}

\section{rehabilitation methods:}

Meeting with a neuro-physiotherapist confirmed the following:

1. The design elements in the game can facilitate the feedback provision mechanisms: Knowledge of performance (KP), Knowledge of results $(K R)$, error feedback and summary provision.

2. The rhythmic rewards level can facilitate RAS.

3. The rhythmic obstacles and the rhythmic steps provide rhythmic cues only, not RAS.

4. The calibration phase should measure if patients have side neglect, and prompt players to go to different locations.

Overall, the neuro-physiotherapist said the game could fit patients in the clinic.

Following the meeting, appropriate iterations were made in the calibration level, and rhythmic rewards were added to the second planet.

\section{Engagement}

The play-game duration time was in the range of 15-40 minutes until the participants got tired. This fits with the research expectations, as the music therapist reported that music therapy sessions would take around 30 minutes until fatigue.
While Tom was engaged in the game completely during the whole gameplay session, it seemed that Joy's sessions would take more than 30 minutes, but she would mostly observe the game, try to engage, but succeed to engage and interact in the game only for around five to ten minutes, completing one to three levels each session. She would then lose her concentration and engage with something else, observe the game or the game controller, interact with the game in different ways, or get tired. Joy had the motivation to play the game, however, her cognitive impairments limited her ability to concentrate in the game for long. The game could provide Joy moments to observe how the game world works without her interaction, and get back to it when she is ready.

\section{Able-M}

Both of the interactions required by the Able-M were facilitated in the game. The participants moved the controller around the surface to navigate in the game world, and lifted their finger up to click and collect oxygen or jump to the next step, according to their ability.

Tom was able to do both of the interactions required by the Able-M. However, Joy was more challenged by the arm and fingers movements, as her arm was often stiff and she could not move. When she moved, her range of motion was limited to a small area, finding it hard to move from one side 
of the screen to the other. Her cognitive impairments limited her as well, often losing her concentration and using the Able-M differently, or trying to interact with the game in different ways such as touching the screen with both of her hands, moving the Able-M above the table surface, or just observing the computer screen or the Able-M.

John could not lift any part of his hand to click the Able-M. Both John and Joy displayed affected side neglect, preferring to move in certain directions and avoid certain movements. At some of the times, the three participants used their unaffected arm to support the affected arm. Only John displayed compensatory contributions using his back and head.

\section{Narrative}

Joy said she liked the narrative. In addition, it was helping her to engage with the game. The narrative in the game is discovered with progress in the game. Before she knew the narrative, in the first session, Joy did not make any progress and in the interview said she did not know what her goal was.

In the second session, she was told she needed to help the astronaut to find oxygen and fuel for the spaceship to get back home to planet earth. Joy liked it and started moving her arm for the first time, reaching the oxygen, smiling and saying "This game is neat!". Following the second session, Joy said she knew what her goal was in the game and was saying she was "definitely better" than last time.

Tom, however, saw this as a "selfdiscovery journey", and said that with each level, he was curious to see what will happen next.

John was asking about the elements and the narrative throughout the gameplay, the observer answered his questions and described to him the narrative and his mission.

\section{Feedback}

Joy had joyful facial expressions when she succeeded in the game, and when suddenly could move the arm and control the game. Feedback provision in the game was helpful, in levels where there were only obstacles with no KP or KR feedback, Joy was less engaged, and eventually gave up.

In successful moments, Tom was asking the observer for feedback. Perhaps he needed to be provided with more feedback in the game, or maybe it was the social aspect that added to his experience. Feedback provision was very helpful in the game, showing Tom where to go and what to do. Tom said that every time a new level started he thought to himself that he seemed to have arrived at somewhere important, thinking where to go next, then seeing the path and taking it forward.

In the second planet, when rhythmic blocks were introduced, they were all 
in yellow. This decision was made in order to help players to differentiate between rhythmic and nonrhythmic blocks. However, Tom was already used to the color rules in the game from the previous planet, and having the color scheme break down was confusing for him. The important thing for him in the game was to follow the colors in the right order, in order to find the path and quickly move forward. John seemed to understand he should follow the KP signs and was curious about the aliens, asking about them after receiving an error feedback. Sometimes it was difficult for him to avoid them, and sometimes he was unsure on what to do, but he kept on going, following his path.

\section{Rhythm}

Tom stayed longer in the RAS level than in other levels, getting his oxygen level as high as possible. His timing and aim were very good. When asked what he thought about the music, Tom said that it didn't influence him.

In the rhythmic elements level, Tom said that he found it very demanding of his attention."I felt I was doing alright, and then when I wasn't moving, I tried to find a pattern... There seem to be a pattern in it to anticipate it".

On the third session, playing the second planet, Tom was moving from note to note playing and exploring, and for a short while, he was moving in the chair according to the rhythmic cue in the game.

At the first level introducing a rhythmic alien, Joy moved her arm to lead her avatar according to the rhythmic pattern. She moved her arm every time a note was playing. However, she did not let her avatar come close to the alien, trying to take the avatar up the mountain until she gave up. Later when asked what she thought of the sounds, Joy said she would have liked it to be faster.

In the RAS level, John had difficulty in getting the oxygen on time. In some cases, he was on time, but mostly arriving after the oxygen was already gone because his ability to control his movements. In the rhythmic steps levels, at the beginning, he was moving fast from block to block, falling from blocks and then starting the level again. Once he understood he will need to start the level again if he falls, John started to be more careful. His strategy was to wait in one place until the block will get to where he was, using his cognitive resources (planning abilities) to proceed forward. Once the block arrived at where he was, John quickly moved his arm to jump forward. Sometimes succeeding, and sometimes moving on time, but in a wrong direction.

This is good as he can exercise to aim and control his movements, it's possible that the use of his cognitive resources can promote neuroplasticity and perhaps help with his aphasia as well 
(Cremer et al., 2011) but more research is needed.

\section{Challenge skill balance}

We learned from Joy that the rhythm speed of obstacles and rewards should adapt to patients' ability and be slow when needed, but this does not mean the overall music in the game should be slow as well.

The game could easily adapt to the players physical abilities.

It seemed that both Tom and Joy did not make any effort in the calibration phase. The calibration should require more effort from players before they can continue, yet, not frustrate or tire them right at the start. On the other hand, John did make an effort in the calibration phase. In the second planet, he went through the calibration three times until he got to a higher difficulty level after practice.

We learned from Joy that adapting the challenges to players' cognitive abilities is the biggest problem. Even though Joy could perform the exercises, her ability to concentrate and stay in the game is limited by her cognitive impairments. It might be that RAS would help by connecting directly to the motor system, making the movements more automatic, and keeping Joy in a flow state. But more research is needed to confirm this. In this study, we combined challenges with rhythmic cues. The rhythmic cues did not help Joy to go through the challenges. It might be that practicing only RAS condition first, and then progressing to a challenge will increase the support of the cues in a cognitive challenge.

John was not able to click the Able-M. After the gameplay, John said that "more circular movements would be good". Even though his range of motion was limited, he was looking for a greater challenge. John did not get fatigued, the cognitive challenge was not too difficult even though sometimes he did not know what to do. However, it was physically challenging for him and after the session, he said he is now warmed up. All the participants showed learning throughout their journey in the game and progress through the levels, making an effort in different ways to engage with the challenges they were confronted with.

\section{Performance}

Tom completed the first planet, and reached the last level on the second planet. Joy completed four levels on the first planet. John completed the two planets one after the other and did not want a break in between when it was offered to him. During the gameplay, he was completely engaged in the game and constantly moving. His gameplay duration was 35 minutes. 


\begin{tabular}{|c|c|c|c|c|}
\hline & $\begin{array}{l}\text { Gameplay } \\
\text { duration }\end{array}$ & $\begin{array}{l}\text { Observed } \\
\text { time of } \\
\text { engagement }\end{array}$ & $\begin{array}{l}\text { Reason for } \\
\text { stopping }\end{array}$ & $\begin{array}{l}\text { Observed physical } \\
\text { engagement }\end{array}$ \\
\hline Tom & 16 minutes & 16 minutes & $\begin{array}{l}\text { Mostly fatigue } \\
\text { and external } \\
\text { factors. }\end{array}$ & $\begin{array}{l}\text { Sometime supported the } \\
\text { affected arm with the } \\
\text { unaffected arm. } \\
\text { No compensatory } \\
\text { contributions. } \\
\text { No physical fatigue } \\
\text { was reported. }\end{array}$ \\
\hline Joy & 30 minutes & 6 minutes & $\begin{array}{l}\text { Mostly } \\
\text { concentration } \\
\text { loss / fatigue. }\end{array}$ & $\begin{array}{l}\text { Sometime supported the } \\
\text { affected arm with the } \\
\text { unaffected arm. } \\
\text { No compensatory } \\
\text { contributions. } \\
\text { Minimal range of motion. } \\
\text { Side neglect. } \\
\text { Physical fatigue was } \\
\text { reported. }\end{array}$ \\
\hline John & 35 minutes & 35 minutes & $\begin{array}{l}\text { Finished the } \\
\text { two planets. }\end{array}$ & $\begin{array}{l}\text { Sometime supported the } \\
\text { affected arm with the } \\
\text { unaffected arm. } \\
\text { Compensatory contributions. } \\
\text { Side neglect. } \\
\text { Physical exercise - reported } \\
\text { that he warmed up after the } \\
\text { gameplay. }\end{array}$ \\
\hline
\end{tabular}




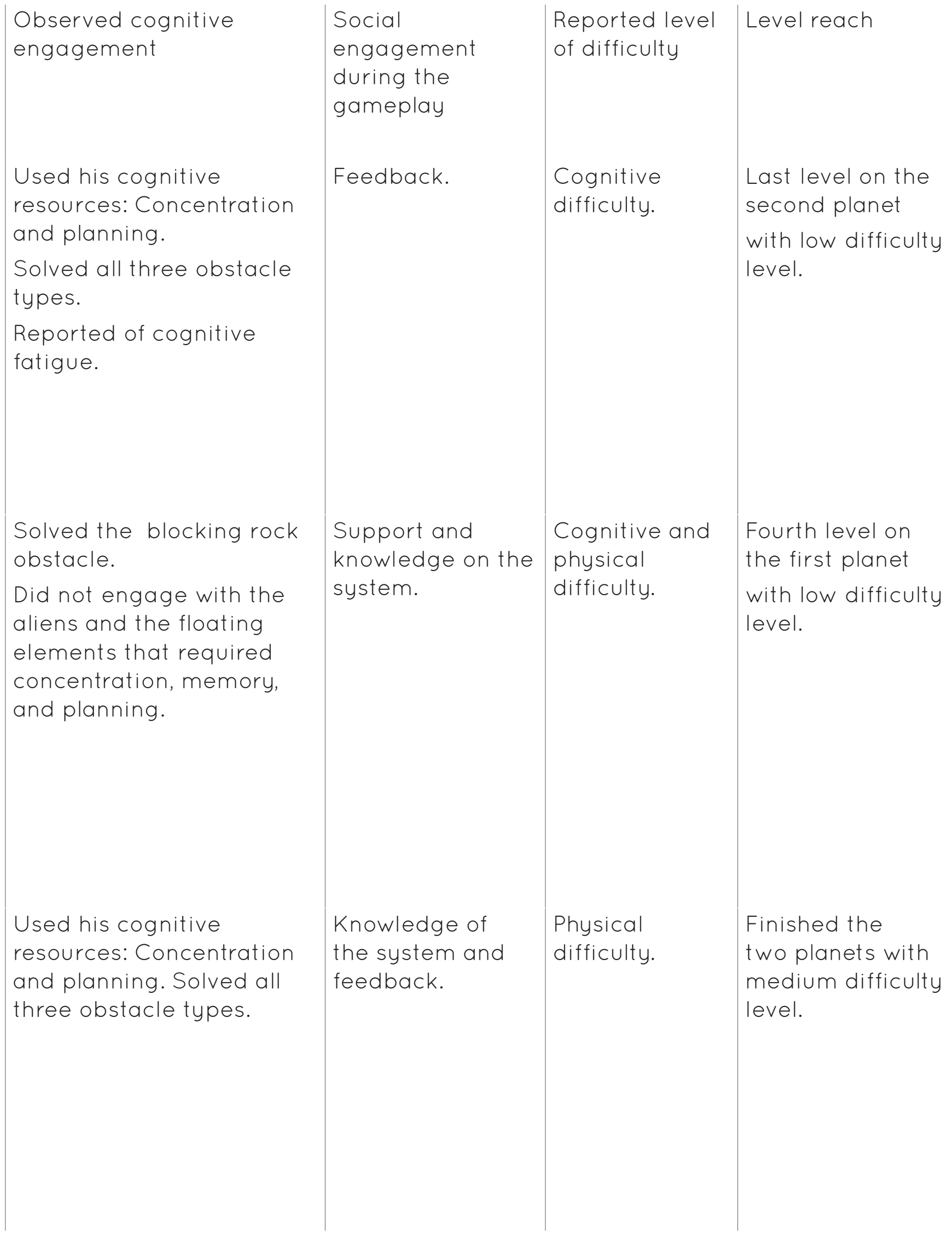

Figure 62: Engagement observations 


\section{Conclusions:}

This research aim was to develop a game for upper limb stroke rehabilitation with Able-M in order to provide stroke survivors more engaging rehabilitation opportunities.

The research proposed design criteria based on literature review, personas generation, discussions with therapists and field observations.

The criteria were established to engage patients with the interactions required by Able-M using design elements such as a narrative, challenge-skill balance and feedback, and the integration of effective rehabilitation methods such as rhythmic auditory stimulation (RAS) and feedback provision.

After establishing the criteria, the researcher used an iterative design process to develop a prototype intending to facilitate the criteria through different design elements.

The process included qualitative studies with healthy individuals to test the criteria and the playability of the game, and iterations were done according to the data analysed through user observations and semi-structured interviews. The criteria in the final prototype was tested with a neurophysiotherapist and with patients. Discussion with a neuro-physiotherapist informed and confirmed the therapy integration in the game. Qualitative studies with patients including user observations and semi-structured interviews informed the research on which design elements facilitate the criteria best and whether the criteria supports the engagement of patients with upper limb stroke rehabilitation using the Able-M. The results from the qualitative studies supported the criteria for engagement and informed the researcher on patients' experience of the game, needed iterations, study limitations and directions for future research.

The results suggest that the three design elements for engagement: Challenge-skill balance, feedback, and narrative influenced patients' engagement with the game. It was confirmed that feedback provision mechanisms can also promote an engaging experience. KP and KR feedback was most needed for the engagement of participants, and when missing for a long time, the engagement was reduced and confusion increased.

A social aspect was not integrated into the game, but the presence of others around the participants, while they are playing, may have encouraged them and influenced their engagement. For example in one session a family member of the participant was present, supporting her through the gameplay. In other cases, the participant would look to share their achievements with others in the room. This can be easily implemented for stroke survivors playing alone at home by allowing them to upload their progress records online to share with others playing the same game, other online social 
networks, or with clinicians, friends, and family. However, more research is needed on how to design a multi-player rehabilitation game without interfering the challenge-skill balance for each of the players.

In addition, some players needed to know the narrative, while others liked the abstract version that gave them the opportunity to develop their own narrative.

Another possibility is to introduce another character like a friendly alien, or someone from planet earth, to guide the players through their journey, give them missions, and support them in challenges just before they are about to give up.

Rhythmic cues of obstacles seem to have a different effect than rhythmic rewards. While the rhythmic rewards facilitated classic RAS where players could easily engage with, the rhythmic cues of the obstacles were more challenging and had a different influence on players, demanding their concentration in the rhythmic pattern to anticipate the next cue, plan their moves, and move forward at the right time to avoid losing oxygen or falling.

This may suit players with physical impairments who want to have some cognitive challenge, and should be accessible for players with cognitive impairments as it may promote neuroplasticity (Cramer et al., 2011). However, more research is needed to confirm this and how should these challenges be designed to promote neuroplasticity and redevelop these skills. If so, the cognitive challenges should be minimal and progress in difficulty slowly throughout the game, with long breaks in between without any cognitive challenges, to reduce the risk of frustration.

This might also suggest that the element of strategy could suit some players, but need to be tailored to players' cognitive abilities. Perhaps allowing players to play the game without a strategy, while giving them the option to use strategy for better performance records could work.

One of the assumptions in this research was that the rhythmic cues will support patients with cognitive impairments. The results suggest that patients with limited cognitive resources might keep moving according to the rhythmic pattern, but not necessarily to solve the challenge.

It might be that the rhythmic cues were not established enough throughout the gameplay, another thing could be the players preferences. An open-ended game could provide players with more options and will have less of a chance of frustrating them. The results suggest that even though the difficulty level can be tailored to patient's ability, some players want to choose their difficulty level, after tailoring the level to players, the game can provide them with choices of difficulty. 


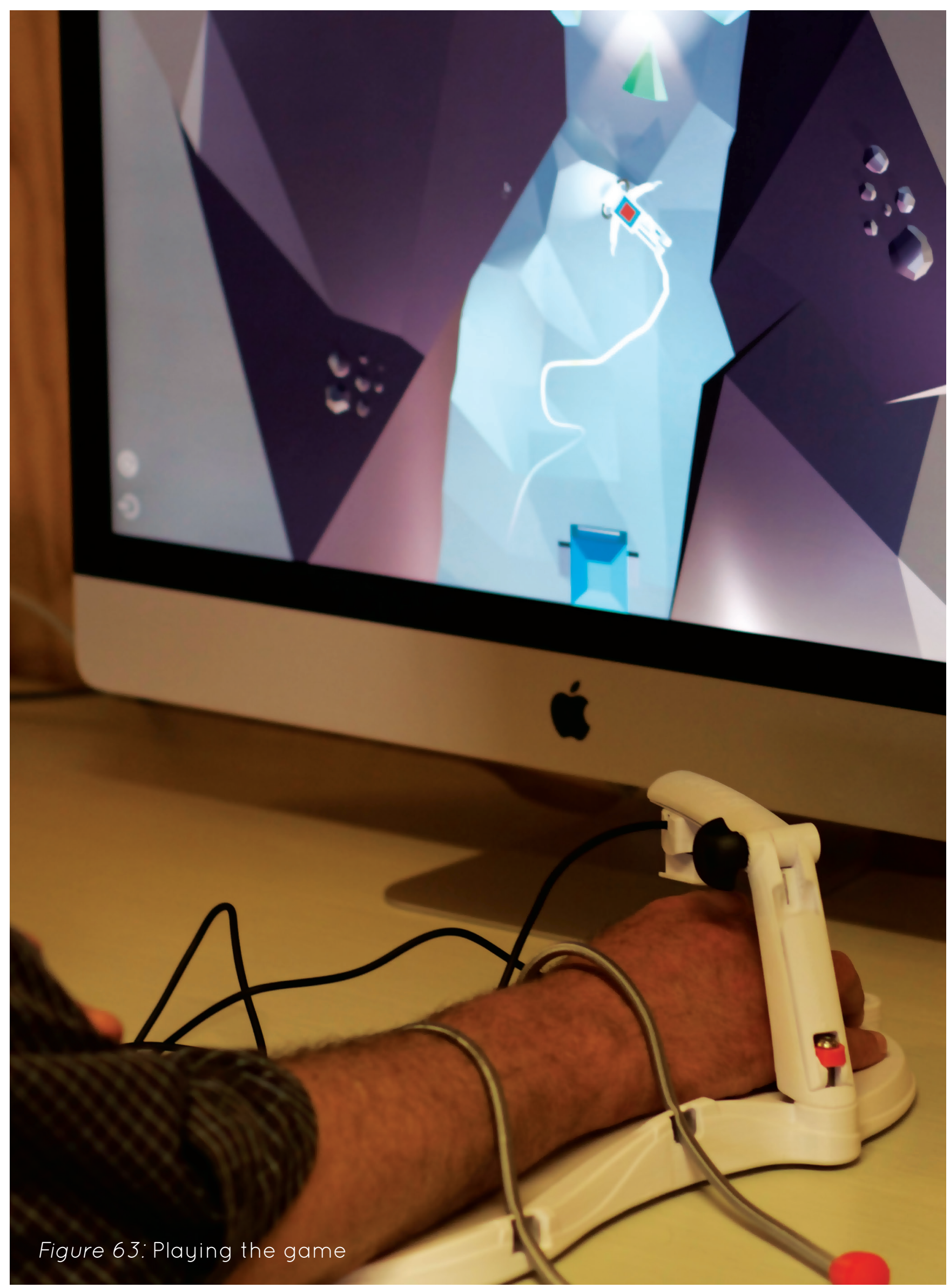


Chance was not included in the criteria as well as strategy and social context, as more research is needed on these elements. The results suggest that some players are driven by curiosity to find out what will happen next in the game world.

Cognitive impairments may reduce players' ability to concentrate, and stop their flow in the game. Future research could explore how the game could support patients with cognitive impairments to concentrate for longer periods of time, or to allow breaks when needed, in order to continue their flow in the game.

All the participants enjoyed the sessions and wanted to keep on playing the game in the future. Overall the study results show the game provided the participants an opportunity to engage with rehabilitation, learn new skills, and be exposed to new stimulations in a safe environment.

The limitations of the study included the number of participants. A Larger sample of patients could provide greater information and ability to conduct a quantitative study. Future research could investigate the longterm effects of playing the game on the return of function. As well as the effectiveness of the game with different game controllers. Further research could identify the effects of cognitive challenges on the rehabilitation outcomes and how can cognitive training be designed to adapt to players' abilities and needs using Rhythmic Auditory Stimulation, physical support, or a different strategy. 


\section{Acknowledgments}

Supervisors: Kah Chan, Dr. Brian Robinson, and Dr. Edgar Rodriguez-Ramirez.

Music therapists: Andrea Robinson.

Neuro-physiotherapists: Dr. Nada Signal

and Dr. Denise Taylor.

Health psychologist: Dr. Nicola Kayes.

The participants and their care givers.

Technical support: Lukas Stoecklein and Matt Everitt.

Equipment: Andrew Matautia and the media design department.

Model: Warwick McLeod.

MDI CoRE scholarship: Smart Interactions

CoRE MedTech.

General support: Family and friends, co-students, the Smart Interactions team, and the staff at Victoria University of Wellington. 

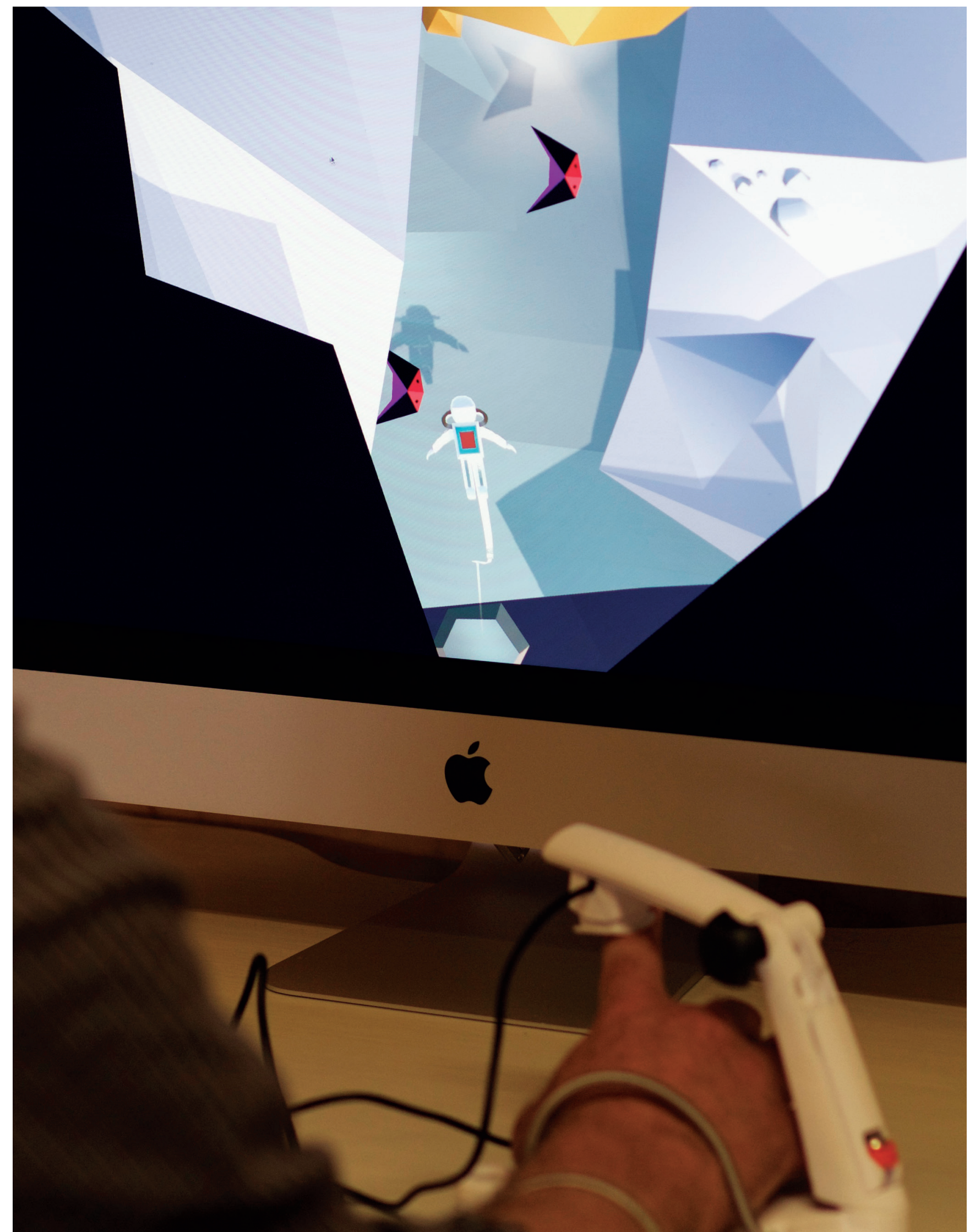

Figure 64: Playing the game 


\section{References}

Alankus, G., Lazar, A., May, M., E Kelleher, C. (2010, April). Towards customizable games for stroke rehabilitation. In Proceedings of the SIGCHI Conference on Human Factors in Computing Systems (pp. 2113-2122). ACM.

Andrews, G., Halford, G. S., Chappell, M., Maujean, A., \& Shum, D. H. (2014). Planning following stroke: a relational complexity approach using the Tower of London. Frontiers in human neuroscience, 8.

Backlund, P., Engstrom, H., Johannesson, M., Lebram, M., \& Sjoden, B. (2008, July). Designing for self-efficacy in a game based simulator: An experimental study and its implications for serious games design. InVisualisation, 2008 international conference (pp. 106113). IEEE.

Brooke, J. (1996). SUS-A quick and dirty usability scale. Usability evaluation in industry, 189(194), 4-7.

Burdea, G. (2002, November). Keynote address: Virtual rehabilitationbenefits and challenges. In 1st International Workshop on Virtual Reality Rehabilitation (Mental Health, Neurological, Physical, Vocational) VRMHR (pp. 1-11). sn.

Burke, J. W., McNeill, M. D. J., Charles, D. K., Morrow, P. J., Crosbie, J.H., E McDonough, S. M. (2009). Optimising engagement for stroke rehabilitation using serious games. The Visual Computer, 25(12), 1085-1099.
Burke, J. W., McNeill, M. D. J., Charles, D. K., Morrow, P. J., Crosbie, J.H., \& McDonough, S. M. (2009, March). Serious games for upper limb rehabilitation following stroke. In Games and Virtual Worlds for Serious Applications, 2009. VSGAMES'09. Conference in (pp.103110). IEEE.

Bright, F. A., Kayes, N. M., Worrall, L., \& McPherson, K. M. (2015). A conceptual review of engagement in healthcare and rehabilitation. Disability and rehabilitation, 37(8), 643-654.

Brown, E., \& Cairns, P. (2004, April). A grounded investigation of game immersion. In CHI'O 4 extended abstracts on Human factors in computing systems (pp. 1297-1300). ACM.

Chang, Y. J., Han, W. Y., \& Tsai, Y. C. (2013). A Kinect-based upper limb rehabilitation system to assist people with cerebral palsy. Research in developmental disabilities, 34(11), 3654-3659.

Cirstea, C. M., Ptito, A., \& Levin, M. F. (2006). Feedback and cognition in arm motor skill reacquisition after stroke. Stroke, 37(5), 1237-1242.

Cramer, S. C., Sur, M., Dobkin, B. H., O'Brien, C., Sanger, T. D., Trojanowski, J. Q., ... \& Vinogradov, S. (2011). Harnessing neuroplasticity for clinical applications. Brain, 134(6), 1591-1609. 
Creswell, J. W. (2009). Research design: Qualitative, quantitative, and mixed methods approaches. Sage publications.

Csikszentmihalyi, M., \& Csikzentmihaly, M. (1991). Flow: The psychology of optimal experience (Vol. 41). New York: HarperPerennial.

De Schutter, B. (2010). Never too old to play: The appeal of digital games to an older audience. Games and Culture.

Eng, X. W., Braver, S. G., Kuys, S. S., Lord, M., \& Hayward, K. S. (2014). Factors affecting the ability of the stroke survivor to drive their own recovery outside of therapy during inpatient stroke rehabilitation. Stroke research and treatment, 2014.

Ermi, L., \& Mäyrä, F. (2005). Fundamental components of the gameplay experience: Analysing immersion. Worlds in play: International perspectives on digital games research, 37.

Feigin, V. L., Forouzanfar, M. H., Krishnamurthi, R., Mensah, G. A., Connor, M., Bennett, D. A., ... \& Murray, C. (2014). Global and regional burden of stroke during 1990-2010: findings from the Global Burden of Disease Study 2010. The Lancet, 383(9913), 245-255.

Finneran, C. M., \& Zhang, P. (2003). A person-artefact-task (PAT) model of flow antecedents in computer-mediated environments.
International Journal of HumanComputer Studies, 59(4), 475-496.

Flores, E., Tobon, G., Cavallaro, E., Cavallaro, F. I., Perry, J. C., \& Keller, T. (2008, December). Improving patient motivation in game development for motor deficit rehabilitation. In Proceedings of the 2008 International Conference on Advances in Computer Entertainment Technology (pp. 381-384). ACM.

Ford, M. P., Wagenaar, R. C., \& Newell, K. M. (2007). The effects of auditory rhythms and instruction on walking patterns in individuals post stroke. Gait \& posture, 26(1), 150-155.

Grahn, J., \& Brett, M. (2007). Rhythm and beat perception in motor areas of the brain. Cognitive Neuroscience, Journal of, 19(5), 893-906.

Haring, H. P. (2002). Cognitive impairment after stroke. Current opinion in neurology, 15(1), 79-84

Harley, L., Robertson, S., Gandy, M., Harbert, S., \& Britton, D. (2011). The design of an interactive stroke rehabilitation gaming system. In Human-Computer Interaction. Users and Applications (pp. 167-173). Springer Berlin Heidelberg.

Heinzen, T. E., Gordon, M. S., Landrum, R. E., Gurung, R. A., Dunn, D. S., \& Richman, S. (2015). A Parallel Universe: Psychological Science in the Language of Game Design. In Gamification in Education and Business (pp. 133-149). Springer 
International Publishing.

Ijsselsteijn, W., Nap, H. H., de Kort, Y., \& Poels, K. (2007, November). Digital game design for elderly users. In Proceedings of the 2007 conference on Future Play (pp. 17-22). ACM.

Jackson, S. A., \& Marsh, H. W. (1996).

Development and validation of a scale to measure optimal experience: The Flow State Scale. Journal of sport and exercise psychology, 18, 17-35.

Jordan, K., Sampson, M., Hijmans, J., King, M., \& Hale, L. (2011). ImAble system for upper limb stroke rehabilitation. In 2011 International Conference on Virtual Rehabilitation.

Kolb, B., \& Whishaw, I. Q. (1998). Brain plasticity and behavior. Annual review of psychology, 49(1), 43-64.

Kowal, J., \& Fortier, M. S. (1999). Motivational determinants of flow: Contributions from selfdetermination theory. The Journal of Social Psychology, 139(3), 355-368.

Krakaver, J. W. (2006). Motor learning: its relevance to stroke recovery and neurorehabilitation. Current opinion in neurology, 19(1), 84-90.

Lai, S. M., Studenski, S., Duncan, P. W., \& Perera, S. (2002). Persisting consequences of stroke measured by the Stroke Impact Scale. Stroke, 33(7), 1840-1844.

Maclean, N., \& Pound, P. (2000). A critical review of the concept of patient motivation in the literature on physical rehabilitation. Soc Sci Med, 50(4), 495-506.

Malcolm, M., Massie, C., \& Thaut, M. (2009). Rhythmic auditory-motor entrainment improves hemiparetic arm kinematics during reaching movements: a pilot study. Topics in stroke rehabilitation, 16(1), 69.

Molinari, M., LEGGIO, M. G., MARTIN, M., Cerasa, A., \& Thaut, M. (2003). Neurobiology of rhythmic motor entrainment. Annals of the New York Academy of Sciences, 999(1), 313-321.

Murray, C. J., Vos, T., Lozano, R., Naghavi, M., Flaxman, A. D., Michaud, C., ... \& Bridgett, L. (2013). Disability-adjusted life years (DALYs) for 291 diseases and injuries in 21 regions, 1990-2010: a systematic analysis for the Global Burden of Disease Study 2010. The lancet, 380 (9859), 2197-2223.

Nacke, L., \& Lindley, C. A. (2008, November). Flow and immersion in first-person shooters: measuring the player's gameplay experience. InProceedings of the 2008 Conference on Future Play: Research, Play, Share(pp. 81-88). ACM.

Norman, D. A. (2005). Human-centered design considered harmful. Interactions, 12(4), 14-19.

Pichlmair, M., \& Kayali, F. (2007, September). Levels of sound: On the principles of interactivity in music video games. In Proceedings of the Digital Games Research Association 2007 Conference" Situated play. 
Poggenpoel, M. (1998). Data analysis in qualitative research. Research at grass roots: A primer for the caring professions, 334-353.

Pollock, A., Farmer, S. E., Brady, M. C., Langhorne, P., Mead, G. E., Mehrholz, J., \& van Wijck, F. (2014). Interventions for improving upper limb function after stroke. Cochrane Database of Systematic Reviews, 11.

Rego, P., Moreira, P. M., \& Reis, L. P. (2010, June). Serious games for rehabilitation: A survey and a classification towards a taxonomy. In Information Systems and Technologies (CISTI), 2010 5th Iberian Conference on (pp. 1-6). IEEE.

Rodriguez R. E., Chan K. \& McCarthy G. (2015, to be presented). Able-M: The design of a system for upper-limb rehabilitation after stroke. Design Semantics of Form and Movement (DeSForM) 2015. Politecnico di Milano: Italy (13 - 17 October 2015)

Rosati, G., Oscari, F., Reinkensmeyer, D. J., Secoli, R., Avanzini, F., Spagnol, S., \& Masiero, S. (2011, June). Improving robotics for neurorehabilitation: enhancing engagement, performance, and learning with auditory feedback. In Rehabilitation Robotics (ICORR), 2011 IEEE International Conference on (pp. 1-6). IEEE.

Sharafi, P., Hedman, L., \& Montgomery, H. (2006). Using information technology: engagement modes, flow experience, and personality orientations. Computers in Human Behavior, 22(5), 899-916.

Sigrist, R., Rauter, G., Riener, R., \& Wolf, P. (2013). Augmented visual, auditory, haptic, and multimodal feedback in motor learning: A review. Psychonomic bulletin \& review, 20(1), 21-53.

Stewart, L., von Kriegstein, K., Warren, J. D., \& Griffiths, T. D. (2006). Music and the brain: disorders of musical listening. Brain, 129(10), 2533-2553.

Subramanian, S. K., Massie, C. L., Malcolm, M. P., \& Levin, M. F. (2010). Does provision of extrinsic feedback result in improved motor learning in the upper limb poststroke? A systematic review of the evidence. Neurorehabilitation and Neural Repair, 24(2), 113-124.

Squire, K. (2008). Open-ended video games: A model for developing learning for the interactive age. The ecology of games: Connecting youth, games, and learning, 167-198.

Tanenbaum, J., \& Bizzocchi, J. (2009, August). Rock Band: a case study in the design of embodied interface experience. In Proceedings of the 2009 ACM SIGGRAPH Symposium on Video Games (pp. 127-134). ACM.

Thaut, M. H., Kenyon, G. P., Hurt, C. P., Mclntosh, G. C., \& Hoemberg, V. (2002). Kinematic optimization of spatiotemporal patterns in paretic arm training with stroke patients. Neuropsychologia, 40(7), 1073-1081. 
Thaut, M. H., Leins, A. K., Rice, R. R., Argstatter, H., Kenyon, G. P., Mclntosh, G. C., ... E Fetter, M. (2007). Rhythmic auditory stimulation improves gait more than NDT/Bobath training in near-ambulatory patients early poststroke: a single-blind, randomized trial. Neurorehabilitation and neural repair, 21(5), 455-459.

Thaut, M. H., Mclntosh, G. C., Prassas, S. G., \& Rice, R. R. (1993). Effect of rhythmic auditory cuing on temporal stride parameters and EMG. Patterns in hemiparetic gait of stroke patients. Neurorehabilitation and Neural Repair, 7(1), 9-16.

Thaut, M. H., Mclntosh, G. C., E Rice, R. R. (1997). Rhythmic facilitation of gait training in hemiparetic stroke rehabilitation. Journal of the neurological sciences, 151(2), 207-212.

Thaut, M. H., Miller, R. A., \& Schaver, L. M. (1998). Multiple synchronization strategies in rhythmic sensorimotor tasks: phase vs period correction. Biological Cybernetics, 79(3), 241250.

Van Vliet, P. M., \& Wulf, G. (2006). Extrinsic feedback for motor learning after stroke: what is the evidence?. Disability and rehabilitation, 28(1314), 831-840.

Whitall, J., Waller, S. M., Silver, K. H., \& Macko, R. F. (2000). Repetitive bilateral arm training with rhythmic auditory cueing improves motor function in chronic hemiparetic stroke. Stroke, 31(10), 2390-2395.
Wilson, S. J., Pressing, J. L., \& Wales, R. J. (2002). Modelling rhythmic function in a musician post-stroke. Neuropsychologia, 40 (8), 1494-1505.

Winstein, C. J., Pohl, P. S., \& Lewthwaite, R. (1994). Effects of physical guidance and knowledge of results on motor learning: support for the guidance hypothesis. Research quarterly for exercise and sport, 65(4), 316-323.

Winstein, C. J., Rose, D. K., Tan, S. M., Lewthwaite, R., Chui, H. C., \& Azen, S. P. (2004). A randomized controlled comparison of upper-extremity rehabilitation strategies in acute stroke: a pilot study of immediate and long-term outcomes. Archives of physical medicine and rehabilitation, 85(4), 620-628.

Topics in stroke rehabilitation, 16(1), 69. Molinari, M., LEGGIO, M. G., MARTIN, M., Cerasa, A., \& Thaut, M. (2003). Neurobiology of rhythmic motor entrainment. Annals of the New York Academy of Sciences, 999(1), 313-321.

Murray, C. J., Vos, T., Lozano, R., Naghavi, M., Flaxman, A. D., Michaud, C., ... \& Bridgett, L. (2013). Disability-adjusted life years (DALYS) for 291 diseases and injuries in 21 regions, $1990-2010$ : a systematic analysis for the Global Burden of Disease Study 2010. The lancet, 380 (9859), 2197-2223.

Nacke, L., \& Lindley, C. A. (2008, November). Flow and immersion in first-person shooters: measuring 
the player's gameplay experience. InProceedings of the 2008 Conference on Future Play: Research, Play, Share(pp. 81-88). ACM.

Norman, D. A. (2005). Human-centered design considered harmful. Interactions, 12(4), 14-19.

Pichlmair, M., \& Kayali, F. (2007, September). Levels of sound: On the principles of interactivity in music video games. In Proceedings of the Digital Games Research Association 2007 Conference" Situated play.

Poggenpoel, M. (1998). Data analysis in qualitative research. Research at grass roots: A primer for the caring professions, 334-353.

Pollock, A., Farmer, S. E., Brady, M. C., Langhorne, P., Mead, G. E., Mehrholz, J., \& van Wijck, F. (2014). Interventions for improving upper limb function after stroke. Cochrane Database of Systematic Reviews, 11.

Rego, P., Moreira, P. M., \& Reis, L. P. (2010, June). Serious games for rehabilitation: A survey and a classification towards a taxonomy. In Information Systems and Technologies (CISTI), 2010 5th Iberian Conference on (pp. 1-6). IEEE.

Rodriguez R. E., Chan K. \& McCarthy G. (2015, to be presented). Able-M: The design of a system for upper-limb rehabilitation after stroke. Design Semantics of Form and Movement (DeSForM) 2015. Politecnico di Milano: Italy (13 - 17 October 2015)
Rosati, G., Oscari, F., Reinkensmeyer, D. J., Secoli, R., Avanzini, F., Spagnol, S., \& Masiero, S. (2011, June). Improving robotics for neurorehabilitation: enhancing engagement, performance, and learning with auditory feedback. In Rehabilitation Robotics (ICORR), 2011 IEEE International Conference on (pp. 1-6). IEEE.

Sharafi, P., Hedman, L., \& Montgomery, H. (2006). Using information technology: engagement modes, flow experience, and personality orientations. Computers in Human Behavior, 22(5), 899-916.

Sigrist, R., Rauter, G., Riener, R., \& Wolf, P. (2013). Augmented visual, auditory, haptic, and multimodal feedback in motor learning: A review. Psychonomic bulletin \& review, 20(1), 21-53.

Stewart, L., von Kriegstein, K., Warren, J. D., E Griffiths, T. D. (2006). Music and the brain: disorders of musical listening. Brain, 129(10), 2533-2553.

Subramanian, S. K., Massie, C. L., Malcolm, M. P., \& Levin, M. F. (2010). Does provision of extrinsic feedback result in improved motor learning in the upper limb poststroke? A systematic review of the evidence. Neurorehabilitation and Neural Repair, 24(2), 113-124.

Squire, K. (2008). Open-ended video games: A model for developing learning for the interactive age. The ecology of games: Connecting youth, 
games, and learning, 167-198.

Tanenbaum, J., \& Bizzocchi, J. (2009, August). Rock Band: a case study in the design of embodied interface experience. In Proceedings of the 2009 ACM SIGGRAPH Symposium on Video Games (pp. 127-134). ACM.

Thaut, M. H., Kenyon, G. P., Hurt, C. P., Mclntosh, G. C., \& Hoemberg, V. (2002). Kinematic optimization of spatiotemporal patterns in paretic arm training with stroke patients. Neuropsychologia, 40(7), 1073-1081.

Thaut, M. H., Leins, A. K., Rice, R. R., Argstatter, H., Kenyon, G. P., Mclntosh, G. C., ... \& Fetter, M. (2007). Rhythmic auditory stimulation improves gait more than NDT/Bobath training in near-ambulatory patients early poststroke: a single-blind, randomized trial. Neurorehabilitation and neural repair, 21(5), 455-459.

Thaut, M. H., Mclntosh, G. C., Prassas, S. G., \& Rice, R. R. (1993). Effect of rhythmic auditory cuing on temporal stride parameters and EMG. Patterns in hemiparetic gait of stroke patients. Neurorehabilitation and Neural Repair, 7(1), 9-16.

Thaut, M. H., McIntosh, G. C., \& Rice, R. R. (1997). Rhythmic facilitation of gait training in hemiparetic stroke rehabilitation. Journal of the neurological sciences, 151(2), 207-212.

Thaut, M. H., Miller, R. A., \& Schaver, L. M. (1998). Multiple synchronization strategies in rhythmic sensorimotor tasks: phase vs period correction. Biological Cybernetics, 79(3), 241250.

Van Vliet, P. M., \& Wulf, G. (2006). Extrinsic feedback for motor learning after stroke: what is the evidence?. Disability and rehabilitation, 28(1314), 831-840.

Whitall, J., Waller, S. M., Silver, K. H., \& Macko, R. F. (2000). Repetitive bilateral arm training with rhythmic auditory cueing improves motor function in chronic hemiparetic stroke. Stroke, 31(10), 2390-2395.

Wilson, S. J., Pressing, J. L., \& Wales, R. J. (2002). Modelling rhythmic function in a musician post-stroke. Neuropsychologia, 40 (8), 1494-1505.

Winstein, C. J., Pohl, P. S., \& Lewthwaite, R. (1994). Effects of physical guidance and knowledge of results on motor learning: support for the guidance hypothesis. Research quarterly for exercise and sport, 65(4), 316-323.

Winstein, C. J., Rose, D. K., Tan, S. M., Lewthwaite, R., Chui, H. C., \& Azen, S. P. (2004). A randomized controlled comparison of upper-extremity rehabilitation strategies in acute stroke: a pilot study of immediate and long-term outcomes. Archives of physical medicine and rehabilitation, 85(4), 620-628. 


\section{Appendix}

\section{Participant Information Sheet}

Study title:

Locality:

Lead investigator:
A Game for Physiotherapeutic Rehabilitation for Stroke Survivors

Wellington

Ethics committee ref:

Contact phone number:
16/CEN/15

(04) 4636155

You are invited to take part in a study on a digital game system on the recovery process from stroke. Whether or not you take part is your choice. If you don't want to take part, you don't have to give a reason, and it won't affect the care you receive. If you do want to take part now, but change your mind later, you can pull out of the study at any time.

This Participant Information Sheet will help you decide if you'd like to take part. It sets out why we are doing the study, what your participation would involve, what the benefits and risks to you might be, and what would happen after the study ends. We will go through this information with you and answer any questions you may have. You do not have to decide today whether or not you will participate in this study. Before you decide you may want to talk about the study with other people, such as family, whānau, friends, or healthcare providers. Feel free to do this.

If you agree to take part in this study, you will be asked to sign the Consent Form on the last page of this document. You will be given a copy of both the Participant Information Sheet and the Consent Form to keep.

This document is 6 pages long, including the Consent Form. Please make sure you have read and understood all the pages.

\section{WHAT IS THE PURPOSE OF THE STUDY?}

This study is to develop a computer game that can be used by people who are recovering from stroke. This is for rehabilitation that they can carry out by themselves at home.

We are wanting to know how you find using the computer, the controller and the game. Our aim is that these will be easy to use and understand as well as challenging and rewarding for you. It is also important that the movements made when using the games will help with stroke rehabilitation.

This game is developed by a student as a requirement for a Masters degree. This research is funded by the School of Design at Victoria University of Wellington.

Any other questions you have can be answered by Dr. Brian Robinson (463 6155)

This research has been approved by the Health and Disability Ethics Committee. 


\section{WHAT WILL MY PARTICIPATION IN THE STUDY INVOLVE?}

We asked you to take part in this research because you have had a stroke in the past 12 months and may have limited use of one of your arms.

The research study will take place either at a Stroke Club or in your home.

If the research study takes place in your home, two research students will come. They will bring mobile telephones with them so that they can contact their research supervisors.

We will ask some questions about you such as how old you are, your ethnic background, how long ago you had the stroke and how the stroke affects you now.

We will show you a computer, a computer controller and a game

You will be asked to use the computer and the control device to play a computer game.

You can play this game for as long as you like and can tell us when you want to stop.

We will take a video and photographs of you using this computer controller and game. This is to make sure that using the controls and the game in ways that will be useful for stroke recovery and not cause harm. Stroke rehabilitation physiotherapists will review these recordings. We will keep the video and photographs securely in the University. Because other researchers will be interested in our research we may show the photographs or a video of you. Your involvement in the study will only be known by the researchers. All photographs and videos will be taken using cameras belonging to the School of Design. The images and videos will be taken off these cameras and immediately after this session and then kept secure in the University computer system.

If we do use photographs or videos of you for presenting our research we will not show any part of you, such as your face, that can tell other people that you have taken part. If we take pictures in your home, we will also make sure that we do not show anything that identifies your house or that you took part. We will do this by blurring parts of the images and videos We will ask you for your thoughts on using the computer control and game. We will record what you say. If you tell us something useful that we quote, we will not use your name with what you say".

Your participation requires your concentration using the game or device. We realize that this can be tiring for you so we ask you can tell that you are wanting to rest or to stop the session. You may be invited to take part again if you would like to help us test changes.

\section{WHAT ARE THE POSSIBLE BENEFITS AND RISKS OF THIS STUDY?}

We know that people who have had stroke cannot access stroke rehabilitation therapy regularly. They have to travel to clinics or hospital. We also know that rehabilitation is more effective when it is carried out for several hours throughout day, every day.

This study is to support people who have had a stroke to provide stroke rehabilitation therapy in their home. This can be by themselves or with the help of carer support or family members.

We are wanting to find out whether this device or game may be useful in stroke rehabilitation. This research is finding out whether you can use it and what you think of it.

This does not replace any other therapy you may be receiving. We are not using the device and game as part of your therapy at this stage. We want to find out whether this might be usable as a therapeutic device.

While you are using the computer and playing the game you will be sitting in a chair. We will want you to stay sitting.

WHO PAYS FOR THE STUDY?

This study is funded by Victoria University of Wellington and the School of Design through medical technology research grants from the Ministry of Business, Innovation and Employment.

You will not incur any costs by taking part and we will travel to you. 


\section{WHAT IF SOMETHING GOES WRONG?}

If you were injured in this study, which is unlikely, you would be eligible for compensation from ACC just as you would be if you were injured in an accident at work or at home. You will have to lodge a claim with ACC, which may take some time to assess. If your claim is accepted, you will receive funding to assist in your recovery.

\section{WHAT ARE MY RIGHTS?}

You are volunteering to take part. You do not have to take part in this study and you can withdraw at anytime.

We can show you the video recording and photographs of you we have collected. We can also give you a copy of what we have recorded you saying to us about using the computer device and game.

It is unlikely that participating will affect your health but if it does, we will contact you immediately.

We will not identify you in any of the students work or presentations of the work.

\section{WHAT HAPPENS AFTER THE STUDY OR IF I CHANGE MY MIND?}

After you have taken part and change your mind about being involved, please contact the researcher (the design student) or the lead investigators (Brian Robinson, in the first instance, or Edgar Rodriguez) and any data, information and images associated with your participation will be destroyed.

We will securely store the information and data you have provided for five (5) years and it will then be destroyed.

We can present the findings of this study at stroke clubs within a year of conducting the study.

We can also send you a summary of the student's thesis describing the outcome of the study.

We may also present this study with other similar studies we are conducting at conferences or in books or journals. 
WHO DO I CONTACT FOR MORE INFORMATION OR IF I HAVE CONCERNS?

If you have any questions, concerns or complaints about the study at any stage, you can contact:

Dr Brian Robinson, Senior Lecturer, Graduate School of Nursing, Midwifery \& Health, Victoria University of Wellington.

Work phone: (04) 9349321

brian.robinson@vuw.ac.nz

24 Hour contact numbers:

Dr Robinson: 0297769321

If you cannot contact Dr Robinson, please contact

Associate Professor Edgar Rodriguez: 0275636544

If you have other questions, concerns or complaints and wish to contact a Māori support person, you can contact:

Katherine Reweti- Russell, Research Advisory Group - Māori, CCDHB

Work phone: (04) 8062524

If you want to talk to someone who isn't involved with the study, you can contact an independent health and disability advocate on:

Phone: $\quad 0800555050$

Fax: $\quad 08002$ SUPPORT (0800 2787 7678)

Email: $\quad$ advocacy@hdc.org.nz

For Maori health support please contact your health provider and they will refer you to the representative Maori health support group.

You can also contact the health and disability ethics committee (HDEC) that approved this study on:

Phone: $\quad 08004$ ETHICS

Email: $\quad$ hdecs@moh.govt.nz 


\section{Consent Form}

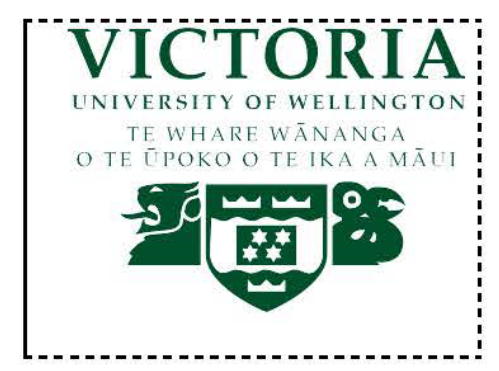

\section{$\Lambda$}

Please tick to indicate you consent to the following

I have read, or have had read to me in my first language, and I understand the Participant Information Sheet.

Yes $\square$

I have been given sufficient time to consider whether or not to participate in this study.

Yes $\square$

I have had the opportunity to use a legal representative, whanau/ family support or a friend to help me ask questions and understand the study.

Yes $\square$

I am satisfied with the answers I have been given regarding the study and I have a copy of this consent form and information sheet.

Yes $\square$

I understand that taking part in this study is voluntary (my choice) and that I may withdraw from the study at any time without this affecting my medical care.

Yes $\square$

I consent to the research staff collecting and processing my information, including information about my health.

Yes $\square$

I understand that my participation in this study is confidential and that no material, which could identify me personally, will be used in any reports on this study.

Yes $\square$

I consent to the research staff taking pictures or video recordings of me and I understand that if used in presentations, these will be altered so that I or my involvement cannot be identified.

Yes $\square$

I understand the compensation provisions in case of injury during the study.

Yes $\square$

I know who to contact if I have any questions about the study in general.

Yes $\square$

\begin{tabular}{ll}
\hline I understand my responsibilities as a study participant. & Yes $\square$ \\
\hline I wish to receive a summary of the results from the study. & Yes $\square \quad$ No $\square$
\end{tabular}


Participant's name:

Signature: Date:

Declaration by member of research team:

I have given a verbal explanation of the research project to the participant, and have answered the participant's questions about it.

I believe that the participant understands the study and has given informed consent to participate.

Researcher's name: Dana Fridman

Signature:

Date: 
Want to Play

\section{your way to recovery?}

Be part of the design process of a computer game for upper limb rehabilitation

Play the game, and let us know what you think about it to make it better.

To participate, contact us on: fridmadana@myvuw.ac.nz 0221369870 


\section{Game Design}

\section{INFORMATION SHEET FOR PARTICIPANTS}

Thank you for your interest in this project. Please read this information before deciding whether or not to take part. If you decide to participate, thank you. If you decide not to take part, thank you for considering my request.

\section{Who am I?}

My name is Dana and I am a Masters student in Media Design at Victoria University of Wellington. This research project is work towards my thesis.

\section{What is the aim of the project?}

The aim of this project is to test the design of a new game developed as part of an MDI research on game design for upper limb rehabilitation following stroke.

Testing the game usability and experience with students will give the designer more information on how to improve the usability of the game and overall experience.

This research has been approved by the Victoria University of Wellington Human Ethics Committee.

\section{How can you help?}

If you agree to take part you will play a computer game at VS234, Te Aro campus, the game performance will be recorded by the game, with screen recording, and with a video camera. In addition, I will be in the studio while writing notes about the observed game play. Following the game you will be asked to participate in a face-to-face interview at the studio, about your game experience. The interview will take a few minuets and will be recoded in writing and with a video camera. You can stop the interview at any time, without giving a reason. You can withdraw from the study up to one day after the interview. If you withdraw, the information you provided will be destroyed or returned to you.

\section{What will happen to the information you give?}

This research is confidential. I will not name you in any reports, and I will not include any information that would identify you. Only my supervisors and I will read the notes or transcript of the interview. All records will be aggregated to inform the researcher how to improve the game design, and so, your confidentiality will be maintained. The interview transcripts, 
summaries and any recordings will be kept securely and destroyed immediately after the conclusions of the research.

\section{What will the project produce?}

The information from my research will be used in my Masters. You will not be identified in my report. I may also use the results of my research for conference presentations, and academic reports. I will take care not to identify you in any presentation or report.

\section{If you accept this invitation, what are your rights as a research participant?}

You do not have to accept this invitation if you don't want to. If you do decide to participate, you have the right to:

- $\quad$ choose not to answer any question;

- $\quad$ ask for the recorder to be turned off at any time during the interview;

- $\quad$ withdraw from the study up until one day after your interview;

- $\quad$ ask any questions about the study at any time;

- receive a copy of your interview recording (if it is recorded);

- $\quad$ read over and comment on a written summary of your interview;

- be able to read any reports of this research by emailing the researcher to request a copy.

\section{If you have any questions or problems, who can you contact?}

If you have any questions, either now or in the future, please feel free to contact either:

\section{Student:}

Dana Fridman

School of design

fridmadana@myvuw.ac.nz

\section{Supervisor:}

Kah Chan

School of design

Kah.Chan@vuw.ac.nz

\section{Human Ethics Committee information}

If you have any concerns about the ethical conduct of the research you may contact the Victoria University HEC Convener: Associate Professor Susan Corbett. Email susan.corbett@vuw.ac.nz or telephone+64-4-463 5480. 


\section{Consent Form for a Study of Game Design}

School of Design, Victoria University of Wellington

- I have been given and understood an explanation of this research project

- I have volunteered to take part in this project

- I understand I can stop taking part at any time, during and after the trials, up until one day after the study, and if I decide to do so, the recordings of my participation will be deleted

- I am satisfied that the recordings will be stored securely

- I understand that the results may be published

- I understand that a video and screen recording of the gameplay will be taken

- I have had the chance to ask questions

- I understand that I will not receive any money for taking part in this research

- I understand that participation or non participation will not be recorded or regarded by the school in either a positive or negative way and will not affect my grades in any courses at Victoria University.

Please tick if applicable:

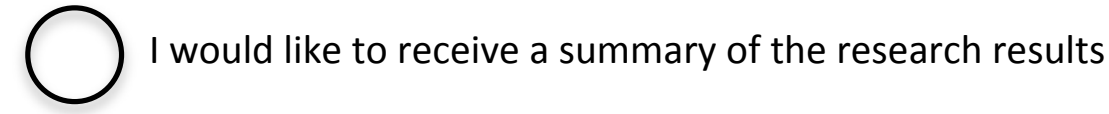

My e-mail, or contact details are:

I have read this form and I understand it. I agree to take part in the project.

Signed (participant):

Date: 


\section{Interview guide}

Face-to-face semi-structured interviews for focus on the subjective aspect of the game.

\section{Purpose}

To improve the prototype usability and user experience.

\section{Objectives}

To measure the challenge level, usability, rhythm and feedback influence in the game.

\section{Questions}

For every question, the interviewer will ask participants to rate their answers on 1-10 scale, and then why they chose this rate.

1. Do you play much compter or video games?

2. What was your goal in the game?

3. What did you do to achive it?

4. How good was your performance in the game? (1-5) Why?

5. Were there situation in the game where you didn't know what to do?

6. How did you overcome these situations?

7. How keen would you be to continue playing the game or try it again in the future?

8. What would you change in the game? Sound (rhythm and feedback):

9. How important are sounds in general for you in games?

10. How important was the sound for you in the level you just played? Usability:

11. Do you think that you would like to play this game frequently? (1-5) Why?

12. Did you find the game unnecessarily complex? (1-5) Why?

13. Did you think the game was easy to use? (1-5) Why?

14. Would you need the support of a technical person to be able to play this game? (1-5) Why?

15. Did you think there was too much inconsistency in this system? (1-5) Why?

16. Would you imagine that most people would learn to use this system very quickly? (1-5) Why?

17. Did you feel confident playing the game? (1-5) Why?

18. Did you need to learn a lot of things before I could get going with this game? (1-5) Why? 


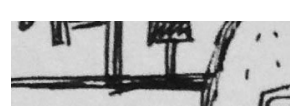

(4)

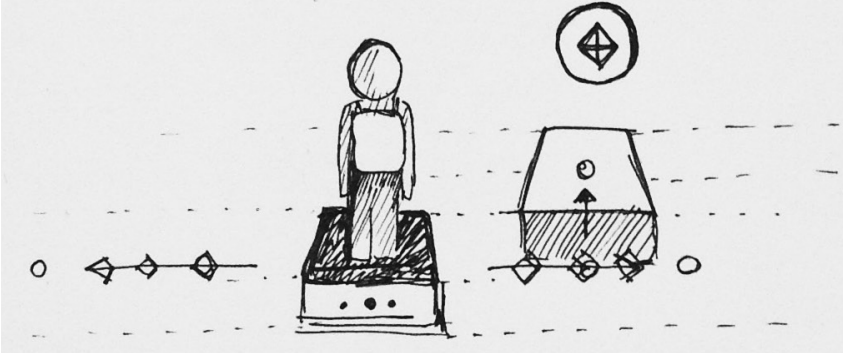

level 1

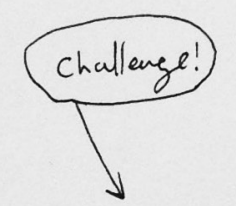

*
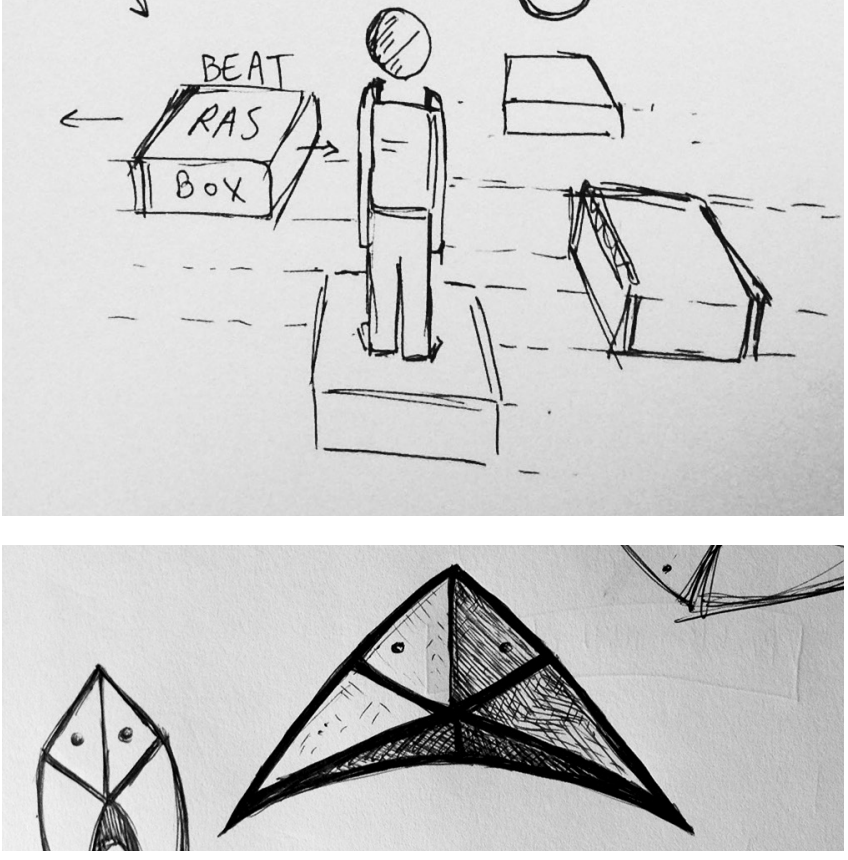
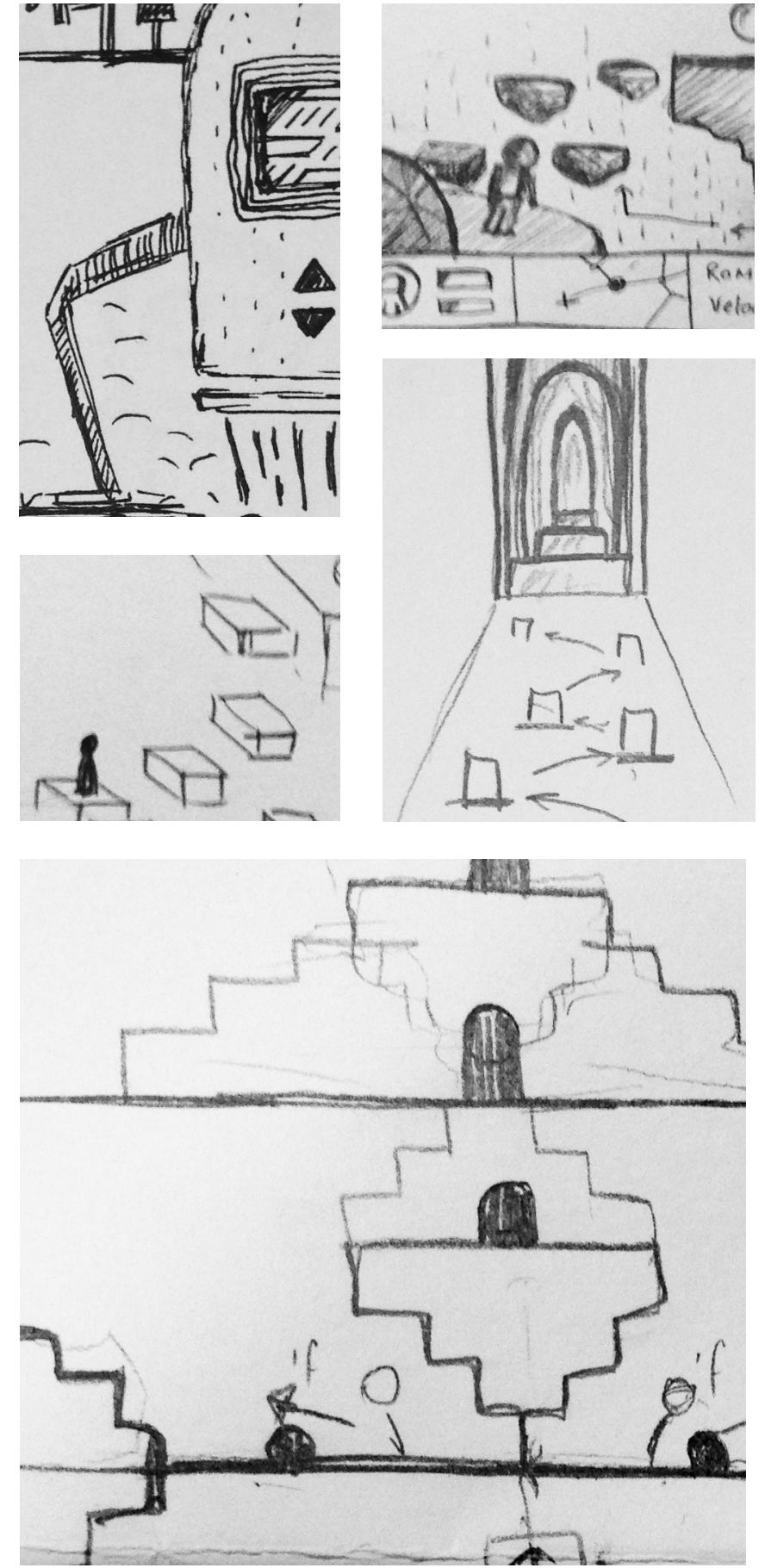
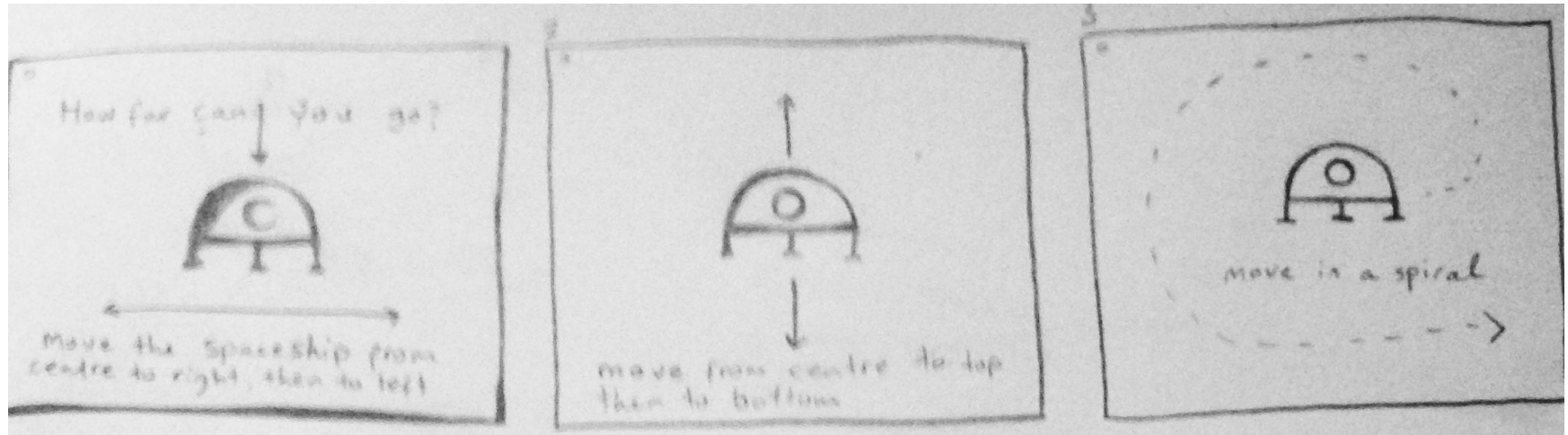

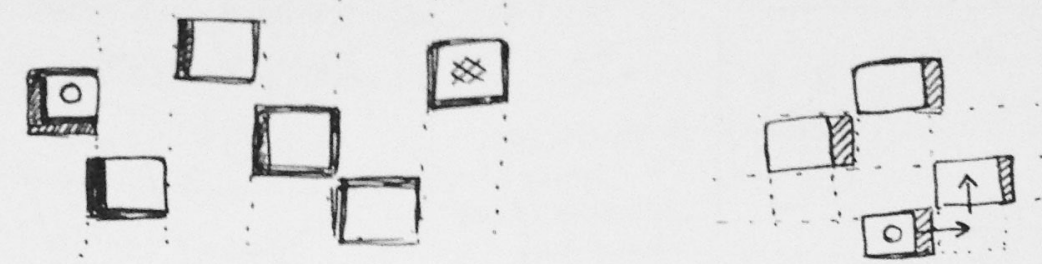

* Have to go right/left + Sound in collision \& different cubes in order to get to the final cube

$\infty$

* planning also reed to

happer when cubes move

= Rhythm defined by

moving objects.

player moves along.

and when the rext step

is not steady, playcer have

to move with the rhythm

to reflect the next step

movement, or Wait is

one of the places where it stops - and activate Cognitive proeess-memory Cognitive planning.
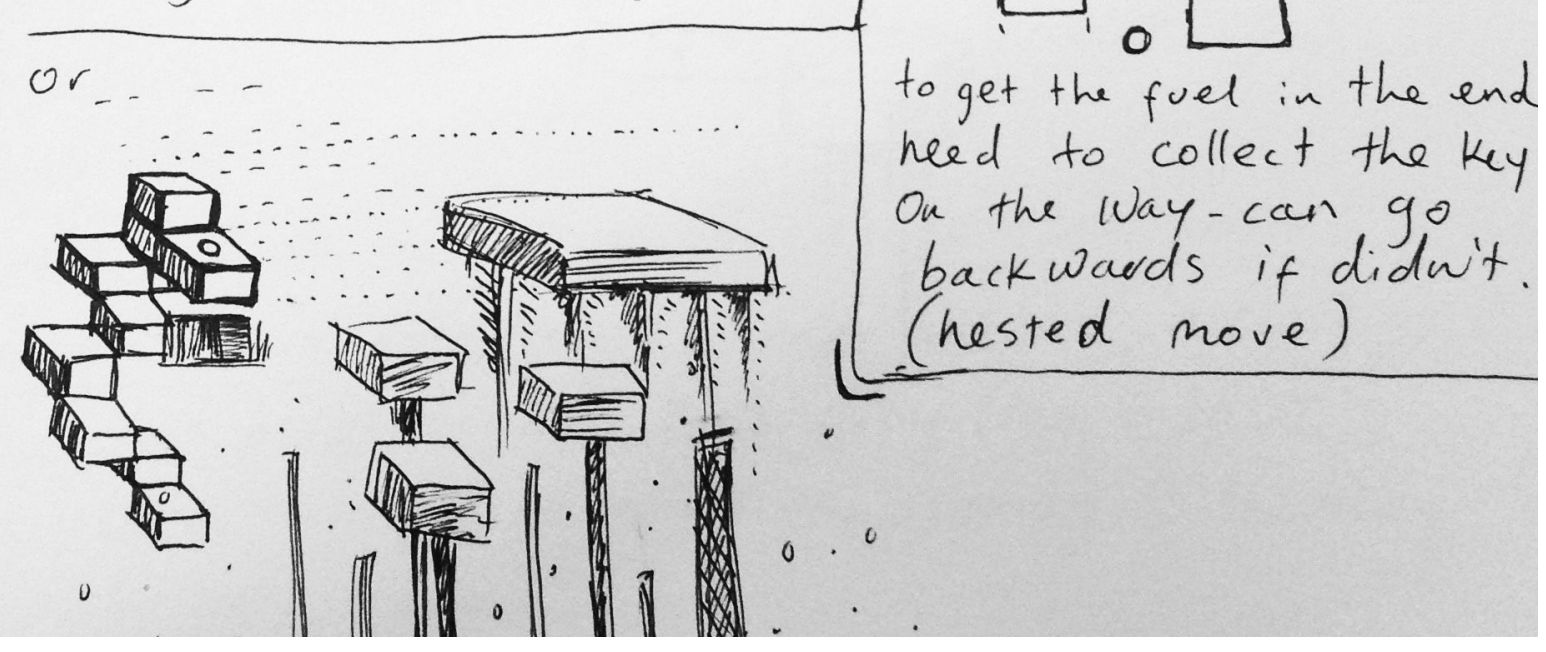

Figure 70: Sketches 

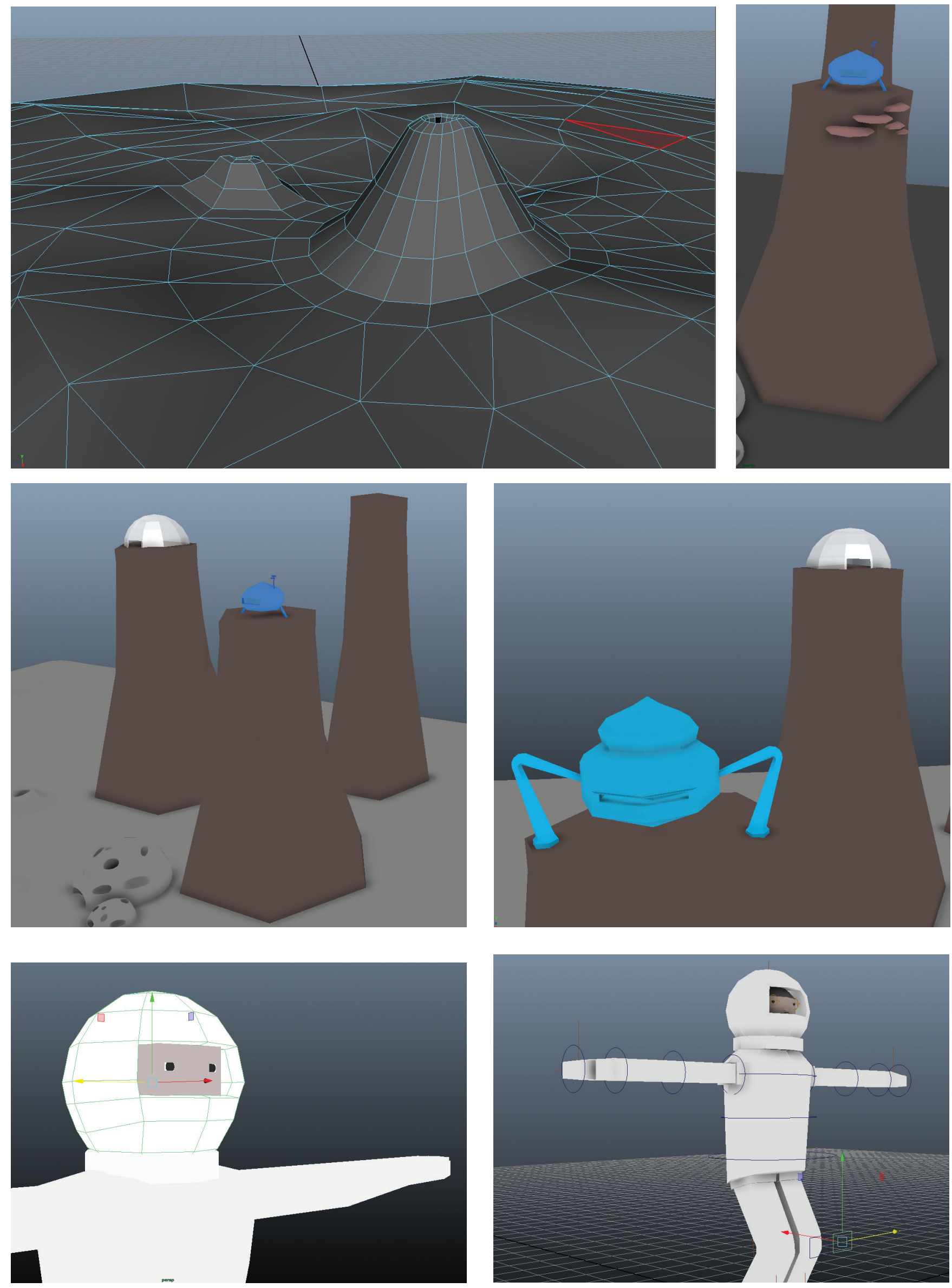

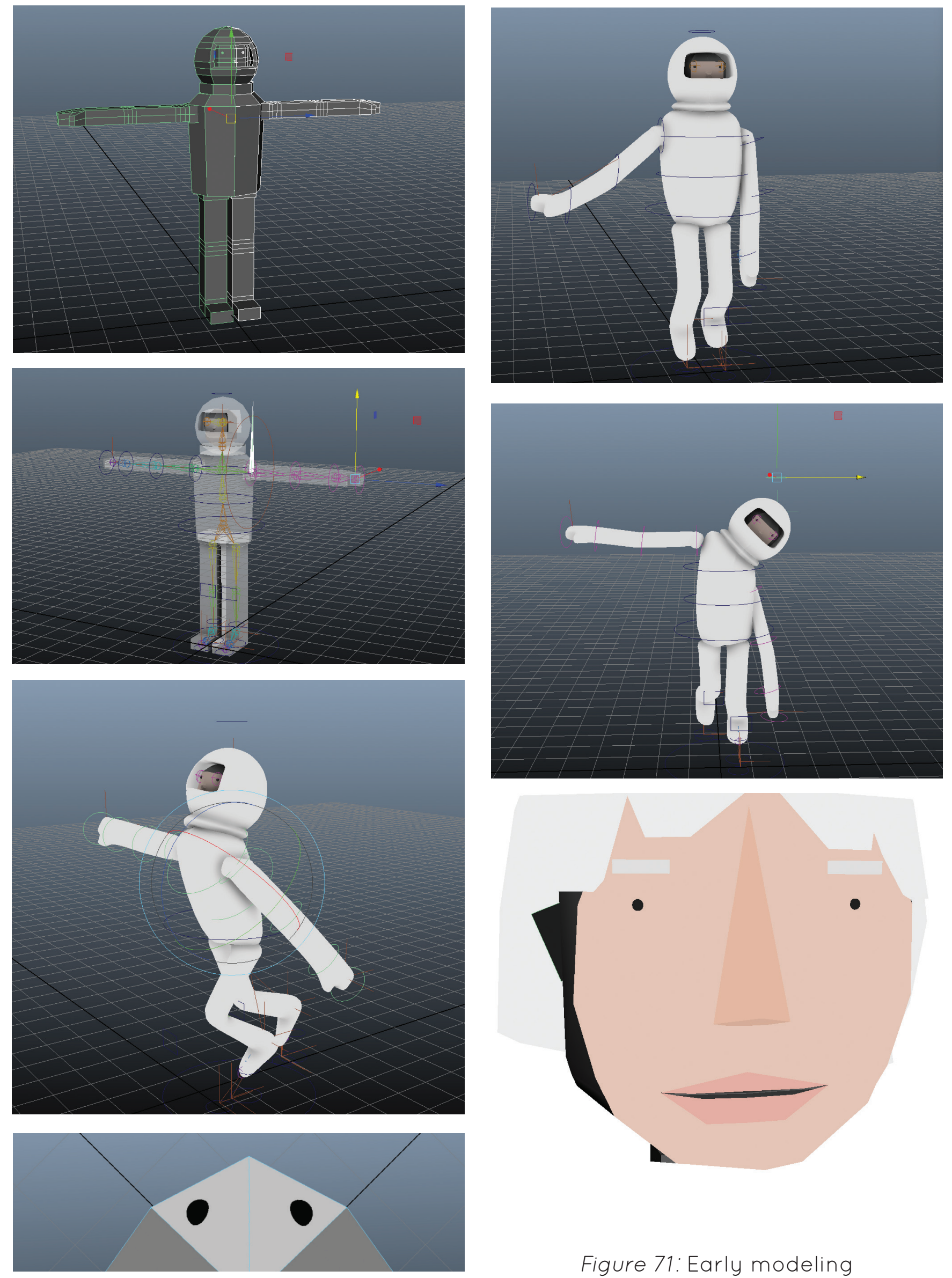

Figure 71: Early modeling 


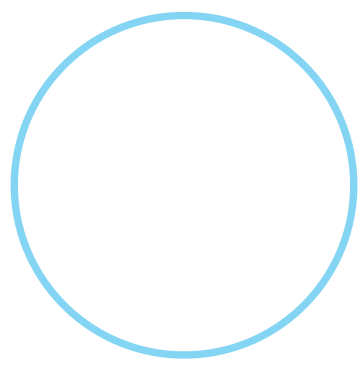

\section{ABOUT}

\section{Condition:}

Age:

Location:

\section{WHAT'S FEELING}

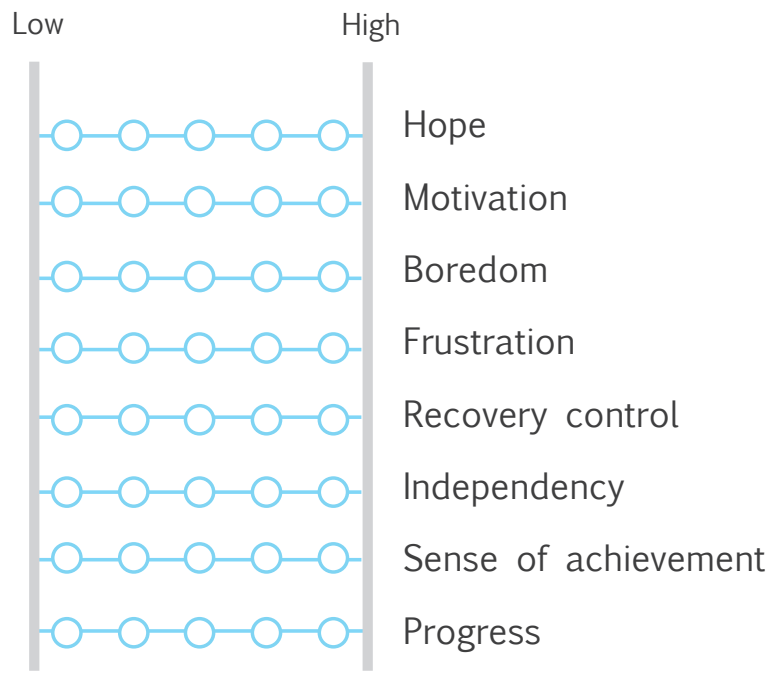

Activities:

\section{WHAT'S HAPPENING}

Where do you spend most of your time?

Daily structure

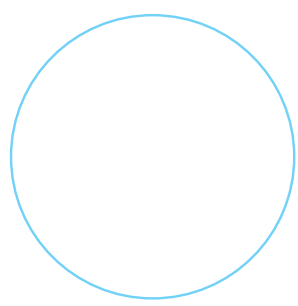

Figure 72: Personas tamplate 


\section{Figure list}

Figure 1: Using the Able-M

Figure 2. 1: personas

29

Figure 2. 2: personas

30

Figure 2. 3: personas

Figure 2. 4: personas

32

Figure 3: Field observations

39

Figure 4: Concepts

43

Figure 5: Music app concept 43

Figure 6: Game model 45

Figure 7: First person rhythm game 47

Figure 8: Third person rhythm game 49

Figure 9: Narrative concept 50

Figure 10: Concept development sketches

Figure 11: Concept development through storyboarding

52

Figure 12: Levels design through sketching

53

Figure 13: Calibration prototype 1

54

Figure 14: Calibration prototype 2

55

Figure 15: Calibration prototype 3

55

Figure 16: Calibration development 56 
Figure 17: Calibration prototype 4

Figure 18: Calibration development 5

Figure 19: Blocks frame the path

Figure 20: Blocks removed

Figure 21: Generating objects

Figure 22: Exploring the world

Figure 23: Clear path forward

Figure 24: Feedback provision

Figure 25: Elements sketch

Figure 26: Rhythmic astroids

Figure 29: The player can only move through the blocks

Figure 30: Generating steps at random locations 64 according to players' ability

Figure 33: Rhythmic rewards

Figure 34: Back in the spaceship 
Figure 39: Rhythmic obstacles

Figure 40: Rhythmic elements

Figure 41: Rhythmic rewards \& elements 73

Figure 42: Error feedback 74

Figure 43: Knowledge of performance 74

Figure 44: Knowledge of results 74

Figure 45: Summary provision 74

Figure 46.1: Calibration 75

Figure 46. 2: Example- influence on path 75

Figure 47: Landing 76

Figure 48: Steering behaviors 76

Figure 49: Drag and drop 77

Figure 50: After landing 77

Figure 51: Following the path 77

Figure 52: Removing the obstacle 78

Figure 53: Two aliens 78

Figure 54: Collecting oxygen 79

Figure 55. 1: Back to the path 79

Figure 55. 2: Back to the path 79

Figure 56: Spiral path 79

Figure 57: Following the path in the second planet 80 
Figure 58: Floating elements

Figure 59: Rhythmic elements

Figure 60: Rhythmic fuel

Figure 65: Participant information sheet and consent 103-108 form (HDEC)

Figure 66: Recruitment flyer 109

Figure 67: Information sheet for participants (Victoria University)

Figure 68: Consent form (Victoria University) 112

Figure 69: Interview guide (Victoria University) 113

Figure 70: Sketches

$114-115$

Figure 71: Early modeling $116-117$

Figure 72: Persona tamplate 118 

